\title{
INTERSTITIAL PLACE
}

by

Timothy Melnichuk B.Arch.Sci. Ryerson University, 2014

A thesis,

presented to Ryerson University

in partial fulfillment of the requirements

for the degree of

Master of Architecture

in the Program of

The Department of Architectural Science

Toronto, Ontario, Canada, 2016

CTimothy Melnichuk, 2016 


\section{AUTHORS DECLARATION}

I hereby declare that I am the sole author of this thesis. This is a true copy of the thesis, including any required final revisions, as accepted by my examiners.

I authorize Ryerson University to lend this thesis to other institutions or individuals for the purpose of scholarly research.

I further authorize Ryerson University to reproduce this thesis by photocopying or by other means, in total or in part, at the request of other institutions or individuals for the purpose of scholarly research.

I understand that my thesis may be made electronically available to the public. 


\section{ABSTRACT}

The fabric of many post WW2 campuses in North America, can be described as a collection of independent buildings rather than as infrastructure that shapes and connects a network of public spaces with character, sense of place and social amenity. The same can be said for our late modernist cities. A re-examination and design of these interstitial leftover spaces can provide much needed public domain for students and faculty while also improving the ambiance and connectivity of adjacent buildings. Through analyzing and intervening within an existing underutilized circulation plaza within Ryerson's urban Toronto campus, this thesis project asserts the importance of public space by creating new connections and relationships between building, landscape, and people using strategies of landscape urbanism and infrastructural urbanism. The synthesis of architecture, infrastructure and landscape has the potential to create public realm by intensifying and uniting new and existing flows within existing urban and social networks. 


\section{ACKNOWLEDGMENTS}

I would like to thank my family and friends for their continuous support during my architectural education and this project, my supervisor Cheryl Atkinson for her help and guidance through all the stages of this thesis, and June Komisar and John Cirka for their insightful critiques. 


\section{TABLE OF CONTENTS}

1.0 Erosion of the Public Realm

1.1 Introduction

1.2 Erosion of the Public Realm

1.3 Reimagining the Contemporary City

2.0 An Interconnected Pedestrian Landscape

$2.1 \quad$ Life Between Buildings

2.2 Why the street?

2.3 Brief History of the Street

2.3.1 Greek Agora

2.3.2 Roman Forum

2.3.3 The Middle Ages

2.3.4 Renaissance

2.3.5 Industrial Age

2.3.6 Modernism

2.3.7 Post War

2.4 Emergence of Lost Spaces

2.5 Attempting to Pedestrianize the City

2.5 .1

2.5.2 Shared Street

3.0 A Place Generating Domain

3.1 Places and Non-Places

3.2 Existential Space

3.3 Sense of Place

Characteristics of Place

3.4.1 Place as Movement

3.4.2 Place as Event

3.4.3 Place as Interaction

01
01
03
05
07
08
09
10
11
11
11
12
13
15
18
18
19
20
20
23
23
24
25
26
27
28
29

4.

Landscape, Infrastructure and Architecture

4.1 Landscape Urbanism

4.2 Integral Urbanism

4.3 Infrastructural Urbanism

5.0 Context

4.3.1 Pedestrian Infrastructures

5.1 Site Context

5.2 Victoria St. an Interstitial Non-Place

5.3 Flow - Ryerson Campus

5.4 Areas with Sense of Place

5.5 Areas With a Diminished Sense of Place 5.5.1 Victoria St.

6.0 Design Proposal

6.1 Introduction

6.2 Design Strategies

6.2.1 Flow/Connectivity

6.2.2 Activate

6.2.3 Engage

6.3 Flow/Connectivity

6.4 Activate

6.5 Engage

6.6 Surface Strategy

7.0 Conclusion

Appendix

References 
Figure 1.1 City as an Egg

http://40.media.tumblr.com/7ca584bf49c321boe7bcca61fdb34311/tumblr

n6zkwtgMx91qkrc4i01_1280.jpg

Figure 2.1 Athenian Agora A.D. 150

https://s-media-cache-ako.pinimg.com/736x/f6/87/9o/f6879oda51898a1093bogdb6442ddf7a.jpg

Figure 2.2 Boulevard Montmartre, 1897

https://upload.wikimedia.org/wikipedia/commons/4/46/Camille_Pissarro,_Boulevard_ Montmartre.jpg

Figure 2.3 Traffic in Chicago, 1909

http://burnhamplanıoo.lib.uchicago.edu/newberryexhibit/images/crossroads3-large.jpg

Figure 2.4 Ebenezer Howard's Garden City

http://www.houseplanninghelp.com/wp-content/uploads/2013/04/garden-city-plans-1.png

Figure 2.5 Corb's La Ville Contemporaine Streets

http://prodavinci.com/sistema/wp-content/uploads/2016/02/C\%C3\%B3mo-construir-una-casaen-las-costas-del-Caribe-por-Federico-Vegas-640b.jpg

Figure 2.6 Corb's La Ville Contemporaine Cruciform Towers

http://prodavinci.com/sistema/wp-content/uploads/2016/02/C\%C3\%B3mo-construir-una-casa-

en-las-costas-del-Caribe-por-Federico-Vegas-640b.jpg

Figure 2.7 Le Soleil et l'Ombre Corb's sketch - Dark old city vs. Bright new city

http://3.bp.blogspot.com/_svAyYhspkJw/S8BIXopqys//AAAAAAAAFEA/jgt4bRZg18U/

s1600/2221+copy.jpg

Figure 2.8 Frank Lloyd Wright's Broad Acre City

https://classconnection.s3.amazonaws.com/804/flashcards/4085804/jpg/designs_for_-

broadacre_city_-142C4F6863154C78339.jpg

Figure 2.9 Non-Places Toronto

Figure 2.10 Conversion of Pedestrian Streets in Copenhagen and Use

Gehl, J. (2010). Cities for people. Washington, DC: Island Press., pg. 12

Figure 2.11 Strogen St. Copenhagen https://hungrytomovedotcom.files.wordpress.com/2014/07/dsc_0868.jpg

Figure 2.12 Las Ramblas, Barcelon

http://pher.ch/photos/cities/barcelona/Barcelona,\%20las\%20Ramblas\%201.jpg

Figure 2.13 Exhibition Rd. London

http://www.e-architect.co.uk/images/jpgs/london/exhibition_road_london_r220612_01.jpg

Figure 2.14 Las Ramblas, Barcelona Street Section

tttp://zhelmick.weebly.com/uploads/1/6/4/3/16430334/3054287_orig.jpg

Figure 3.1 Tschumi's Park De La Villette

https://s-media-cache-ako.pinimg.com/originals/f3/8c/a2/f38ca281022240481b429d22708 bd639.jpg

Figure 3.2 OMA's Parc De La Villette Submission - Vignette

http://images.oma.eu/20150804051219-2934-w1vf/700.jpg

Figure 3.3 OMA's Parc De La Villette Submission - Horizontal Strips

http://images.oma.eu/20150804051245-722-m8kf/700.jpg

Figure 4.1 Olympic Sculpture Park - Continuous Park Surface

http://www.weissmanfredi.com/media/files/eefb26451552f1937e02d79721f3egoe.jp

Figure 4.2 FOA's Yokohama Terminal

http://www.idesignarch.com/wp-content/uploads/2010/08/YokohamalnternationalPortTerminal-3.jpg

Figure 4.3 Teruel-zilla - Axo

http://static.dezeen.com/uploads/2012/06/dezeen_TERUEL-ZILLA-by-Mi5-Arquitetosand-PKMN-Architectures_11a.jpg

Figure 4.4 Teruel-zilla - Aerial View

http://static.dezeen.com/uploads/2012/06/dezeen_TERUEL-ZILLA-by-Mis-Arquitectos-and-

PKMN-Architectures_21.gif

Figure 4.5 Toronto Waterfront - Wavedec

http://www.mascontext.com/wp-content/uploads/2010/06/06_in_front_of_the_sea_021.jpg

Figure 4.6 Wavedeck Concept Diagram

https://calpolyla201.fles.wordpress.com/2012/10//imcoe-wave-bridge1.jpg 
Figure 4.7 Ponte Vecchio - 1345

https://upload.wikimedia.org/wikipedia/commons/1/1b/Ponte_Vecchio_Firenze.jpg

Figure 4.8 Team 10's Noahs Ark

http://loveyousomat.tumblr.com/post/15288950412

Figure 4.9 Paul Rudolph - Lower Manhattan Expressway

http://socks-studio.com/img/blog/rudolph-section-12.jpg

Figure 4.10 New York's Highline

https://www.asla.org/2013awards/images/largescale/524_11.jpg

Figure 5.1 Ryerson Campus Growth 1963- 1980

Figure 5.2 Ryerson Campus Growth 1990 - 2007

Figure 5.3 RG 95.1.41.42.06 - Aerial View of Ryerson Campus - 1963 Photographs courtesy of Ryerson University Archives

Figure 5.4 RG 122.10.93.02 -Completed Library Building, ca. 1974

Photographs courtesy of Ryerson University Archives

Figure 5.5 RG 122.10.93.01 - Construction of Library Building as seen from the Kerr Hall Quad, ca. 1973

Photographs courtesy of Ryerson University Archives

Figure 5.6 RG 122.10.93.03 - Podium and Library along Victoria Street, ca. 1974

Photographs courtesy of Ryerson University Archives

Figure 5.7 Existing Kerr Hall + Podium Entrances 1970's

Figure 5.8 Flow Diagram + Area of Intervention

Figure 5.9 Areas with Sense of Place

Figure 5.10 Gould St. Boundaries

Figure 5.11 Gould St. Perspective Farmers Market

http://food.ryerson.ca/wp-content/uploads/2014/06/Ryerson_Farmers_Market_Appletree_Sugar_ Mamma_Mini_Donuts_Gould_Street.jpg

Figure 5.12 Gould St. Perspective

http://ryersonian.ca/wp-content/uploads/2014/10/1.-Gould-Street_FEATIRE.jpg

Figure 5.13 Student Learning Center Boundaries

Figure 5.14 Student Learning Center Perspective 1

Figure 5.15 Student Learning Center Perspective 2

Figure 5.16 Lake Devo Boundaries

Figure 5.17 Lake Devo - Winter Ice Rink

https://project416.files.wordpress.com/2013/01/a05aa-ryerson1.jps

Figure 5.18 Lake Devo Summer

ttp:///urbantoronto.ca/sites/defaut//iles/magecache/display-slideshow/images/

articles/2012/11/6772/urbantoronto-6772-22362.jpg

Figure 5.19 Areas with a Diminished Sense of Place

Figure 5.20 Victoria St. Boundaries

Figure 5.21 Existing Site Plan, 2016
Figure 5 22 Existing Level B, 2016

Figure 5.23 1. Existing Victoria St.

Figure 5.24 2. Existing Victoria St.

Figure 5.25 3. Existing Victoria St.

Figure 5.26 Library, Podium, Jorg Hall Elevation + Entrances

Figure 5.27 Kerr Hall Elevation + Entrances

Figure 6.1 Flow Diagram 1

Figure 6.2 Flow Diagram 2

Figure 6.3 South Perspective

Figure 6.4 Sectional Perspective 1

Figure 6.5 Sectional Perspective 2

Figure 6.6 Sectional Perspective 3

Figure 6.7 Sectional Perspective 4

Figure 6.8 North Perspective

Figure 6.9 Level 2

Figure 6.10 Level

Figure 6.11 Level B

Figure 6.12 Hub Perspective

Figure 6.13 Engage

Figure 6.14 Interaction Vignettes

Figure 6.15 Surface Strategy Plan

Figure 6.16 Surface Strategy Axo

Figure 6.17 Aerial Perspective 1

Figure 6.18 Aerial Perspective

Figure 6.19 Sectional Perspective 5

Figure 6.201 . Gould St. Perspective

Figure 6.21 Sectional Perspective 6

Figure 6.22 2. Podium Entrance Perspective

Figure 6.23 3. Kerr Hall Stepped Study Spaces Perspectives

Figure 6.24 Sectional Perspective 7

Figure 6.25 4. Ramp Stepped Seating Perspective

Figure 6.26 5. Hub Perspective 2

Figure 6.27 Sectional Perspective 8

Figure 6.28 6. Surface Perspective

Figure 6.29 Sectional Perspective

Figure 6.30 7. Hub Perspective 3

Figure 6.31 Sectional Perspective

Figure 6.32 8. Bike Rack North Perspective

Figure 6.33 Surface Perspective 2 


\subsection{Introduction}

Civic spaces were always one of the primary foci of city design. They were of great importance in the past, as demonstrated by cities in ancient Greece, sixteenth century Rome and nineteenth century Paris. However, the introduction of cars fundamentally changed the urban fabric. In the twentieth century, the mass production and proliferation of cars altered the logic and scale of movement in the city. Vehicular transport was prioritized over the pedestrian experience and what was considered most important was getting efficiently from point $A$ to $B$ over the course of a journey. This change in attitude caused a separation in land uses, buildings, and activities, enabling urban sprawl that consisted of low-density suburban environments linked by highway to cityscapes composed of high-rises (Ellin, Integral Urbanism, pg. 18).

Cedric Price offers an interesting analogy of the progression of the city in the form of a series of eggs (Fig 1.1). He represents the ancient city as a hardboiled egg with a clear city center enclosed within a defined hard shell or perimeter. The 17-19th century is described as a fried egg where the city is still very centralized but with more fluid boundaries. Finally, the modern city is characterized as a scrambled egg, a fragmented and decentralized city without any clear organizational structure. "The traditional notion of the city as a historical and institutional core surrounded by postwar suburbs and then open countryside has largely replaced by a more polycentric and web like sprawl: the regional metropolis" (Wall, 1999, 234).

One result of this changing urban landscape is an absence of "quality public spaces, local character, and multi-functional spaces (combining housing work, circulation, and recreation) that was of importance of previous centuries" (Ellin, 2006, pg. 18) Additionally, the fragmentation of public space has resulted in a lack of connectivity, walkability and sense of place (Ellin, 2006, pg. 18).

According to Alex Wall, this fragmentation and decentralization has resulted in cities that are polycentric, that is, have multiple centers. These multiple centers are served by multiple layers of infrastructure in which the flux of people, vehicles, goods and information has become more significant than spatial boundaries. This shift of emphasis has produced a more dynamic and temporal urban landscape focused on the process of urbanization rather than on form (Wall, 1999, pg. 234). Three new characteristics of urbanism have developed in the contemporary metropolis.

The first is the emergence of a new kind of urban site that can be described as 


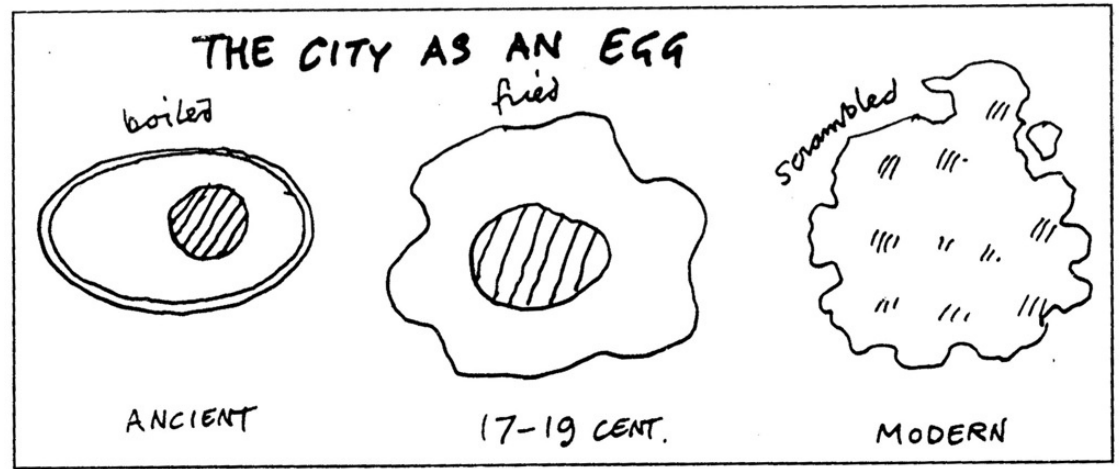

a peripheral site, middle landscape or non-place. These sites include streets, laneways, thoroughfares and parking lots; all disrupt urban cohesion and flow (Wall, 199, pg. 234).

The second effect is an increase of mobility and access as a result of the privatization of automobiles and transportation alternatives, the rising density of population and the abundance of information and media (Wall, 1999, pg. 234).

The third effect is the paradigm shift in the way we view cities, from looking at them in formal terms to viewing them in dynamic ways (Wall, 1999, pg. 234). Infrastructures, network flows and other polymorphous conditions that make up the contemporary city are becoming as significant if not more so than such familiar typologies as the park, square or district. (Wall, 1999, pg. 234).

\subsection{Erosion of the Public Realm}

The contemporary city can be described as a splintering metropolis where tensions between "fragmenting physical fabric and multiplying electronic socioeconomic networks" are emerging (Stickells, 2008, pg. 253). Architecture is becoming increasingly more dematerialized due to the rise in digital technologies that include the electronic screen and global communications. Manuel Castells speaks about a 'space of flows' that describes the phenomena of a new social space: the virtual one. The rise of technology has transformed the city, but most notably it has changed the logic of organization of our cities from a center/periphery-based one to one that looks more like a network (Castells, 1996, pg. 6). According to Deluze and Guattari, the organizational structure of the contemporary metropolis is unlike that of traditional cities-sometimes described in terms of a tree. Instead, they resemble rhizomes in that they are dispersed and diffused (Wall, 1999, pg. 234). In regards to urbanism, the urban milieu is no longer tied to a hierarchical public realm since it is now dominated by complex networks rather than spatial boundaries (Stickells, 2008, pg. 254). Koolhaas calls this condition the Generic City.

"The Generic City is ... a place of weak and distended sensations, few and far between emotions, discreet and mysterious like a large space lit by a bed lamp. Compared to the classical city, the Generic City is sedated, usually perceived from a sedentary position... The urban plane now only accommodates necessary movement, fundamentally the car; highways are a superior version of boulevards and plazas, taking more and more space; their design, seemingly aiming for automotive efficiency, is in fact surprisingly sensual, a utilitarian pretence entering the domain of smooth space." (Koolhaas, 1995, pg. 1251).

Koolhaas also argues that the shopping mall has become a means of defining public space in the contemporary metropolis. In Koolhaas's book Harvard Design School Guide to Shopping, he starts off with the statement "shopping is arguably the last remaining form of public activity...shopping has infiltrated, colonized, and even replaced almost every aspect of urban life." (Chung, Judy, Koolhaas, 2000, pg. 405). Commercialization has taken over the duties of the public domain through accommodating some of the functions associated with public 
life such as the ancient Greek agora: a gathering public place, and a market place found in squares. Koolhaas argues that urban conditions are closely related to the impact that shopping and capitalism have had on cities: "By linking into the existing infrastructures, such as pedestrian routes, road systems, or subway systems, or by mechanically inducing movement through devices such as the escalator or the moving sidewalk, shopping has managed to profoundly influence the way movement through cities is experienced" (Koolhaas, 2001, pg. 140).

Urban sprawl, commercialization and privatization of public spaces have created a decrease in the amount of informal social activity commonly found in third places in the city. Third places are social places such as pubs and cafes in between work and home. Physical social interaction has been replaced by virtual interaction and this change presents one of the biggest limitations in the virtual social realm. Engaging in social interactions within the physical realm allows us humans to experience each other and our physical surroundings phenomenologically. A sense of space is created through sensual experience of space and engaging in social activity is important for our social health.

\subsection{Reimagining the Contemporary City}

One of the signs of a livable city is a certain vibrancy within the public realm. A variety of informal public spaces interwoven into an urban network creates the opportunity for the public to define their own spaces and create events. Events such as market days, communal gatherings or just 'getting together' help establish the cultural, unified meaning of a particular space which in turn reinforces the local community identity and creates a sense of belonging within a place. A cyclical process emerges in which community building is dependent on the quality of social spaces within the public realm; this is turn creates the social infrastructure of a healthy and livable city.
The need for good quality public spaces is an issue currently being dealt with in many mega-cities. They are implementing strategies to ensure that the public realm is planned with such spaces in mind. Such movements as Landscape Urbanism and Integral Urbanism have emerged in response to this need for quality public spaces. Additionally, Privately Owned Public Spaces (POPS) and Public Private Partnerships (PPPs) are starting to be legislated into North American cities where land development typically has maximized private space to the detriment of public space.

Criticisms of a lack of public space as a result of modernism and contemporary developments has impacted the design of our contemporary cities. However issues of public space and the role of public space within the city stretches back much further. Understanding how and why our cities and notions of public space have changed is important in understanding how to address the status quo. Today architects and planners have turned to viewing the city as a field, using landscape as a medium for the creation of the city's public spaces, reinforcing the importance of networks and flows, enabling social cohesion and promoting equity through the synthesizing of landscape, architecture and infrastructure.

"Architecture today cannot concern itself only with that one set of structures that happen to stand upright and be hollow "buildings" in the conventional sense. It must concern itself with all man made elements that form our environments: with road and highways, with signs and posters, with outdoor spaces as created by structures, and with cityscape and landscape." (Wall, 1999, pg. 235) 


\subsection{Life Between Buildings (Gehl, 2010)}

The city is a unique human creation containing complex physical constructions and infrastructural networks, with a vast collection of people and institutions. Arguably, one of the most unique characteristics of a city arises from the constant encounters within it. The exchange of ideas and information in cities has allowed for their growth and innovation. This is evidenced throughout the history of the city wherever social, economic and political conversations have been discussed. The concept of life between buildings begins to define the extent of the public realm. It is where urban city life is experienced through recreation, a wide variety of activities and through the visual and sensory experiences. Characteristics of vibrant city life include an overlap of activities such as walking, resting, staying, exercise, dancing and street entertainment, all different types of social behavior. According to Jan Gehl and Lewis Mumford, a strong social presence in the public realm is vital to the maintenance of a vibrant and interesting city life. Mumford argues that one of the cities primary goals is "to permit the greatest number of meetings, encounters, challenges, between varied persons and groups, providing as it were a stage upon which the drama of social life may be enacted." (Mumford, 1964, pg. 173). Life between buildings has always enabled the exchange of ideas though a physical manifestation of a public realm.
Public space is only the physical manifestation of life between buildings. However, before discussing the sociability of the public realm further, we must first define what is public space. Some define public spaces as "space that is not controlled by private individuals or organizations and hence is open to the general public" (Madanipour, 1996, pg. 144). Others base their definitions on access, use and ownership, and consider how people can engage in individual or group activities (Mehta, 2013, pg. 20). Public spaces include spaces between buildings; their edges define the boundaries of the public space and include artifacts such as the benches and seating found there. It is open space that generates public use and social behaviour. Historically, public space has depended on the town square or the piazza for basic religious, political, economic and social functions. While contemporary city space no longer relies solely on the town square and piazza, quality public space is still required for the social and psychological health of communities, as well as for the city's livability (Mehta, 2013, pg. 21).

\subsection{Why the street?}

Within the domain of public space in urban areas, streets make up the largest percentage of the open public space. Streets are arguably the purest form of common ground, for they are the most accessible to all. The street defines 
the experience of the city through representing its identity, organization, and diversity. It is therefore the most accurate representation of social life of the city to be found.

The street in of itself is a simple construct that can host numerous functions. Streets provide an easy way to divide land, provide access and circulation, provide light and air, form networks for utilities and service, and to provide immediate and intimate public spaces for dwelling and physical and social networks (Mehta, 2013, pg. 10). From a morphological perspective, Rapoport defines the street as a "the more or less narrow, linear space lined by buildings found in settlements and used for circulation and sometimes other activities" (Rapoport, 1987, pg. 81). This definition of the street puts a strong focus on the street as circulation and also indicates a shift in perception of the street, rethinking it as a social space rather than a place of movement. Arguably, social affordances which include the presence of people on the streets can be even more important than the physical affordances the environment offers (Mehta, 2013 pg. 12).

\subsection{Brief History of the Street}

Historically, the term 'street' was used to define the settlement patterns of cities and towns in some of the earliest forms of civilizations such as Mesopotamia, one of the earliest civilizations (Mehta, 2013, pg. 28). It is possible that the idea of a space for linear movement existed even before the earliest forms of civilization since it is human nature to create basic patterns of movement to fulfill such basic survival needs as food and shelter (Mehta, 2013, pg. 27). However, in the context of the city, streets were used to define movement public from private - and to provide distinctions between different areas of use such as production, consumption and leisure. Certain earlier cities were laid out in arrangements that signified a connection to the cosmos; for instance, the orthogonal layouts of Chinese, Indian, and Japanese cities, or the utilization of the Christian cross in certain Roman towns to create a dominant north-south, east-west grid. (Mehta, 2013, pg. 28). Streets have been used universally for the purpose of defining and directing circulation, for providing a means to exchange goods, for defining social structures and classes, and most importantly of all, for proving a place for the exchange of ideas. The balance of movement, exchange and communication on the street has keep cities important.

\subsubsection{Greek Agora}

Although the Greek Agora and the Roman Forums were not actually streets, they both were precursors of the concept of the public open space that has influenced public streets, squares and plazas ever since. The word 'agora' means "open place of assembly" and was a place for citizens to gather and to discuss a range of topics and issues (Agora, 2009). The Greeks strategically placed a variety of buildings around open spaces to create an overlap of activities that in turn created a dynamic and rich public life. The agora acted as the living heart of the Greek city as it put on display artistic, religious, commercial, political and spiritual activities. The Greeks developed long continuous colonnades

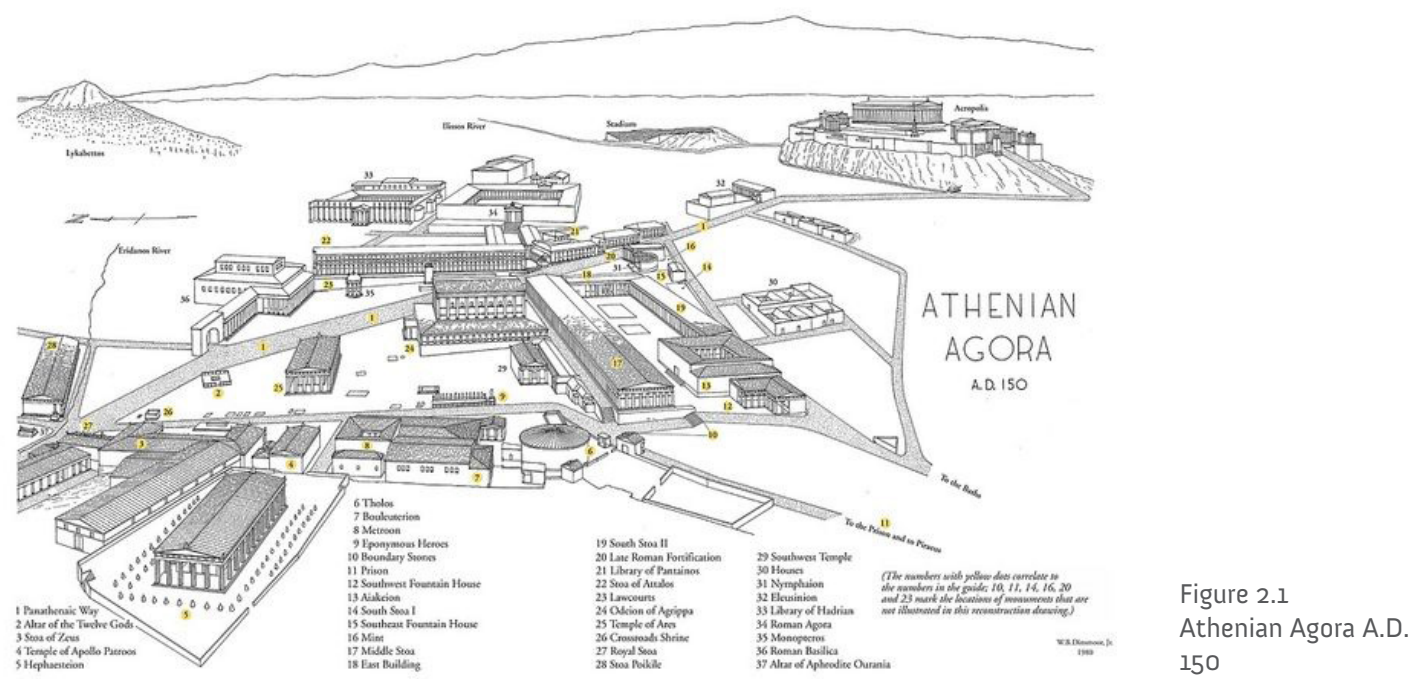


along linear streets to create a buffer zone that offered shelter to pedestrians. This thoroughfare was converted into a marketplace through the leasing out of adjacent spaces to shops to create an interesting and vibrant urban spectacle (Agora, 2009).

\subsubsection{Roman Forum}

The Roman Forum was very similar to the Greek Agora: it had the same basic concept with some differences. The Romans took the idea of a central open public space with various supporting programs and intensified it. The Roman Forum was a much larger open space and had a variety of open, enclosed and semi-enclosed spaces. It gained definition as more buildings came to surround and enclose the open space, thereby turning it into more of a square. The surrounding buildings continued the idea of the Greek colonnades and were filled with shops, temples, and offices to support the religious, political, commercial and sports activities of the Forum. The ideas of the Roman Forum also started to inform the characteristics of the street. For instance, colonnades along linear streets created a softer street edge that added activity and vibrancy. There were restrictions on the amount of wheeled traffic on the street so the street was predominantly pedestrian. Islamic cities also adopted the soft building edge condition, creating the first bazaars and street markets within its cities (The Roman Forum, 2012).

\subsubsection{The Middle Ages}

After the fall of the Roman Empire, cities made providing security for their inhabitants their main priority because of the unstable political situation at the time. Labyrinthine medieval streets were born out of an attempt to provide defensive spaces. The streets shrank, became narrower and taller, and were built on higher ground (Mehta, 2013, pg. 32). The town square or plaza became the heart or center of the city and was for its social life. However, the street
- in contrast to the functions of open spaces previously in history - became an area where public and private uses overlapped. "The narrow overcrowded buildings bordering it spilled into the street and transformed it into a place of workshops, kitchens and merchandising, into a place of leisure and sociability, and confrontation of every kind. It was this confusion of functions, the confusion of two different realms of law and custom that made the medieval street a kind of city within a city" (Jackson, 1985, pg. 289-90). The overlap of public and private was not by choice but out of necessity because of the largely illiterate population.

\subsubsection{Renaissance}

During the Renaissance, designers and artists became concerned with visual expression. Many structures in Italy give evidence of this as they explore composition, symmetry and balance. The boulevard and the avenue, unlike their medieval counterparts, became planned units that accommodated population growth and the increase in wheeled traffic. The city started to become more orthogonal and geometric as compared to the organic structure of the medieval street. An increase in traffic led to the appearance of the "modern" pedestrian

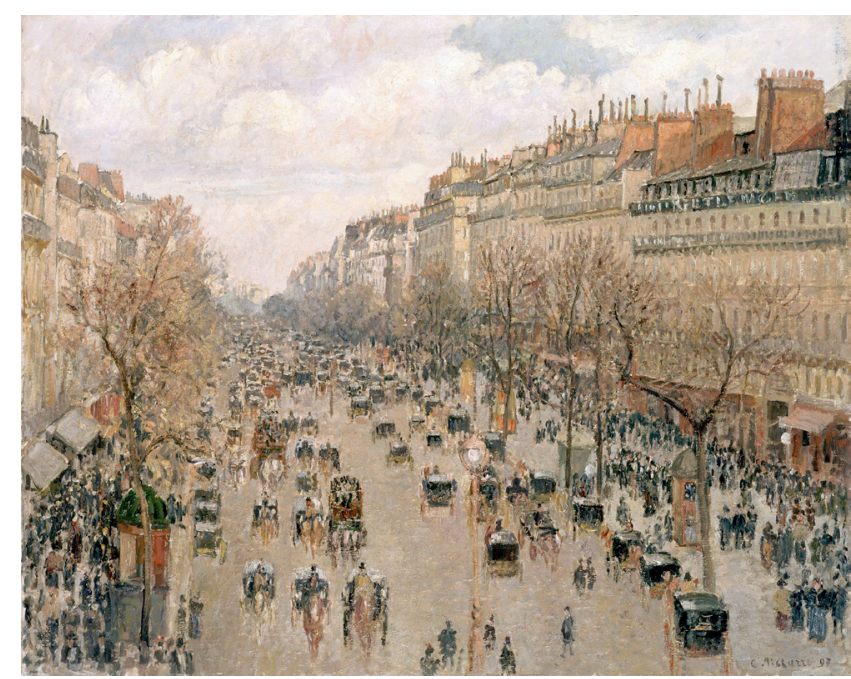


sidewalk in London around the seventeenth century (Mehta, 2013, pg. 35). However, these changes in the seventeenth and eighteenth centuries resulted in the disappearance of vibrant street life and the rise of the boulevard as the focus of public life. The boulevard became a large, expansive place for all classes of the public as well as a stage on which society people could promenade their culture and beauty. (Mehta, 2013, pg. 35). Boulevards and avenues were laid out so as to reclaim parts of the city from problems areas such as slums. These new linear streets broke the pattern of pre-existing smaller squares and plazas that acted as the nuclei of medieval neighbourhoods. Now all avenues were routed towards the palace (Mehta, 2013 pg. 38). This urban design of linear boulevards was used to control and govern space as well as to bring a new order to the city and to display power. The European boulevard started to be seen in America, most notably in Washington DC, as part of the City Beautiful movement. The idea was to add hierarchy to city planning and to connect and put on display important civic buildings. The American boulevards never achieved the same intensity and success as their European counterparts due to the lack of density adjacent to them, and to slow speeds of growth (Mehta, 2013, pg. 39). Nonetheless, the grid with its efficient way of dividing land, became prevalent in America as an organizational tool that provided an easy method for accommodating city growth.

\subsubsection{Industrial Age}

During the Industrial Revolution, the urban-rural balance shifted greatly as a large flux of people moved into cities to work in factories. Urban areas including New York, London, Berlin and Chicago experienced an explosion in population growth. For instance, London grew from one to seven million between 1801 and 1910 (Mehta, 2013, pg. 40). Many of these cities could not cope with the rapid growth and as a result took on the social problems that came with it. Mumford described the new urban conditions: "The main elements of the new urban

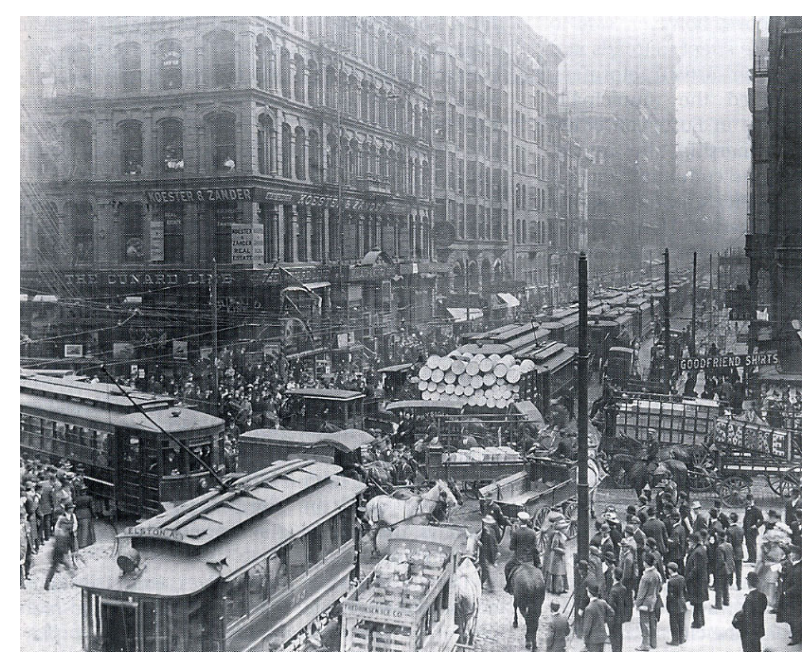

complex were the factory, the railroad, and the slum...The factory became the nucleus of the new urban organism. Every other detail of life was subordinate to it." (Mumford, 1964, pg. 458). The quality of urban life dropped drastically due to pollution caused by the factories that resulted in dark and airless, deteriorating streets. In hopes of fixing these issues, urbanists prescribed for the city the implementation of sunlight, fresh air and greenery. These prescription "fixes" for the city inspired three utopian concepts of cities.

Ebenezer Howard envisioned the Garden City that sought to bring the benefits of the countryside into the town. There was a strong emphasis on nature as the tool for the layout of the town. The proposal was to create self-contained communities that were separated from industrial areas and connected with grand tree-lined avenues (See Fig. 2.4). Homes became separated from work, from leisure and from other venues. This was the beginning of a definite separation of zoning areas and of a separation of uses. Due to this "in all these iterations of Howard's Garden City one thing was common - gone were the hustling, bustling, chaotic and energetic multiuse streets of the city" (Mehta, 2013, pg. 44). 


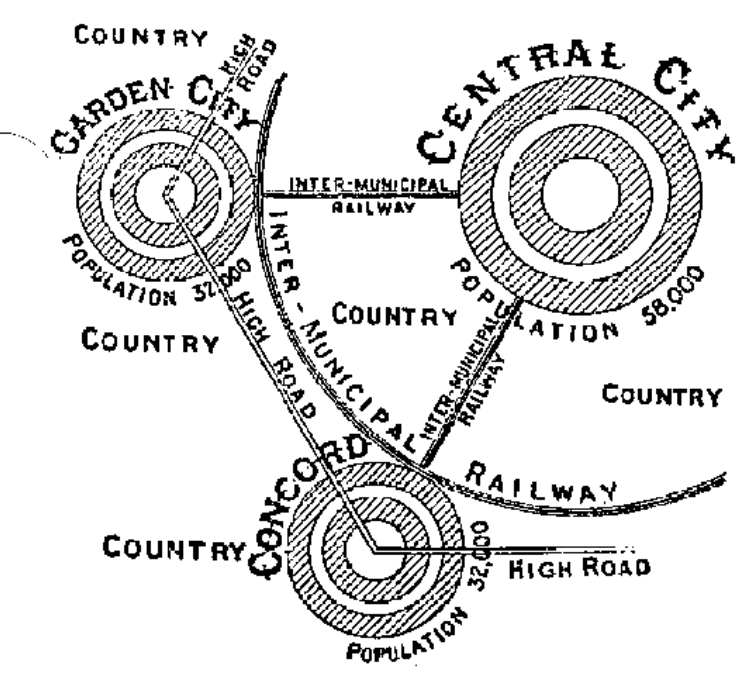

\subsubsection{Modernism}

Just after the proposal of the Garden City, members of the Bauhaus were developing their own ideas regarding how to counter the inadequate historic city. While the members of Bauhaus all produced their own ideas for the new city, only Le Corbusier created a complete vision for the new ideal city. Corbusier designed three utopian cities. The first was La Ville Contemporaine (Contemporary City), followed by the Plan Voison, and lastly La Villa Radieuse (Radiant City). These city designs were celebrations of the machine age where order and speed were prioritized in order to achieve efficiency. La Ville Contemporaine featured a series of cruciform high-rise towers arranged in a very symmetrical and orthogonal grid, and connected by a grid of highways and roads (See Fig. 2.6). The pedestrian and the vehicle were segregated, with the use of the vehicle being glorified. The slow pedestrian-filled streets of the historic city were a thing of the past where "There are no more "corridor streets,' as [Le Corbusier] called them - no more narrow roadways filled with traffic, completely lined with five or ten-storey buildings (See Fig. 2.5). Instead, the 'streets' are elevators, rising straight up instead of spreading out over a whole district" (Fishman, 1982, pg. 192). Le Corbusier saw the overlap of living working and leisure as one the issues of the historic city, and designed a city that separated them, emphasizing the Pack-Donkey's way for connecting separate places.

Frank Lloyd Wright was also designing his own ideal utopian city around this time, called the Broad Acre City. However, the design was less of a city and more of a rural community as Wright considered the city obsolete. Wright's design considered that with the increasing prevalence of the automobile, personal transport and mass communication, there would be no need for centralized
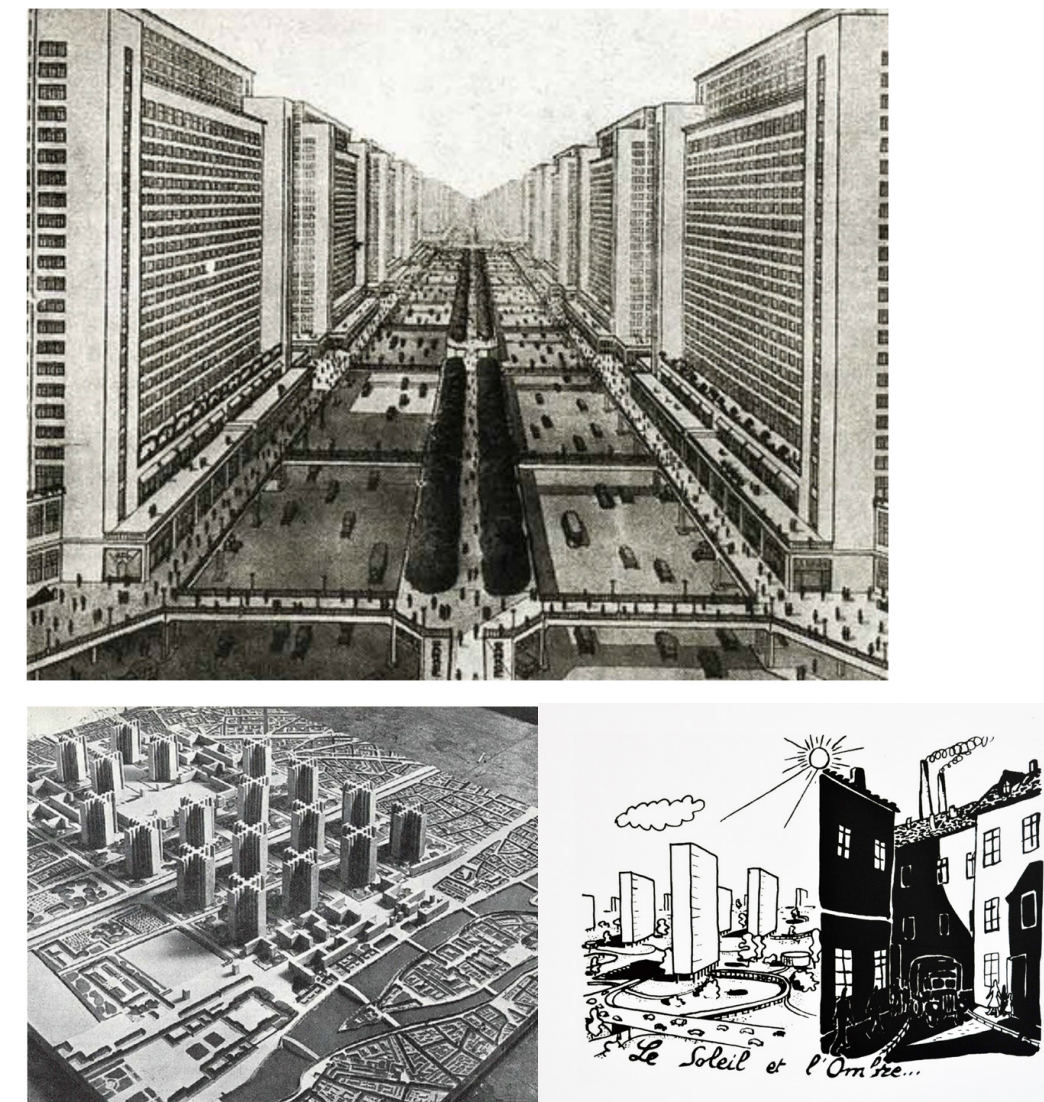

Figure 2.5 Contemporaine Streets

Figure 2.6 Corb's La Ville
Contemporaine Cruciform Towers

Figure 2.7

Le Soleil et l'Ombre old city vs. Bright new city 
places of social and economic exchange. Instead, citizens could travel by personal transport to school, work, church and other community venues, and could live on an acre of land (See Fig. 2.8).

Although these utopian cities were never fully realized, they have had a large impact on urban planning since their inception. Modern suburbs can be seen as a combination of both Howard's Garden City and Wright's Broad Acre city, while modern downtown areas can be seen as versions of Le Corbusier's Contemporary City (Mehta, 2013, pg.48).

It was in the 1920's when streets were still lively and vibrant that pre-modern North American cities hit their peak. However, with increased automobile use came traffic congestion and various types of pollution including noise pollution that transformed the streets from places to socialize to routes for people to hurriedly go from one place to another (Mehta, 2013, pg. 48).

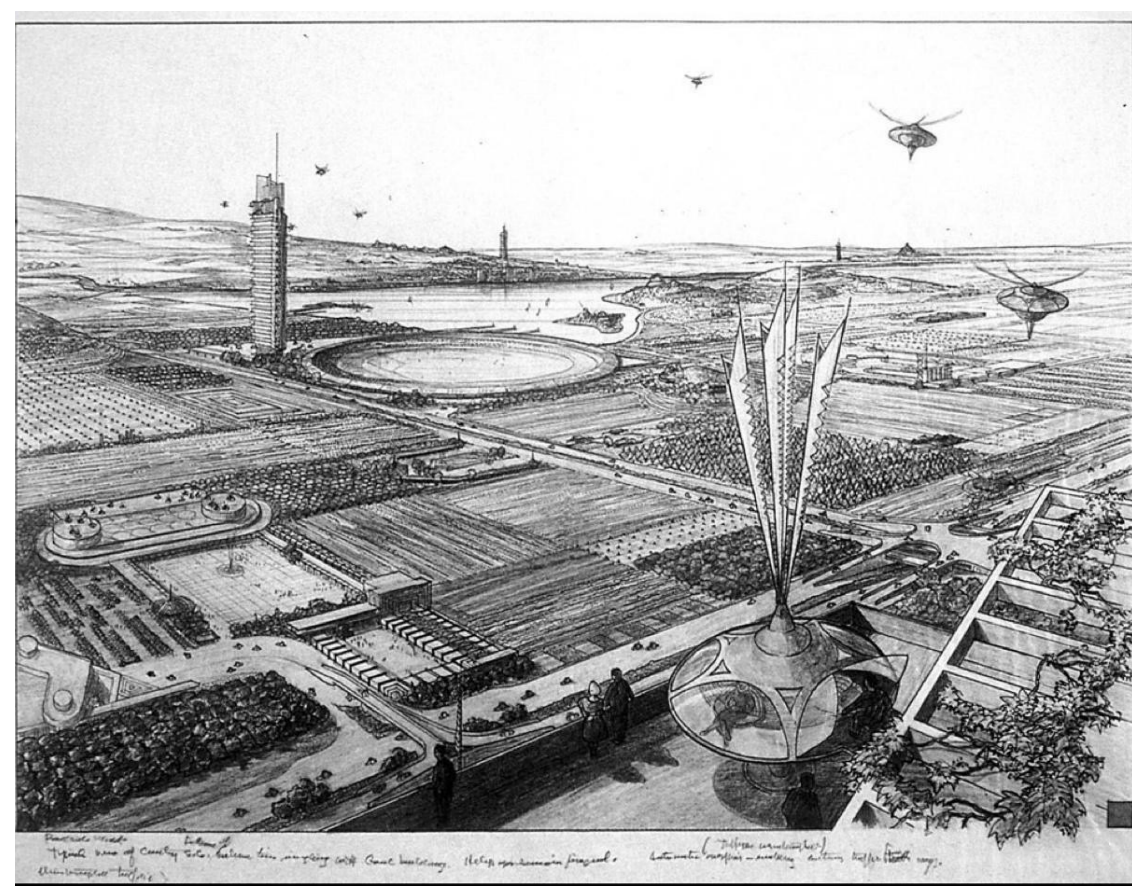

2.3.7 Post War

Reconstruction of postwar cities in Europe drastically changed their urban landscapes, particularly in areas damaged by the war. Monolithic towers and modernist landscape took over these areas. In the USA, urban renewal and the federal highway program changed city neighbourhoods, replacing them with modernist towers. The highway system took over the image of the street, and connected the entire country, sometimes demolishing parts of the city to make room. The suburbs were efficiently connected to downtown cores while leftover downtown streets were transformed to efficiently accommodate the automobile with little or no concern for the pedestrian. The street prioritized the vehicle, transforming what had been meaningful social streets central to peoples lives into places whose only purpose was to accommodate the movement of the automobile. "Within a course of forty to fifty years, the open space in the center of cities, particularly the downtowns of most North American cities, were transformed from a typology of vibrant, lively and sociable streets up until the early twentieth century into the privatized plazas of the mid- to late twentieth century" (Mehta, 2013, pg. 49).

\subsection{Emergence of Lost Spaces}

In the contemporary city, the erosion of public life is clear to see. When the dominance of the automobile in the 1960's made urban sprawl possible, city streets and plazas were traded for the suburbs. People and industries began to move towards the peripheries of the city. As people started moving towards the suburbs, the once vibrant plazas and squares lost their relevance as places for social and civic events. Urban planners and architects designed city spaces through the lens of the automobile and no longer saw them as venues of public life. This changed attitude towards the city resulted in the emergence of nonplaces or lost spaces. Previously usable land became less viable, resulting in vacant deserted areas. Changing economic, industrial and employment patterns 


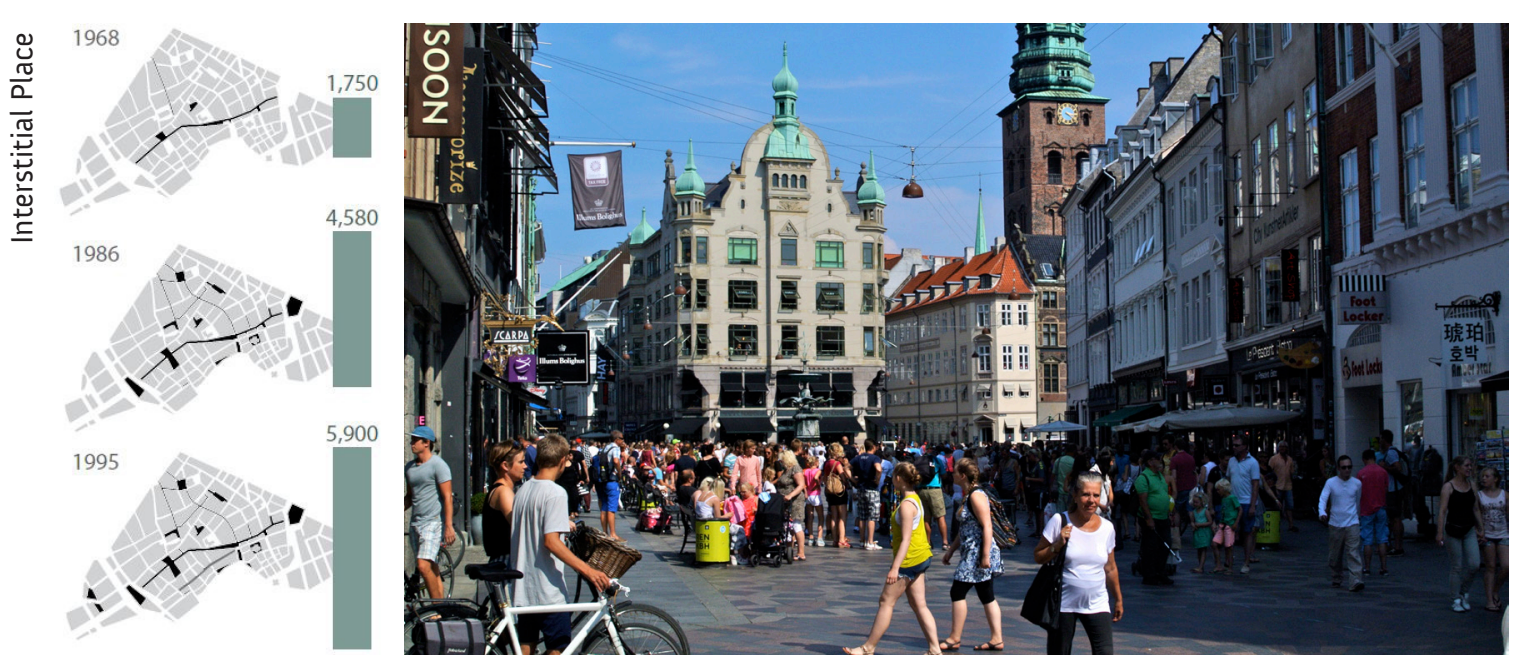

Figure 2.10

Conversion of

Pedestrian Streets in
Copenhagen and use

Figure 2.11

Copenhage transportation (car, bike, and walking) are treated equal and share the whole street. In this version of the street, curb and barriers are eliminated to blur the boundaries between different types of traffic and to ensure that all traffic proceeds at a reasonable pace. An example of this is Exhibition Road in London, a wide and linear street that was converted into this kind of shared space. The redesign was fairly simple but very effective. One of its notable features is its bold diamond-patterned paving that unifies the entire street from one side to the other. The street becomes a place of destination and encounter rather simply a place to past through (See Fig. 2.13).

Other versions of the shared street popular are in Europe in cities like Barcelona. They are pedestrian-dominated: central grand boulevards surrounded by twolane vehicular traffic. This streetscape makes for a very vibrant pedestrian street with lots of public activity, at the same time as it manages vehicular, and bicycle traffic (See Fig. 2.12, Fig 2.14). The edges of the central pedestrian walkway are lined with little kiosks and shops as well as small cafes and seating. Trees also line the streets providing shade during the hottest times of the day.
The image of the street has gone from being lively, vibrant, and sociable place into a place of rapid circulation. The early street was a place for the exchange of ideas and events, and represented public life in the city. However, as the vehicle took prioritization of the street, the street stopped being a place of event. Recent efforts to transform the street back into a place of public life have prioritized the pedestrian over the vehicle successfully creating pedestrian thoroughfares. However, issues of place and lateral connectivity to adjacent buildings is to be further explored.
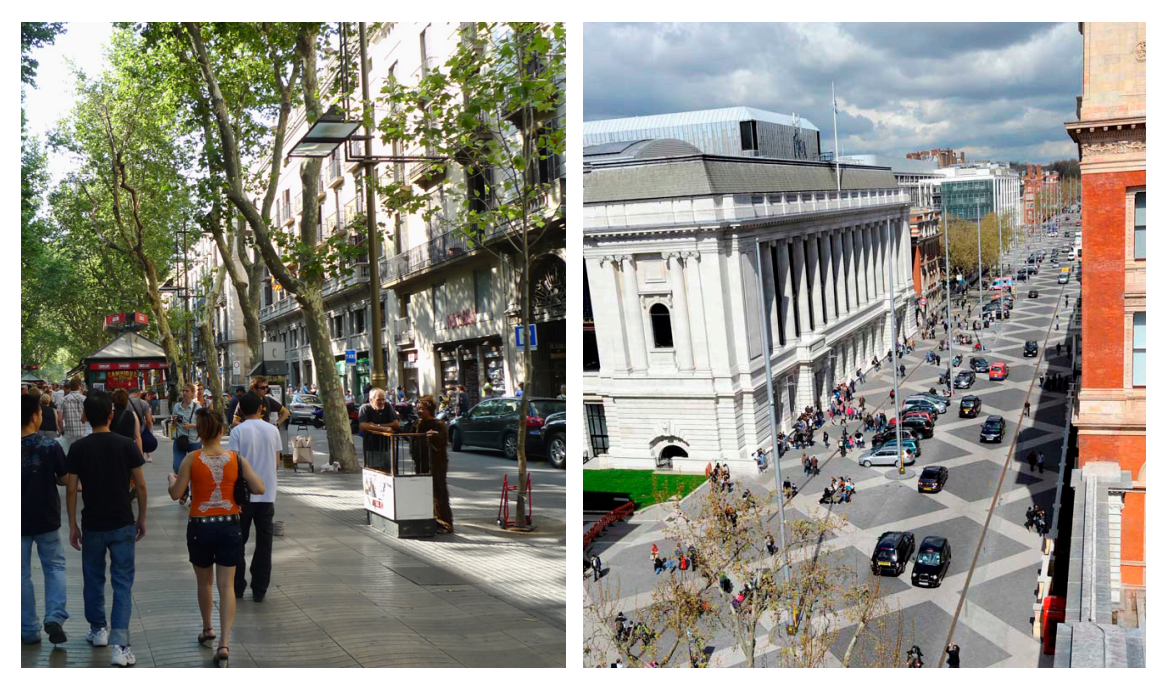

Figure 2.12 as Ramblas, Barcelona Figure 2.13 tion Rd, London Figure 2.14 Las Ramblas, Barcelona Street

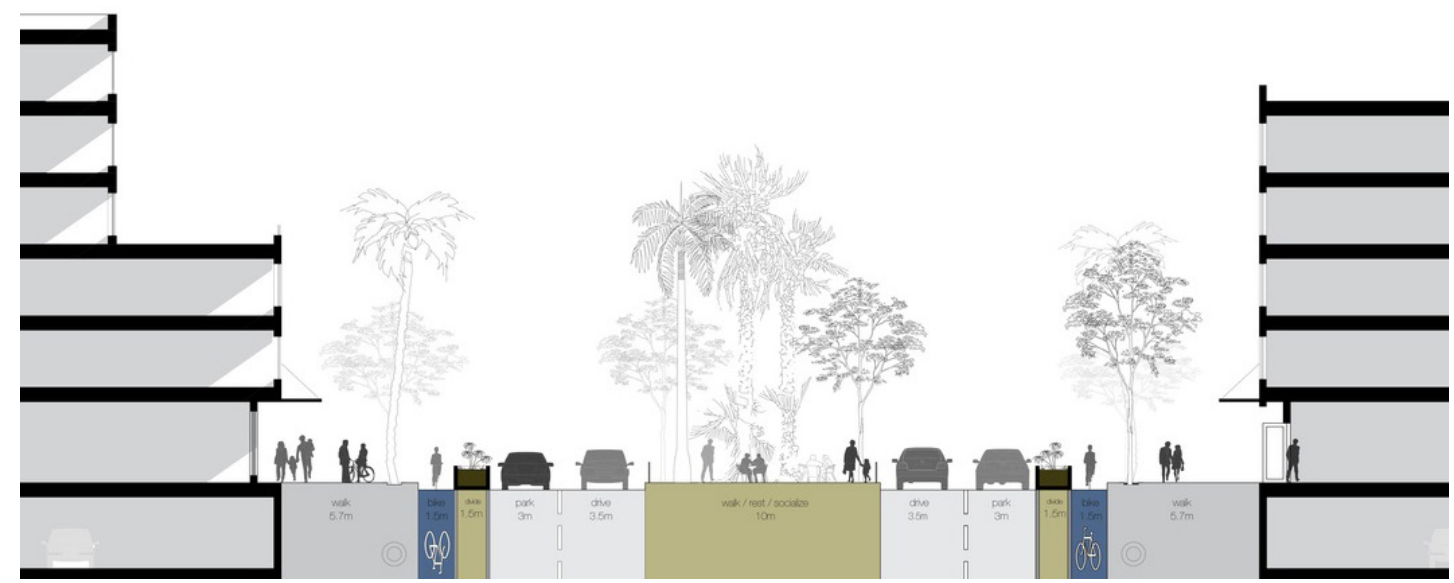


The concepts of place-making and of the creation of a sense of place emerged from a general increase in the homogeneity of public urban spaces in the twentieth century. Economic and cultural forces have resulted in more increasingly privatized urban spaces that do not establish a sense of place. Countering this issue, the concept of place-making isn't a really a new one but actually has ties with New Urbanism. It focuses on designing urban spaces that prioritize people rather than the car or other components. It's goal is the creation of lively, inviting public spaces that reinforce community. Visionaries such as Jane Jacobs and William Whyte have explored this concept of creating places for people. Jane Jacobs spoke about the importance of the sidewalk as the city's common ground: it can function socially as part of the community through such initiatives as 'eyes on the street' and become a safe and popular place.

\subsection{Places and Non-Places}

The word "place" is a unique word in the sense that it is a simple word that everyone understands, and yet at the same time can be ambiguous and a challenge to define in the context of architecture. In general, the difference between "space" and "place" is not clearly distinguished. The concept of place is multilayered and can be subjective. When significant meaning is attached to a space, it is transformed into a place. There are also non-places in opposition to places, Marc Auge describes as transitory and in-between spaces or spaces that are not significant enough to be called places. They are detached from any social networks or any localization. "If place can be defined as relational historical and concerned with identity, then a space which cannot be defined as relational, or historical, or concerned with identity will be a non-place." (Auge, 1995, pg. 7879). These non-places can be described as lost spaces: spaces that one simply passes through or that are consumed (for instance, by commercialization, media etc.) rather than ones that can be appropriated or that can engage users within.

\subsection{Existential Space}

In his book Genius Loci, Norberg-Schulz uses the term existential spaces to define the relationship between man and his environment. Existential space is divided into the concepts of space and character, which represent the psyche functions of orientation and identification respectively (NorbergSchulz, 1986, pg. 5). Norberg-Schulz defines place as space with distinct character and therefore place and existential space become synonymous. One of the roles of architecture is the concretization of existential space. The meaning of concretization can be understood by considering the meanings of "gathering" and "thing". According to Heidegger "A thing gathers the world". 
This together with Heidegger's concept of "Dwelling" provides catalysts for creating existential spaces (Norberg-Schulz, 1986, pg. 5). “Man dwells where he can orient himself within an environment or in short when he experiences the environment as meaningful" (Norberg-Schulz, 1986, pg. 5). Dwelling in this sense means more than just shelter; it implies "spaces where life occurs are places" and is an important aspect of architecture (Norberg-Schulz, 1986, pg. 5). In short, architecture as a means to the creation of place is invaluable for giving man an existential foothold.

\subsection{Sense of Place}

The creation of a sense of place can be interpreted using a multitude of concepts: space and place, time and place, and people and place. Simon Unwin defines sense of place as: "[place] is where mind touches the world", "a place is a configuration of architectural elements that seem (to the mind informed by senses) to accommodate, or offer the possibility of accommodation to an object, person, an activity, a mood...", "through identifying places and organizing them, we make sense of the world we inhabit." (Unwin, 2003, pg. 25). To Unwin, place is something that users identify with and is a space that users can become familiar with.

Norberg-Schulz believes genius loci has a lot to do with how a place is experienced or lived in phenomenologically. Phenomenology can be seen as involving the 'whole place' while things that happen there 'take place'. The physical environment impacts and influences the activities that happen in a place. Elements such as colour, texture, materiality, scale, texture, atmosphere and character all combine to create a sense of place. Humans can experience these different architectural elements and interpret them in their own way. In combination, they can affect humans' moods and feelings and create atmosphere. Each has been designed to provide cultural significance individually and as part of a whole. Each place has its own distinct and unique characteristics and all of these contribute to a sense of place. The genius loci that originates from spirit of place is interpreted today as a distillation of the essence of a place into its separate and distinct physical, social and cultural characteristics.

Human Geographer Yi-Fu Tuan describes place as “...a type of object. Places and objects define space, giving it a geometric personality." (Tuan, 1977, pg. 17). He further discusses place in "knowing a place, in the senses, clearly takes time. It is a subconscious knowing. In time we become familiar with a place, which means that we can take more and more of it for granted. In time a new house ceases to make little demands of our attention; it is as comfortable and unobtrusive as an old pair of slippers." (Tuan, 1977, pg. 184). For Tuan, it is clear that sense of place has a component of time attached to it with activities and events contributing to its creation.

In People and Place: The extraordinary geographies of everyday life, Lewis Holloway and Phil Hubbard suggest: “... It is the relationship of people with places that is so important to geographical understanding. So, when we talk about 'people and place', it is important to be unambiguous as to the definition of the people or the place concerned. As a discipline which focuses on the role of space and place, it has become an axiom within geography that as people construct places, places construct people (inferring a reciprocity between people and place)" (Holloway \& Hubbard, 2001, pg. 7). Further: “...people and places derive their identities from each other to a significant extent. Going a step further, we also need to emphasize that this relationality is not something which is fixed and unchanging. Relationships between people and places are always in a state of becoming rather than of simply 'being"' (Holloway \& Hubbard, 2001, 7- 8). 


\subsection{Characteristics of Place}

The concept of creation of a sense of place recognizes that architecture transcends building and simply creating monuments and artifacts. Instead, it is about creating places for people. We live in a physical world and move to and from a collection of public and private spaces, each with the potential to be places where people interact socially and form a community. Place in this context means a powerful connection between people and settings. Place is a space imbued with meanings and values assigned by its users. Place has identity and embodies memory. Alan Gussow author of Sense of Place, says: "the catalyst that converts any physical location-any environment if you will- into a place, is the process of experiencing deeply. A place is a piece of the whole environment that has been claimed by feeling" (Gussow, 1971, pg. 27). The following explores three versions of the creation of place, through movement, event, and interaction.

\subsubsection{Place as Movement}

In the paper Neuroscience and Architecture: Seeking Common Ground, it is made evident that a space become a place depending on how a user interacts with it. The connection to place is largely influenced by how one moves through between different places. The sense of place in this context refers to how the brain resolves spatial awareness and deals with way-finding. The article gives the example of when circulation in buildings is very linear and consistent, this pattern creates within the brain a weak overall sense of place. (Sternberg, Wilson, 2006). When the environment presents possibilities for a free exploration of space, a strong sense of place is created, along with an attachment to the environment. This is because the user does not feel like they are just passing through, but rather have a sense of being part of the environment. Their experience of the place is therefore not so strongly influenced by the circulation or paths they take through the 'place' (Sternberg, Wilson, 2006). Rem Koolhaas' work is strongly ordered by the trajectories of movement through his projects and buildings. Koolhaas' goal through focusing on how people move through spaces is to create an "internalized culture of congestion" through a synthetic field (Dovey, 2010, pg. 104). Koolhaas wanted to create an eruption of events such as increasing social encounters through fluid pedestrian flows. He therefore designs his interiors as if they were exterior urban spaces (Dovey, 2010, pg. 105).

\subsubsection{Place as an Event}

Aldo Rossi says that architecture is "the fixed stage for human events" while Tschumi says "there is no space without event, no architecture without program" (Rossi, 1982, p. 22) (Tschumi, 1983). Both speak of architecture not just beyond the built form, but also of how humans' actions play an integral role in creating architecture. Architecture in this light is "not defined by its formal container, but rather by its combinations of spaces, movements, and events"

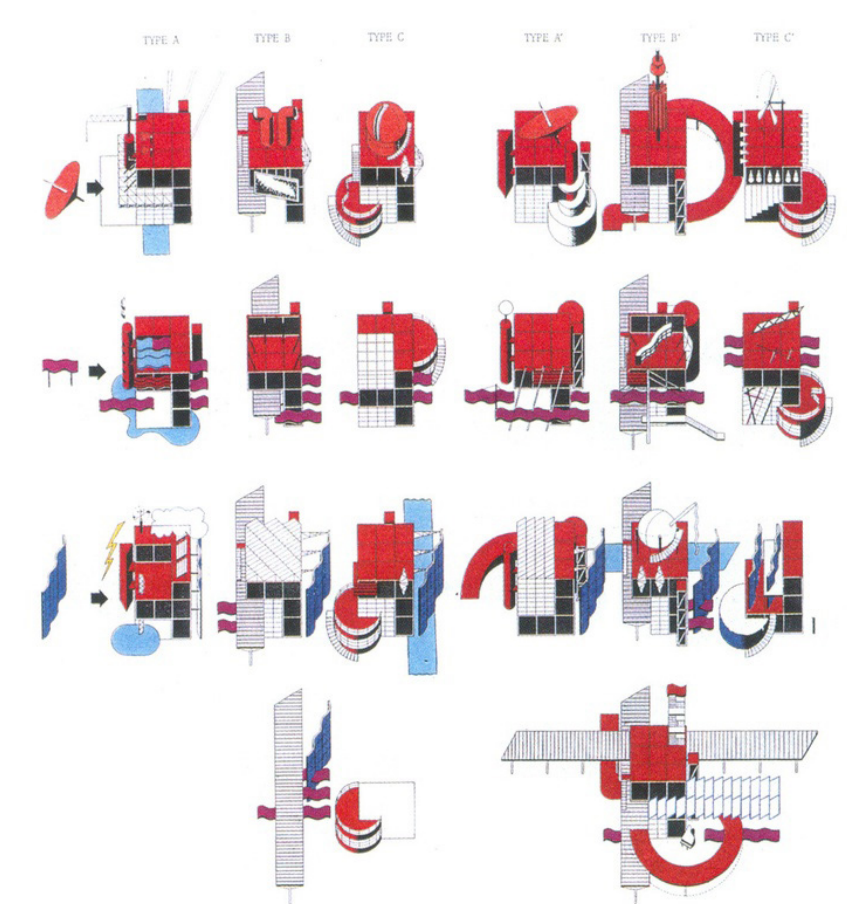



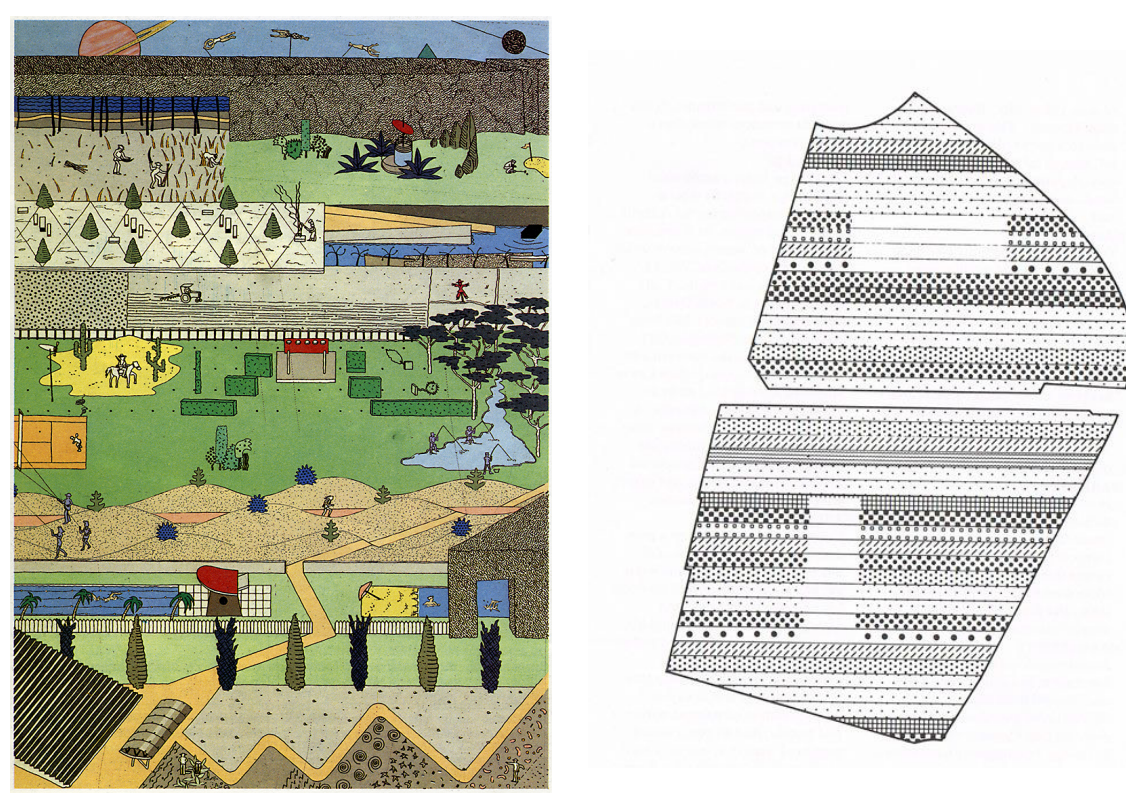

Figure 3.2 OMA's Parc De La Villette Submission Vignette

Figure 3.3 OMA's Parc De La
Villette Submission Horizontal Strips

(Tschumi, n.d.). Tschumi's Park de la Villette recognized that buildings respond to and intensify the activities that occur within them, and that events alter and creatively extend the structures that contain them. Similar thinking was behind OMA's competition where they proposed a horizontal skyscraper with parallel strips of activities and programming; these were intended to maximize the amount of borders between programs, to maximize the amount of connective collisions, and to promote continuity, involvement and coexistence. Strategies for hybridizing architecture with landscape and infrastructure in an attempt to create activities and events will be explored in the next chapter.

\subsubsection{Place as Interaction}

Where there is dependence on the car and densification in urban centers, a certain social presence is often lacking. This loss of place or sense of place could also be the cause of the absence of informal life in the twentieth century (Oldenburg, 1999, pg. 9). Oldenburg offers the concept of the third place as a solution for the creation of place. With the first place defined as the home and the second place as the workplace, the third place is any informal social place such as a café, pub, or main street where people meet. Characteristics that make up a third place include neutrality and a warm and inviting atmosphere that ensures a diverse and rich environment. Within the third place, the main activity is conversation: people can stop, meet, relax and interact socially.

Viewing the city and its streets as a third place can engender meaningful interactions between people and their environment for the creation of a vibrant urban life. Jan Gehl describes the importance of the presence of people as a catalyst for vibrancy in a city "people gather where things are happening and spontaneously seek the presence of other people" (Gehl, 2013, pg. 25). The social activities in public spaces vary in intensity and start with large group events such as markets, parades and demonstrations. The medium level of intensity includes social activities such as people meeting each other and exchanging greetings and small talk, and chance encounters amongst people who are just hanging out. The most passive social activity includes people-watching which as Gehl describes is "a modest and unpretentious form of contact and is the most widespread activity." (Gehl, 2011, pg. 17). Where there is no potential for any form of activity, the lower forms of social intensity such as people watching, disappear (Gehl, 2011, pg. 17).

The design of public spaces should be designed with place in mind. Moving beyond a goal of consumption, recognizing that the creation of place in public spaces is an important task where enabling social engagement and creating meaningful connections to place can help prevent the erosion of the public realm. These three themes in the creation of place: movement, event and interaction will be explored in the next chapter through new ways of creating public space by combining architecture with landscape and infrastructure. 


\section{Landscape Urbanism}

Landscape urbanism is a fairly recent concept that views the medium of landscape as the new basis for urban design. It was born out of a critique of contemporary urbanism that considered architecture as the model for city planning. It involves the realization that a synthesis of landscape and architecture is necessary. Neither should be considered separately with one or the other taking precedence, but rather both should be integrated and work together. Stan Allen (2001) describes the potential of the landscape: "Increasingly, landscape is emerging as a model for urbanism. Landscape has traditionally been defined as the art of organizing horizontal surfaces...by paying close attention to these surfaces conditions designers can activate space and produce urban effects without the weighty apparatus of traditional space making" (Waldhiem, 2006, pg. 38).

James Corner outlines a few schematic themes that describe the nature of landscape urbanism. The first of these addresses a process over time that deals with the intangibles that make up a metropolis. Modernist planning tried to control urbanization of the city through the built form and rigid planning. However, in reality, a city's complex intangible cultural and social layers can not be simply resolved through the rigid planning of modern buildings and structures.
The utopian bird's-eye methods of Modernist planning were not derived from such dynamic processes, nor did they try to re-direct these processes within them. A fundamental, underlying principle of landscape urbanism is its attempt to understand the complex intangible networks and layers of urban environments over time, and to use them as bases for design (Corner, 2006).

The second theme that landscape urbanism explores is that of the surface. Corner describes the surface as "the phenomenon of the horizontal surface, ground place, the "field" of action." (Corner, 2006, pg. 30). Landscape, in that it occupies all the surfaces in the voids between buildings, unifies the urban fabric. In an urban context, the surface that consists of roads, fields, blocks, buildings and utilities is conceived of as a landscape. In other words, landscape can be seen as an infrastructure. However, it is an infrastructure that provides more than just mobility, a concept that recalls Gehl's analysis of Life Between Buildings. Landscape can be seen as a dynamic tissue that links both spaces and objects with the processes and events that move through them (Wall, 1999, pg. 221). Landscape, however, is not limited to the space between buildings, nor to green spaces; rather, the urban landscape comprises the field of the city and the complex matrix that makes it up (Wall, 1999, pg. 233). Where architecture "consumes the potential of a site in order to project", redefining landscape 
as an active surface opens up possibilities of creating new connections and interactions that bind and relate all involved elements (Corner, 2006, pg. 31).

Since its conception, there have been few realized landscape urbanism projects. However, the Seattle Olympic Sculpture Park by Weiss Manfredi is a clear manifestation in landscape urbanism principals. The site of the Olympic Sculpture Park was an industrial brownfield that had train tracks and a road cutting through it. Its project proposed a continuous surface that would connect the waterfront to a pavilion at the top of the site, capitalizing on the forty-foot change in gradient. The project seamlessly connects the city to the waterfront through the use of landscape over existing infrastructure. Its sculptural element activates $Z$ circulation paths and creates a new identity for the site. It functions as an infrastructure that moves and connects people from two previously disconnected parts of the city; it thereby contributes to a continuous public realm. Its artificial surface articulates flows on the site, while the grass supports the sculptures; other site areas have been left unprogrammed for future appropriation.

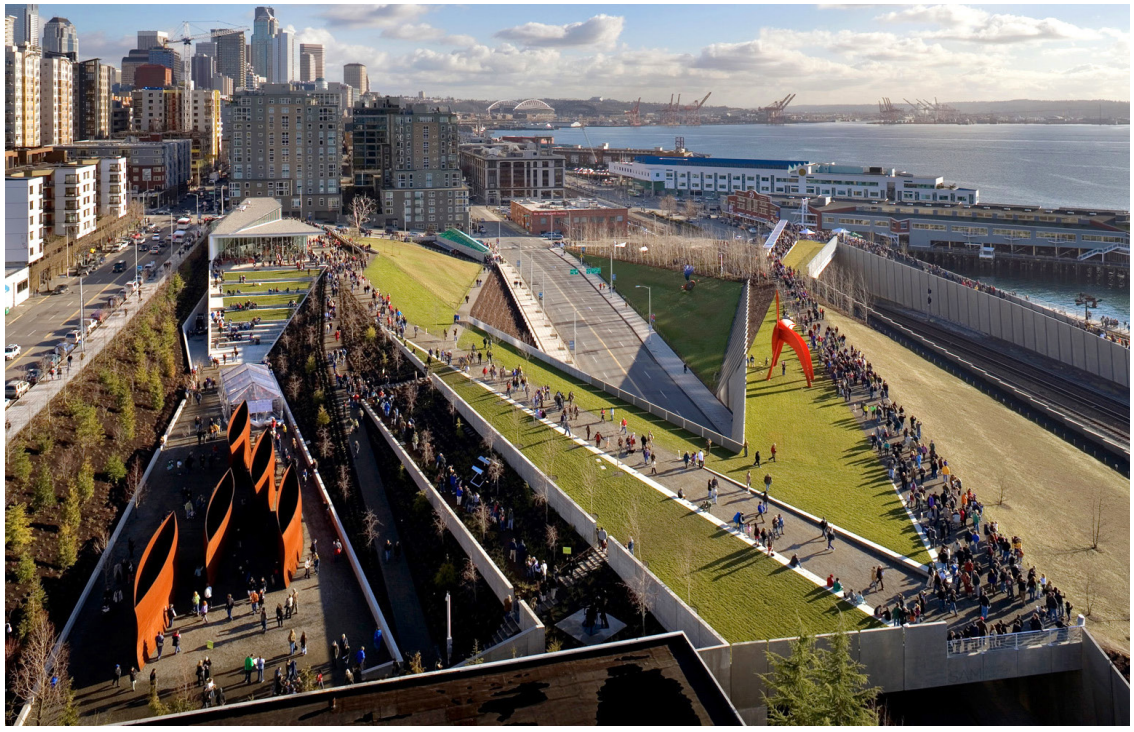

\subsubsection{Landform Building}

While landscape urbanism has produced promising concepts and theories on organizing the urban fabric as a field, as stated previously, to date only a small number of projects have been realized. Landform buildings emerged as a concept that built upon ideas brought forth by landscape urbanism. Landform buildings explore the limits of landscape urbanism formally and programmatically, working on a scale between the landscape fields and the object building. Where architecture has traditionally associated itself with the vertical plane, through the synthesis of landscape and architecture, landform buildings explore the possibilities of flexible boundaries and a horizontal field of interconnected surfaces (Allen, \& McQuade, 2011, pg. 23). These projects tend to evoke an architectural language that is inspired by topography, or by natural landscapes that balance formal continuity and programmatic flexibility. In the essay Programming the Urban Surface, Alex Wall outlines current trends regarding urban landscape surfaces. It presents precedents such as the FOA's Yokohama terminal to outline strategies for surfaces.

Thickening: Adding multiple number of public ground planes produces a dynamic thickened surface that connects flows of people through elevators, escalators, ramps.

Folding: Warping or folding the surface to blur the distinctness of the floor, wall and ceiling can create a continuous surface. In the Yokohama terminal, there is one continuous surface that directs the flow of the people going to and from the city. The traditional understanding of zonal separation is put into question where the zones become fluid and interactive.

Material: The use of material such as asphalt, rubber, metal and wood can express and provoke activities as well as orienting or helping with way-finding. The urban landscape can be made more diversified through utilizing a range of materials.
Figure 4.1
Olympic Sculpture

Park - Continuous Park

Surface 


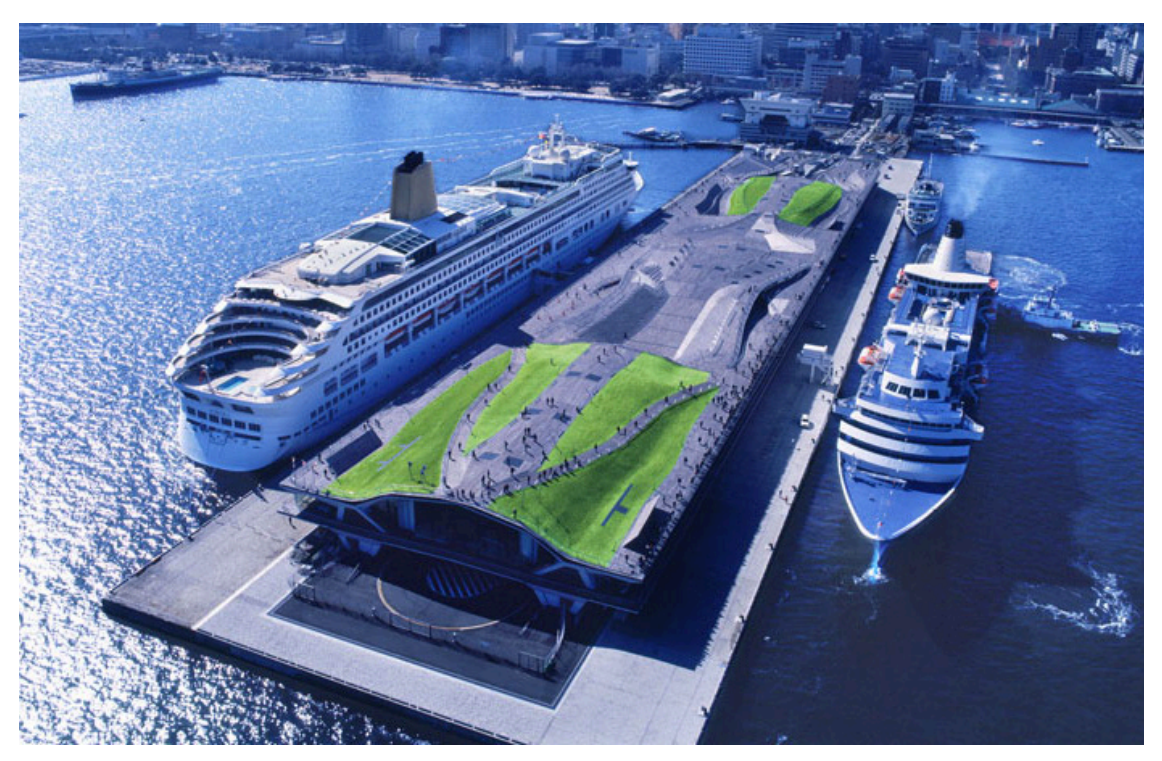

Non Programmed use: Instead of using elements that serve only one function in a space, allowing the programming to be ambiguous and subjective according to its users can encourage use of spaces and can enrich the social experience of the place.

Impermanence: Flexibility and interchangeable programming and functions must be designed to respond to the constantly changing demands of any project. Any project should be able to respond to future demands without diminishing its own integrity (Wall, 1999, pg. 245).

This exploration of fluid boundaries in landform buildings explores the boundaries between public and private. Heterotopia, a term coined by Foucault, means 'other places'; it refers to the realm between private and public spaces and can be called a third place that is concerned with leisure and culture. Heterotopias, as opposed to Auge's 'non-places', have emerged in response to the post-modern city's preoccupation with constant change and flux (Dehaene, 2008, pg. 5). Firms such as UN Studio, FOA, OMA, and MVRDV have pursued formal strategies to deal with the dynamics of the city through the projection of socially integrated spaces (Stickells, 2008, pg. 247). FOA's Yokohama Terminal best explores the concept of the landform building through deploying a smooth 'surface' that generates a new form of public space. The terminal operates less as a gate and more as a field of movements as it blurs the boundaries between the interior and exterior, and as floor turns into ceiling. These spaces intentionally "attempt to refocus the public life (normally associated with the square, the piazza, the static place) of the city within spaces of intense movement" (Stickells, 2008, pg. 247).

\subsection{Integral Urbanism}

As an alternative to landscape urbanism, urban theorist Nan Ellin, inspired by ecological design, proposes an integral urbanism to contrast with the Modernist and post-Modernist ideas of master-planning. Ellin proposes acupuncture for the city to heal the wounds created by a diminished sense of place and community and by a lack of public space. Through enhancing flow in the city to activate neglected non-places and abandoned in-between, spaces can begin to act as catalysts for other interventions and can produce a domino effect on the surrounding areas (Ellin, 2006, pg. 6). They can open urban blockages to facilitate connections and ease movement. To achieve this, Integral Urbanism proposes five qualities: hybridity, connectivity, porosity, authenticity and vulnerability. These qualities blur the boundaries between functions and bring activities and people together. This is in opposition to modern urbanism, which presents clearly defined separations.

One example of Integral Urbanism is the Turuel-zilla project in Spain by Mi5 Arquitectos. It necessitated improving the quality of life in a square within a historical part of the city. With two nearby public squares functioning as public space, the Teruel City council proposed turning the third square into a leisure node. The architects decided to go two levels underground, mixing in sports, 


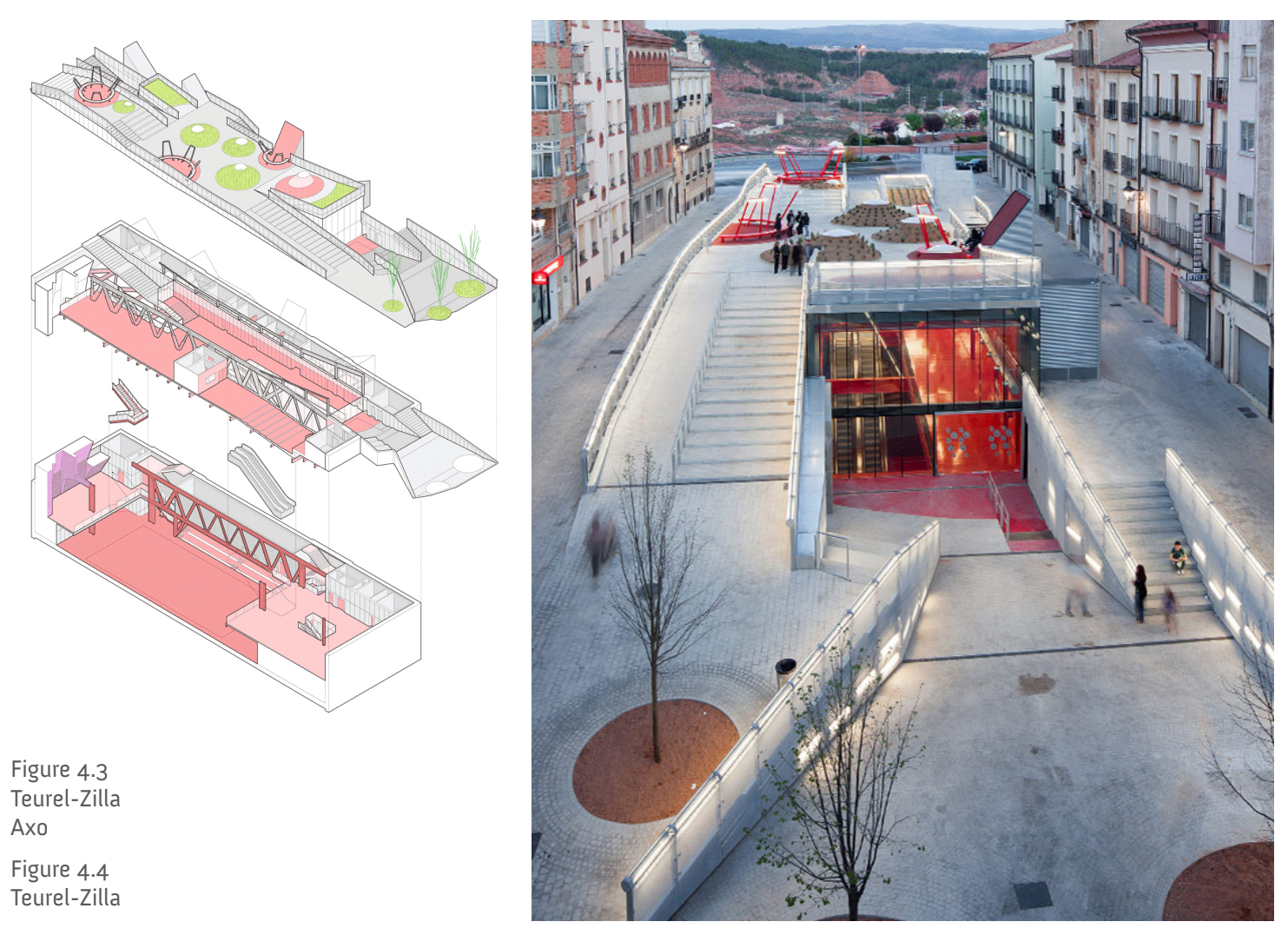

leisure and commercial activities and allowing for a flexible range of activities such as football, ice skating and concerts. On the top of the underground structure is an urban landscape that allows for continuous flows over it. It doesn't disrupt the surrounding urban fabric but rather provides a dynamic public space. The goal of the project was to push boundaries to achieve densification and public enhancement within a historical urban fabric by bringing in vibrant city life. The main building serves as an extension of the landscape and embodies the interstitial space by creating a void carved out of the ground.

A second project is Toronto's Wavedeck designed by West 8 and DTAH Architects on the waterfront. Its unique design features 'waves' of different heights. This unique and dynamic structure acts as a pathway to direct pedestrian flow and provides connections to the waterfront; people interpret the Wavedeck as a flexible gathering place. Pedestrians experience the vertical and horizontal movement of the wooden waves as they sit and pause along their edges. Its elevation encourages pedestrians to walk, sit or play and thereby creates a dialogue between the body and space.

Both projects activated two non-places in a city and filled them with activity and intensity through the creation of quality public spaces. The sites have become integral parts of their city that act as connectors and enhance flow.

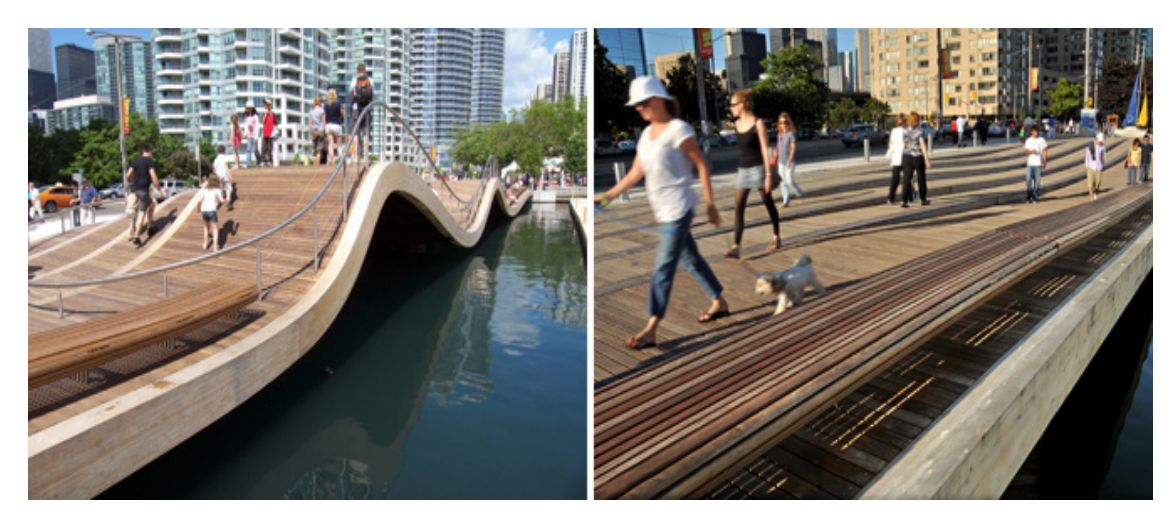

Figure 4.5 Toronto Waterfront -
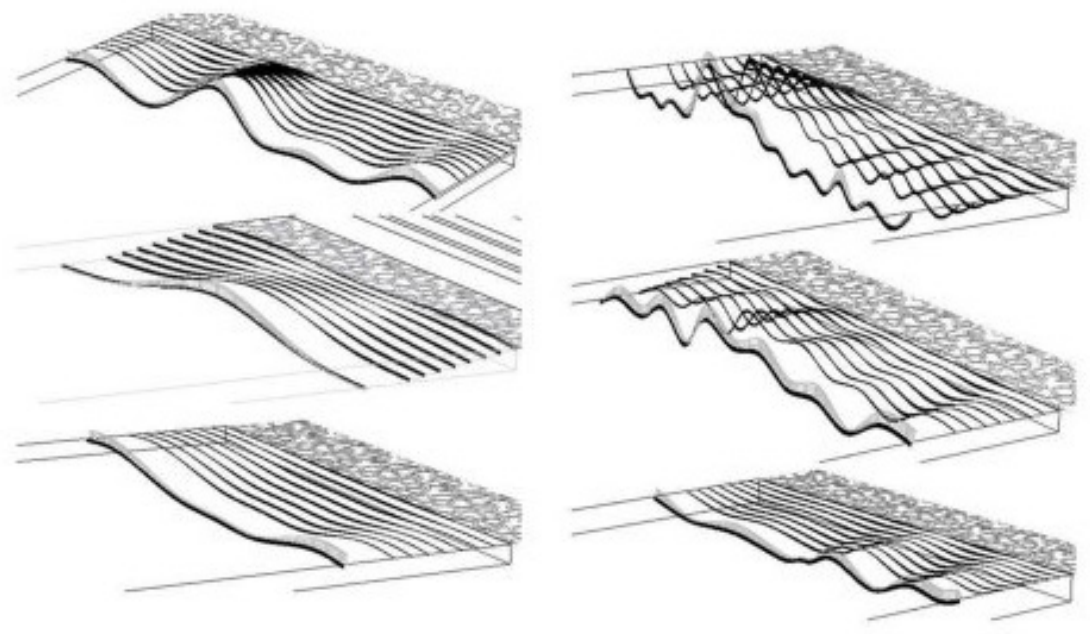


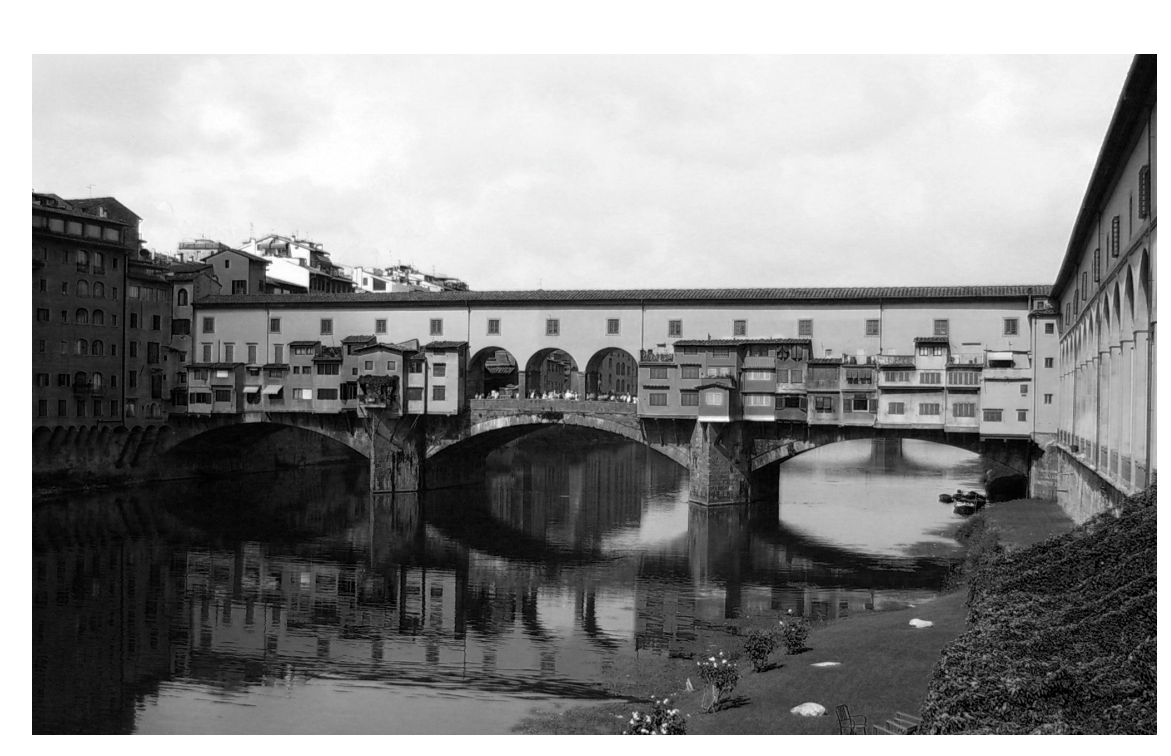

Infrastructure and architecture have traditionally been treated as separated media. This could be due to an architect/engineer divide in regards to building/ landscape (infrastructure) in city planning. With engineers being the ones responsible for designing infrastructure systems, it is easy to see why these systems are designed primarily for efficient transportation and rarely for anything beyond the movement of people and goods. Nevertheless, infrastructural urbanism emerged as a derivative of landscape urbanism to explore how infrastructure and architecture could be combined rather than treated separately in the creation of public realms. Infrastructural urbanism departs from landscape urbanism in that it re-establishes architecture as the backbone to urbanism, rather than strictly dealing with landscape. Stan Allen (2010) discusses the limitations of landscape urbanism where realized projects have more or less stayed within the bounds of landscape architecture (Allen, 2010). Alternatively, Stan Allen presents the new potentials of infrastructural urbanism in Points + Lines where he re-establishes architecture's instrumentality: "Infrastructural urbanism understands architecture as a material practice-as an activity that works in and among the world of things, and not exclusively with meaning and image...It is a way of working at the large scale that escapes suspect notions of master planning and the heroic ego of the individual architect. Infrastructural urbanism marks a return to instrumentality and a move away from the representational imperative in architecture." (Allen, 1999, pg. 52).

Historically, the integration of architecture with infrastructure has been explored in a number of ways. One of the earliest examples of architecture and infrastructure working together is Florence's Ponte Vecchio built in 1345. This bridge supports pedestrian flows while supporting shops and housing along its sides. (See Fig 4.7)

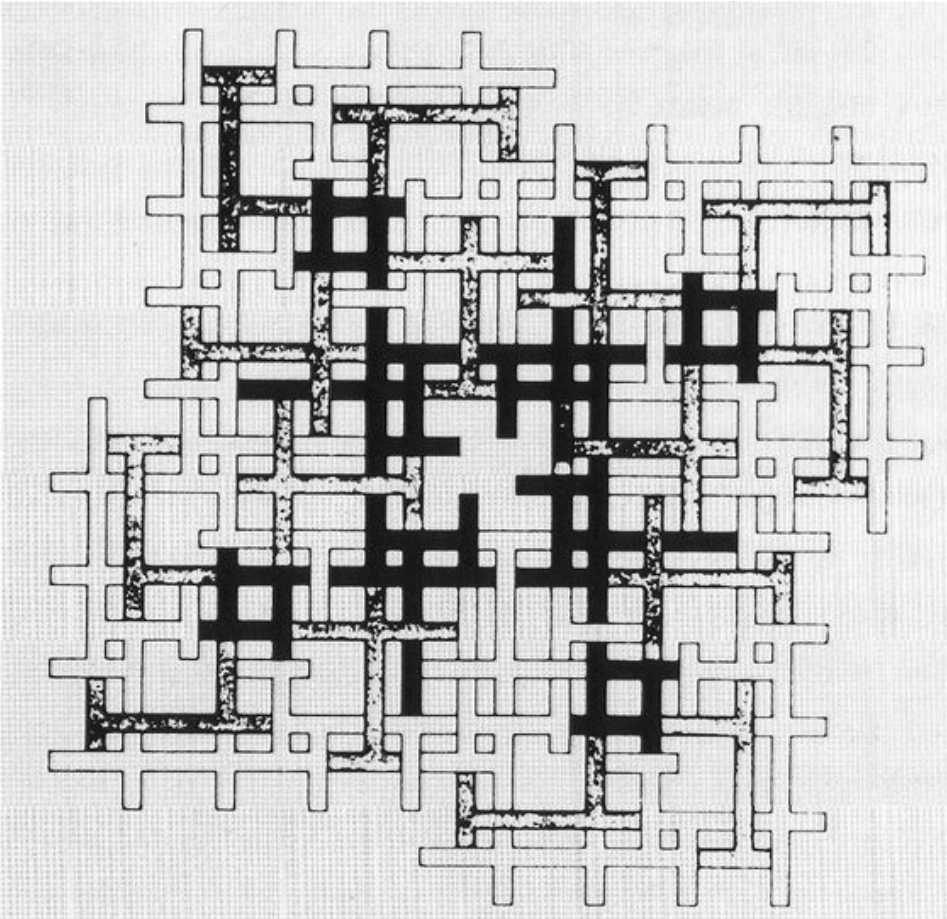


In the 6os, the concept of a MAT building was introduced. In 1962, Aldo Van Eyck proposed 'Noah's Ark' to the members of Team 10. Although the proposal was fairly abstract, it suggested a strategy for a city's growth through a complex network of clusters with a range of functions and a four-level road network interwoven through them. The concept of a MAT building negates the notion that architecture is restricted by existing infrastructure and sites and presents the concept of architecture as infrastructure, a hybrid of two concepts. (See Fig 4.8)

Paul Rudolph's proposal for the lower Manhattan Expressway in 1962 presented a mega-structure that combined different scales and typologies of architecture that worked well with infrastructure. The proposal consisted mainly of a submerged highway with buildings above it (See Fig 4.9). These systems were conceived of as parallel and both dependent on the other; people movers were integrated into the system. However, as the project became more and more refined, issues started to emerge. There were health concerns over the enclosed vehicular highway's exhaust and proximity to the dwellers. Another issue was the division between public-private negotiations for the proposal. Perhaps the biggest issue of all was that the quality of the public/pedestrian realm was lost because of the scale of the proposal. Projects conceived on this scale of urbanity received the same criticism as Corbusier's La Ville Contemporaine. The concern was that master planning at this level tends to overlook the scale of the individual, and fails to design spaces for people.

Explorations like Paul Rudolph's that combined architecture and infrastructure dealt mostly with the realm of the automobile. This has proven to be a difficult area to deal with due to issues of noise, pollution, exhaust fumes, etc. Any approach that combines architecture and infrastructure inevitably gives in and favors the vehicle as the dominant entity, rather than having both elements

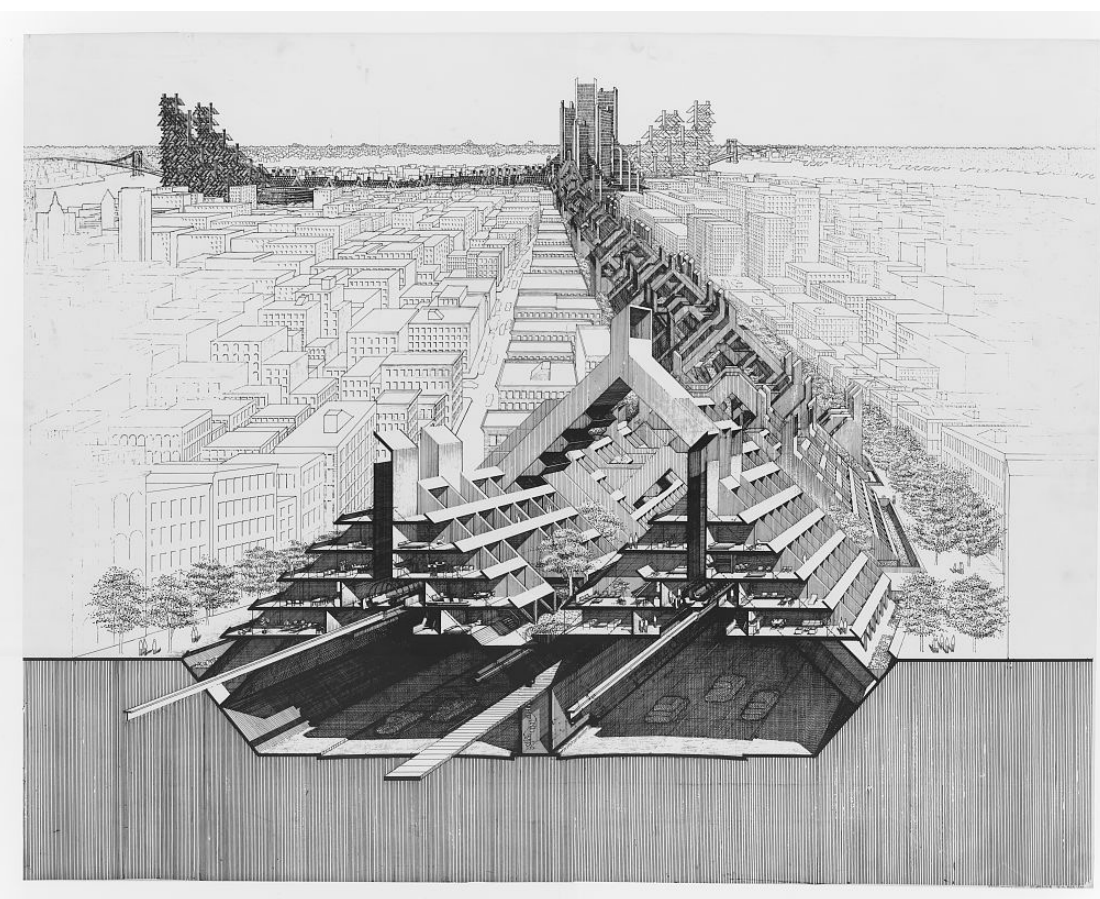

Figure 4.9 Paul Rudolph - Lower Manhattan Expressw

work together for mutual benefit. Contemporary precedents have shifted focus to emphasize accommodation of the pedestrian. Seeking ways to integrate the public realm within the scope of pedestrian infrastructure has given rise to new possibilities for public uses.

\subsubsection{Pedestrian Infrastructures}

The most notable example of a pedestrian infrastructure in place is the Highline, an old, abandoned railway track that was elevated above the streets of New York but was converted into a piece of New York's public realm. The project took an existing piece of infrastructure on the brink of demolition and used it as a catalyst to transform a formerly industrial area of Manhattan. The project consists of a strategically placed landscape, circulation and places to sit that maintained the distinctive railroad character of the existing bridge. There are a few specific areas that break free from the predominant linearity of the project 


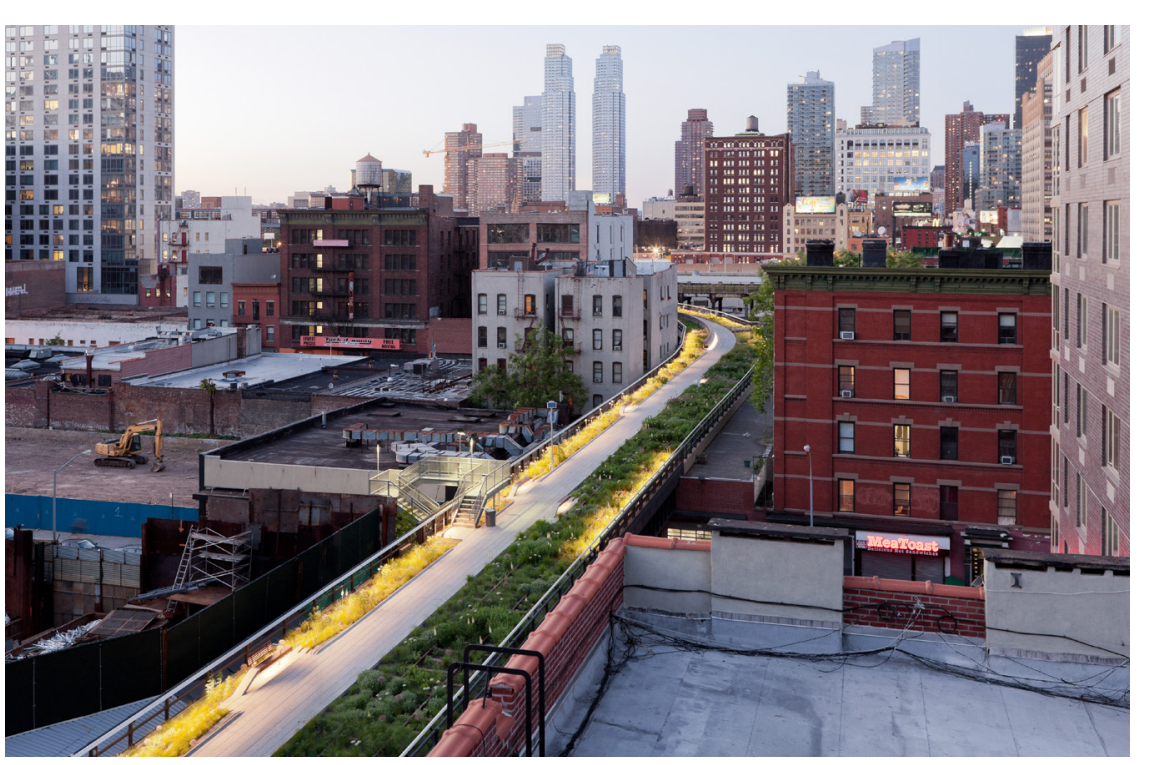

Figure 4.10

and offer views of the city. These areas relate the project back to the city and infuse it with additional activity

In contrast to New York's highline, Toronto's version of a pedestrian infrastructure is the PATH network. The PATH is an underground pedestrian network that connects prominent buildings such as the Union Station, the Eaton Centre and everything in between. The system became a relevant option for Toronto after the completion of the Dominion Center in 1967 in which an underground shopping network connected a series of towers. The success of the network allowed for expansion and it now connects to the Eaton Centre, and to as many as eighty buildings, for the creation of a massive underground shopping center. Major criticisms of the system are that it displaces the pedestrian from the street level, and that each portion of the system is privately owned which means that each space is an indeterminate public/private space. Since the entire system is an underground shopping mall, the shops close according to business hours and it is a very desolate place on Saturdays and Sundays. Jane Jacobs has criticized the underground network as being an isolated place that contributes to loss of engagement with society. "You no longer encounter the other - the homeless, people on the margins. You avoid them by using the PATH system or moving to a condo tower, where you can go down to your garage and drive off - it's a homogenized and sanitized environment." (Scrivene, 2007).

Calgary's +15 network uses the same concept as Toronto's underground network, except it is above ground. The +15 network consists of a series of elevated pedestrian bridges that connect most of the major buildings downtown 15 feet from the street level, hence the name. The system also is similar to Toronto's PATH in that it has rendered street life non-existent.

The reason the Highline works in contrast to the pedestrian systems of Toronto and Calgary, is that through quality place making design, the Highline becomes a unique destination as an alternative from the grit of New York. Providing relief from the cities busy streets and cars the Highline offers unique views of the city, a connection to nature and a place to pause; all things both the PATH and the +15 network do not strive to establish. Juxtaposing the city, the continuation of the unique character of the railway infrastructure carried throughout the design of its surfaces and recreational elements such as the benches and planting, make it a desirable public place. Projects such as the Highline illustrate the redefining of infrastructure in a way that prioritizes the pedestrian. It shows that creative use of infrastructure can open up new possibilities for public uses and can successfully relate infrastructure to architecture. 


\section{CHAPTER 5 - CONTEXT}

\subsection{Site Context}

In order to better understand the context one must study the history of the site's evolution over time. The Ryerson Institute of Technology started out as a training ground for a growing work force in a post-war economy when it began offering postsecondary education in 1948. The Institute was located in the Toronto Normal School buildings near St. James Square until the late 1950s when a modernization program was launched to accommodate the school's rapid growth. This led to the building and opening of Kerr Hall in 1963, at which time Ryerson officially became a Polytechnic Institute. In the 1960s, Ryerson acquired buildings on Gould St. and Gerrard St, and converted them to accommodate their respective institutional programs. Jorgenson Hall, Podium building and Library were all built from 1971-1974, as well as Devonian Park across from Kerr Hall and the Library building. From 1980-1990, Ryerson built Pitman Hall, the Architecture Building and the Rogers Communications Center. In the 1990s, Ryerson acquired a few more structures and re-purposed them for its institutional needs. From 2000 to the present, Ryerson has seen significant expansion with the addition of buildings such as the School of Graphic Communications Management, the Sally Horsfall Eaton Centre, the George Vari Engineering Building, the Chang School Building, the Student Campus Centre, the Ted Rogers School of Management, the renovation of the Image

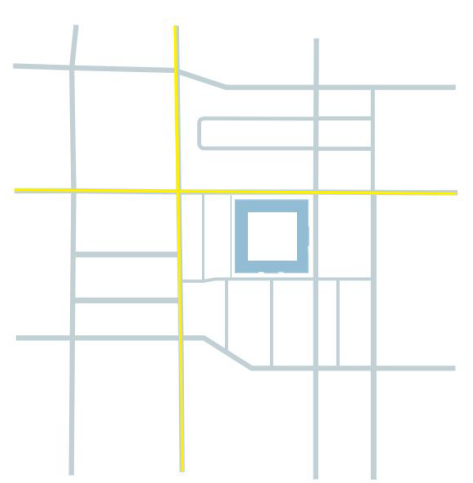

GFA IS

A A

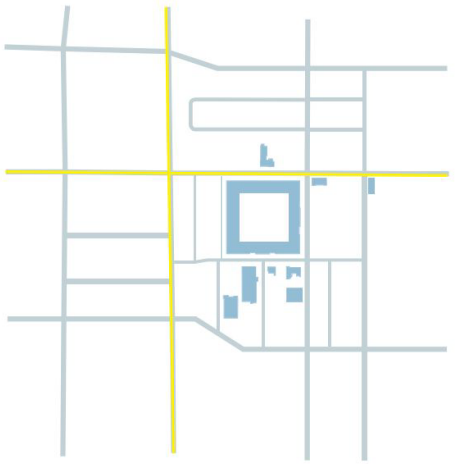

GFA ISH

940,674

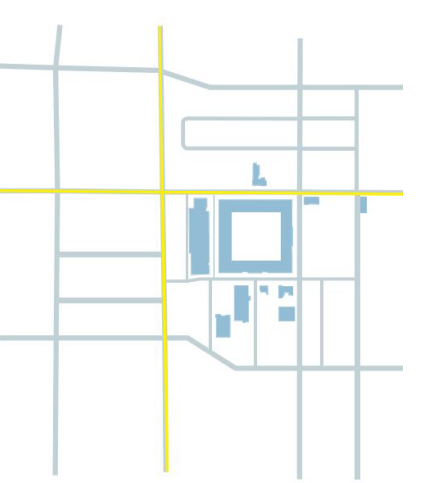

1980
GFA (SF) Student Enrolment $\quad \begin{aligned} 1,487,943 \\ 9,176\end{aligned}$

Figure 5.1 Ryerson Campus

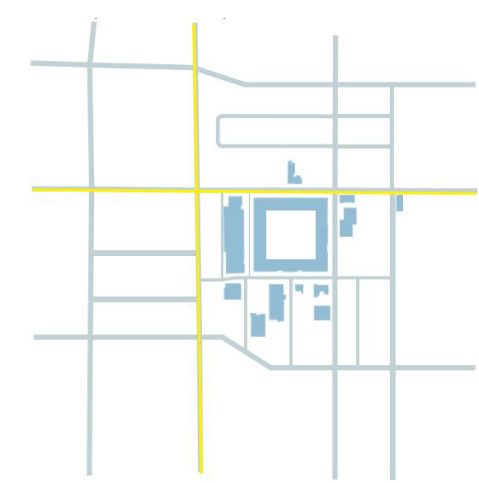

1990 $1,745,549$ Student Enrolment $\quad 10,835$

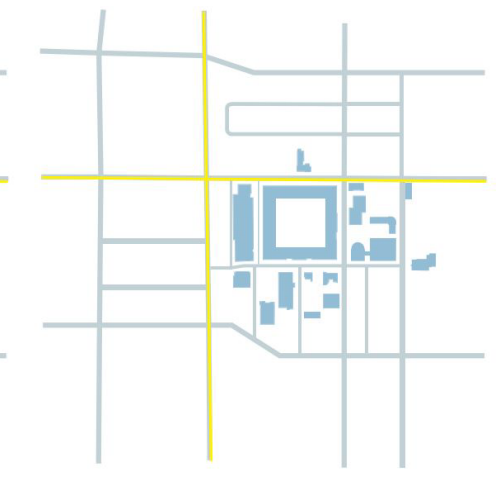

2000 Student Enrolment $2,273,377$

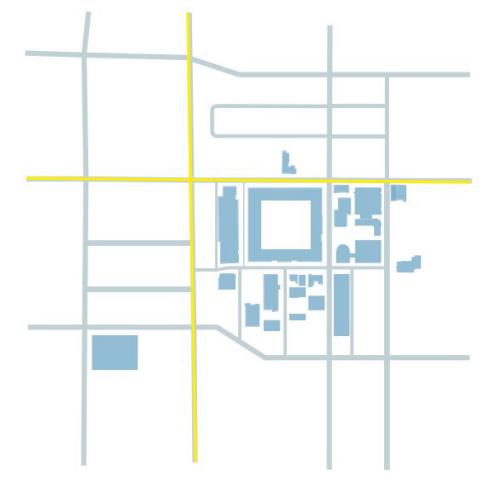

2007 GFA (SF) $\quad 3,200,772$ igure 52 Figure 5.2 Growth 1990 - 2007 
Figure 5.3

RG 95.1.41.42.06
Aerial View of Ryerso Campus - 1963

$$
\begin{aligned}
& \text { Figure 5.4 } \\
& \text { RG 122.10.93.02 } \\
& \text { Completed Library } \\
& \text { Building, ca. 1974 } \\
& \text { Figure 5.5 } \\
& \text { RG 122.10.93.01 } \\
& \text { Construction of Library } \\
& \text { Building as seen from } \\
& \text { the Kerr Hall Quad, ca. } \\
& 1973 \\
& \text { Figure } 5.6 \\
& \text { RG } 122.10 .93 .03 \\
& \text { Podium and Library } \\
& \text { along Victoria Street, } \\
& \text { ca. } 1974
\end{aligned}
$$
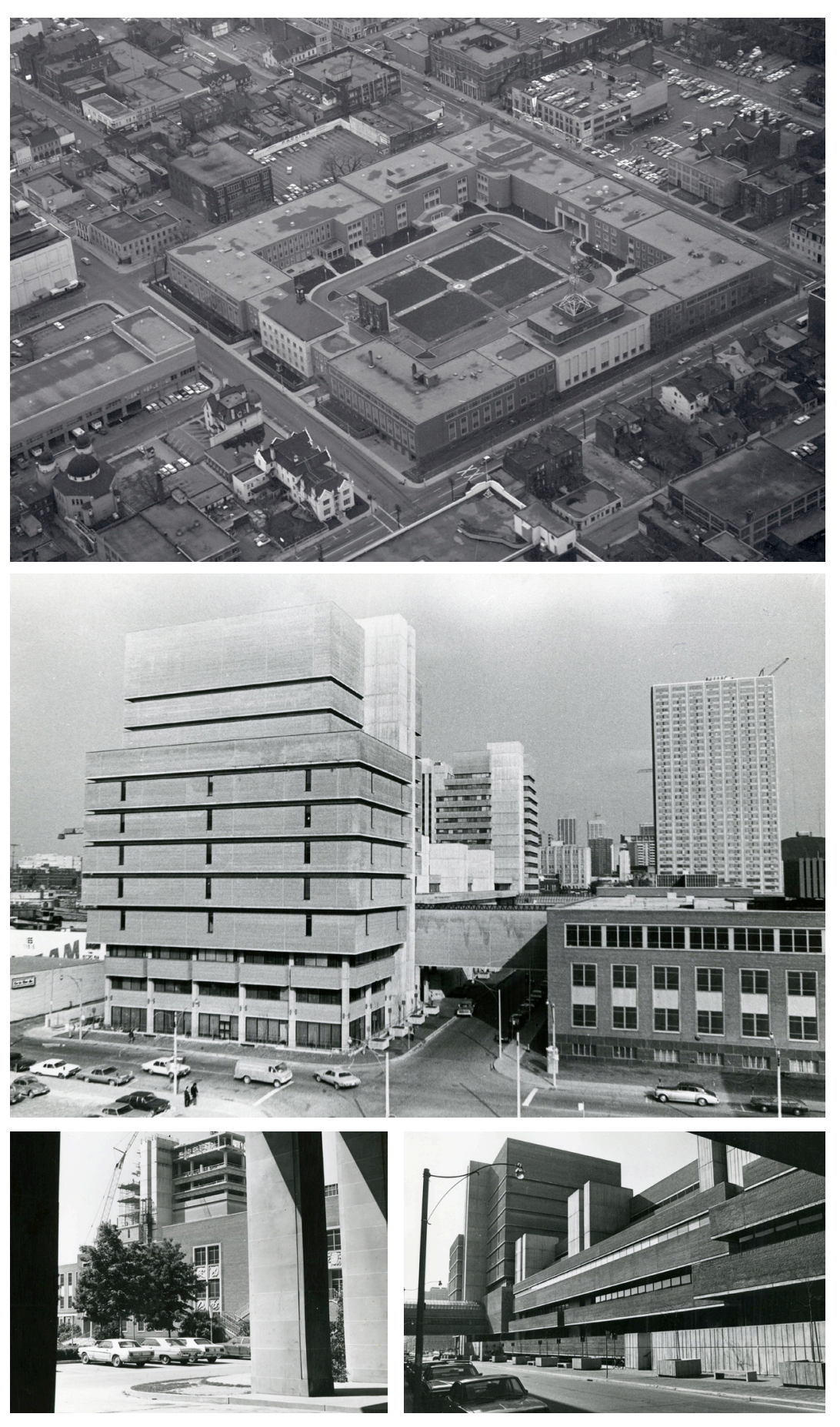

Arts building, the building of the Student Learning Centre, and the construction of a new Health Sciences Complex scheduled for completion in 2018 (A Brief History of Ryerson University, 2012) (See Fig. 5.1, 5.2).

\subsection{Victoria St. An Interstitial Non-Place}

Kerr Hall is the original Ryerson Building, built in the 1963 to accommodate the school at its inception. It was built as a quadrangle around the Normal School (which only a facade remains) and housed the necessary programming for a growing institute that included classrooms, offices, labs, and a gym and theatre. The result was a fairly large building that spanned a few blocks in each direction. The original plan reflected car-centered ideals of the city in the 1960s: the interior of the quad was effectively an interior car loop with parking (See Fig. 5.3, 5.6). As a result of this design, the main entrances into Kerr Hall were designed to be located in the interior of the quadrangle with only a few necessary entrances on the perimeter of the quadrangle (See Fig. 5.7).

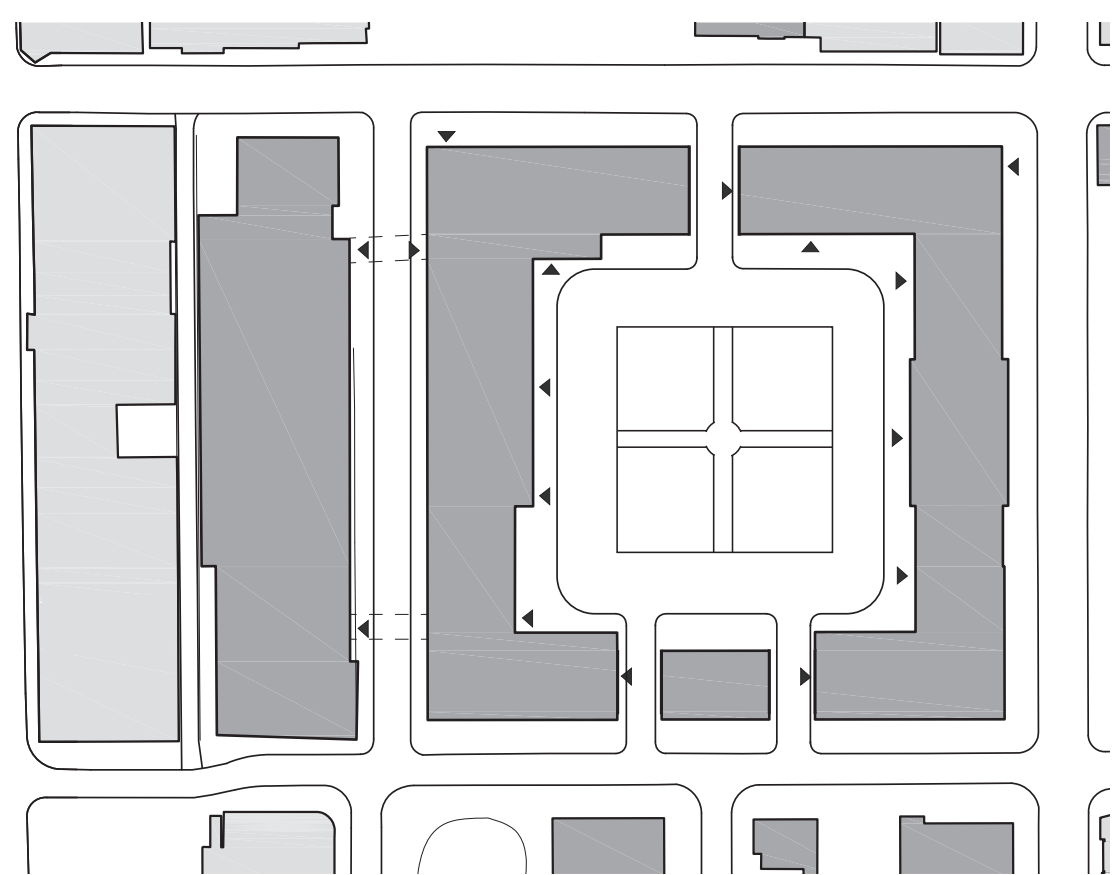


The next buildings built as part of Ryerson's expansion were the Library/Podium/ Jorgenson Hall buildings of the 1970s. This complex consisted of two towers (the Library and Jorgenson Hall) linked by a four-storey mass (the Podium). This series of buildings was designed in the brutalist style that was popular in the 1970s. One of its characteristics was the hiding of entrances from the street, so the two main entrances on Victoria St. are not immediately apparent. Further, since at the time of the construction, Victoria St. was a vehicle street, two bridges were constructed linking the two towers to Kerr Hall (See Figure 5.4). These extended over the main entrances into the Podium building and were in the heavy brutalist style as well. They were installed as a way of elevating the pedestrian over the street in accordance with the car-centric city model. This design for convenience resulted in a lack of vibrancy on the street because of the displacement of pedestrians from the street.

Shortly after the completion of these buildings in 1974, Ryerson closed Victoria St. in an effort to create an on-campus pedestrian core that included the Devonian pond at Gould and Victoria Streets. (Stagg, A History of Ryerson Polytechnic University, pg. 19). However, the street became essentially a pedestrian thoroughfare consisting of a path and of landscaping along its length, due to its lack of engagement and connectivity to the adjacent buildings. As Ryerson's campus has grown over time, Gould St. instead evolved to become its pedestrian core and Gould St. became a permanent pedestrian street in 2012 after multiple years of proposals (Pedestrianizing Gould Street, n.d.).

\subsection{Flow - Ryerson Campus}

Ryerson is located in an ideal location, taking into account its proximity to the Yonge and Dundas Square, the Eaton Centre, and the liveliness of Yonge Street itself. However, one issue Ryerson is dealing with currently is its presence in the city, as outlined in the 2008 Ryerson Masterplan Where RU? campaign (Ryerson
University Master Plan, 2008). It is clear that Ryerson's pattern for growth has been a radial expansion from Kerr Hall, the original central building. The strategy for growth has been the maintenance of a balance between the acquiring and re-purposing of existing buildings, and new construction. Ongoing expansion

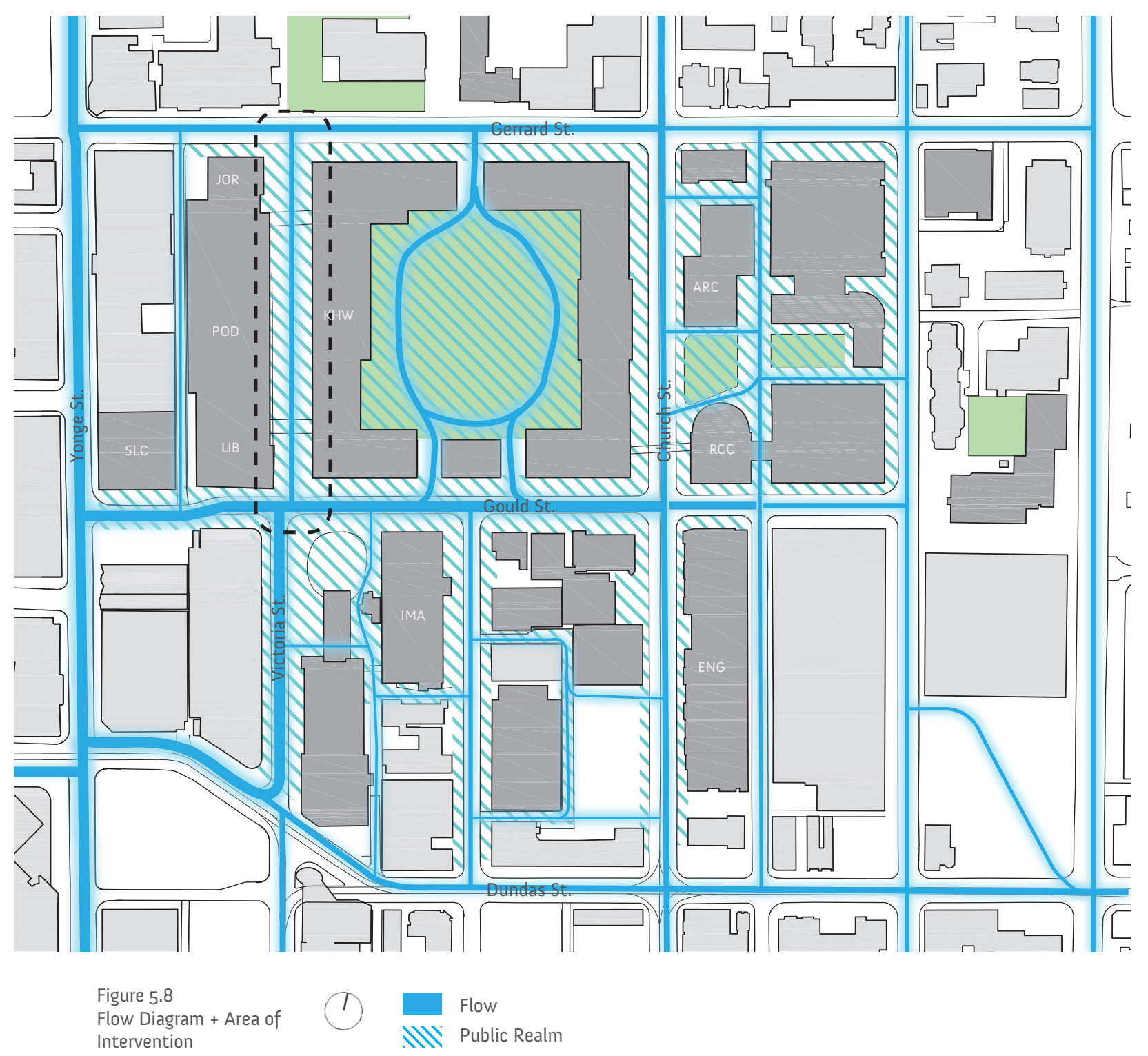


saw the campus limited to existing street networks and infrastructure, and to include a series of laneways and a network of small streets. For a campus located in close proximity to one of Toronto's main public spaces and amongst such vibrancy and energy, Ryerson's campus unfortunately has areas that lack the energy and vibrancy that its context would suggest. (See Fig. 5.19). Currently, the majority of pedestrian traffic occurs on the south part of the campus because of the location of the subway station and the public square at Yonge and Dundas. Gould St. is the main pedestrian access and social spine of the campus; however, the majority of streets that branch off it do not share its vibrancy. (See Fig. 5.8). Additionally issues such as a lack of access and connectivity make navigating the campus difficult.

\subsection{Areas with Sense of Place}

Ryerson has established a few successful public spaces on its campus, most notably the original green space in the middle of Kerr Hall: The Quad. Although the Quad was originally designed as a parking lot with a simple green space in the middle, it has transformed into a quite successful public place on campus after it was pedestrianized and additional green space was added. The open middle landscape serves as a multifunctional space hosting large events to casual sporting activities. Pedestrianizing Gould street has established it as the main social spine of the campus and has begun to start tying the campus together (See Fig. 5.9)

Figure 5.10: Gould St. is the major social spine of the campus that ties the major buildings along the strip. The street serves as a marketplace, or a multi-purpose space used as a concert venue and activated by a cross-programming that includes cafes that offer entrance to the buildings. To engage the students, the planter edges provide seating along the street as well as movable furniture to provide places for student social interaction.
Figure 5.13: The Student Learning Center has become the new gateway for the campus off Yonge St. Its highly permeable entrance seamlessly connects it to the Library building. This addition adds much needed presence to campus and

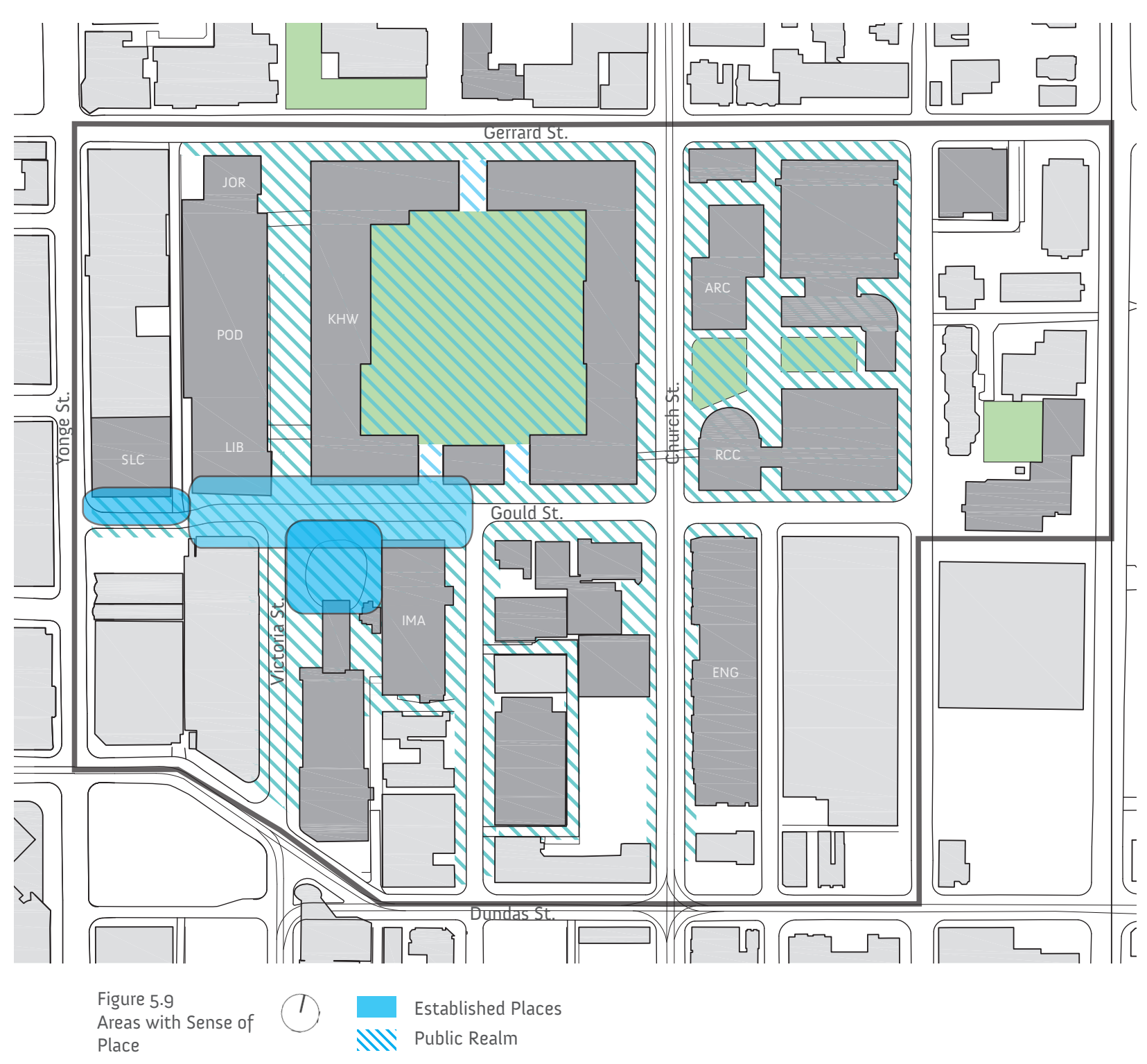


Figure 5.10
Gould St. Boundaries

Figure 5.11

Market

Figure 5.12
Gould St. Perspective
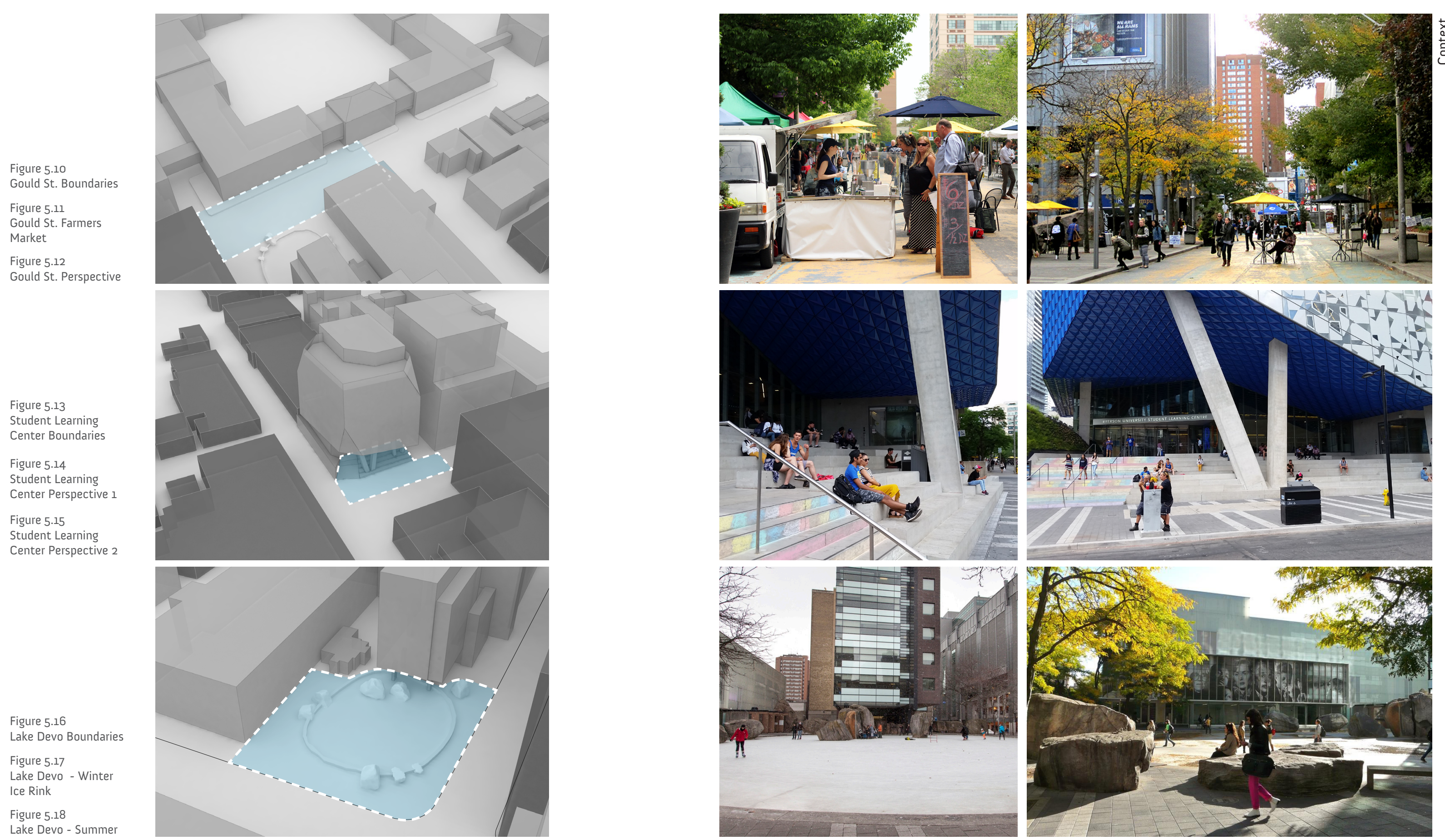
meets its needs for social contacts through the provision of stepped seating inside and outside. The building activates the street through both retail and its café inside. The stepped seating can be found occupied year round, especially in the summer with its building form offering copious amounts of shading.

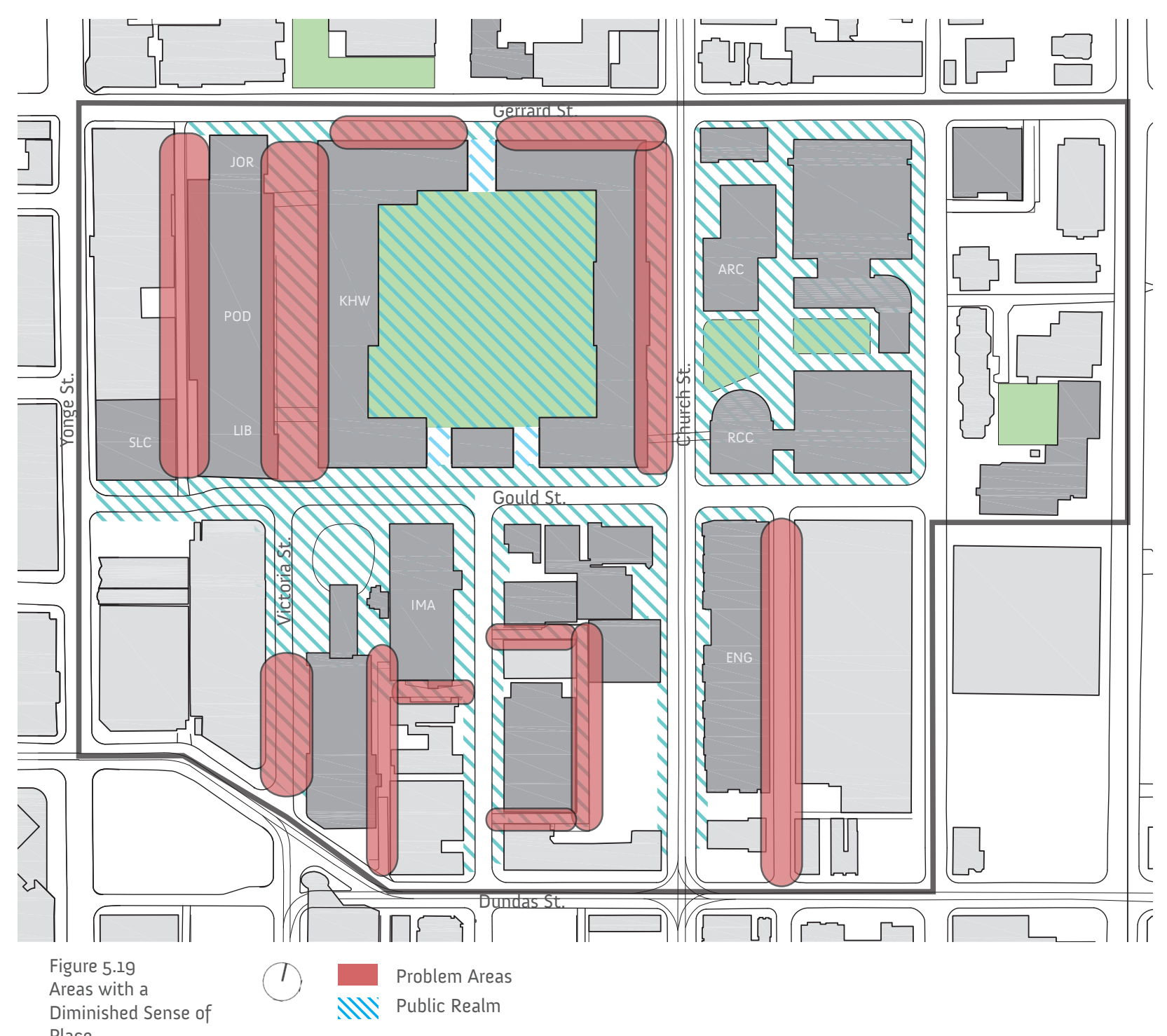

Figure 5.16: Lake Devo is the central focal point on Gould St. The pond activates the street through its constantly changing program. It provides a multi-purpose space with such features as a pond in the summer, skateboarding when the water is absent, and ice-skating in the winter. Along the lake is a series of large boulders that make the location unique. The pond edge and rocks provide a place for students to stay and interact both socially and with the physical environment.

\subsection{Areas With a Diminished Sense of Place}

As mentioned previously, due to the nature of Ryerson's growth over the years, a large amount of the campus involves smaller streets and laneways; this has resulted in the presence of many backdoors. A re-thinking of the campus should not emphasize elimination of these backdoors, but rather should consider using them to animate the adjacent public spaces. (See Fig. 5.19).

\subsubsection{Victoria St.}

Victoria St. runs the length of the campus and intersects with Gould St. At

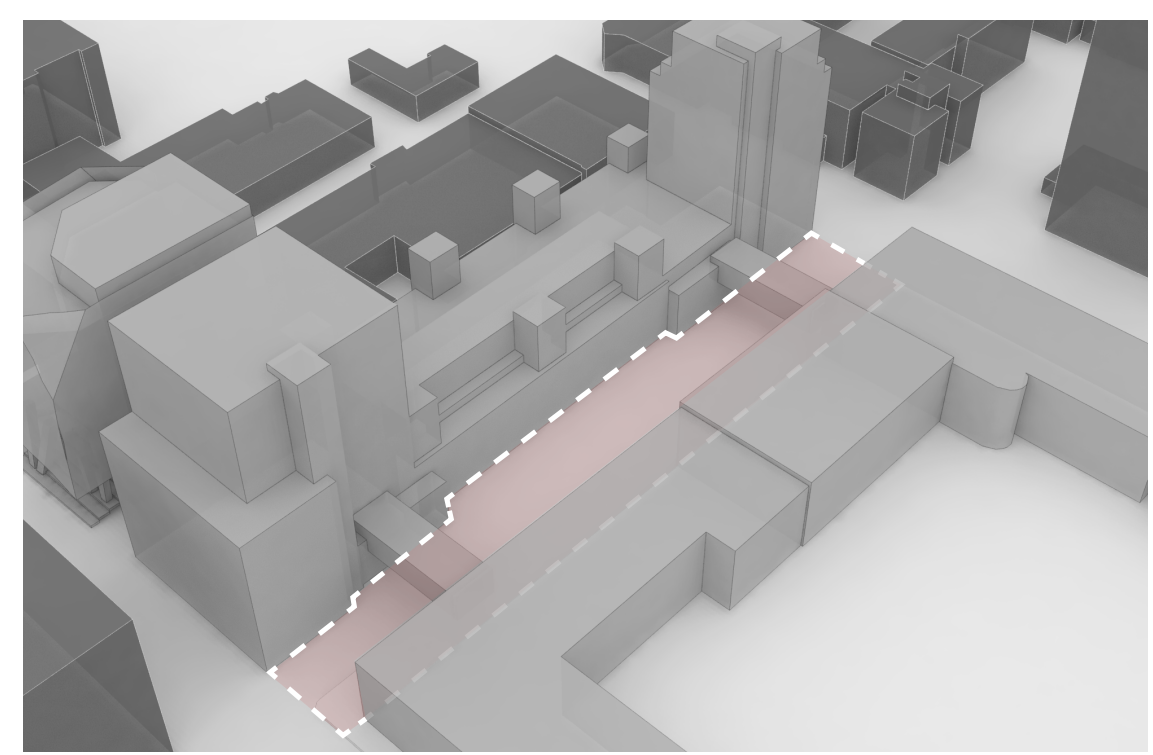


this intersection is Lake Devo, which is a successful public space; however, the areas north and south of Lake Devo present a different situation. North of Gould St, Victoria St. runs between both the Podium building and Kerr Hall. The street itself acts as a thoroughfare instead of serving as a destination or place. On this portion of the street, Kerr Hall offers no permeability, or even an interesting façade, as it fails to engage with the street. The podium is disjointed from the entrance level and the terrace level does not connect efficiently to the street. (See Fig. 5.26, 5.27). The opaque concrete walls do not encourage people to linger and stay while the landscaping narrows the available space and limits the use of the street, further emphasizing the street as a thoroughfare. Currently the site has bike storage on the south end under the bridge and a fountain on the north end. The existing Podium and Kerr Hall buildings have initiated some programming that has begun to activate the street. The Podium has a newly renovated dining area and hub to better serve the students; also, some classrooms and gyms in Kerr Hall can serve as potential programmatic anchors for the site (See Fig. 5.21, 5.22). Lastly, the existing bridges serve more to provide convenient access between the two adjacent buildings rather than to the street, with the ultimate effect that they displace the pedestrian and make the street a less vibrant space.

Based on Corbusian principals of a separation of pedestrian and vehicles, the original design for Kerr Hall and the library/podium/Jorgensen hall buildings was functional. However, as the city evolved and priorities changed to become increasingly more pedestrian, Victoria St. has emerged as an interstitial nonplace due to its lack of engagement, connectivity to the neighboring buildings, and unique character. The general lack of public space on campus should lead to an extension of the social nature of Gould Street-the major pedestrian social spine- across campus.

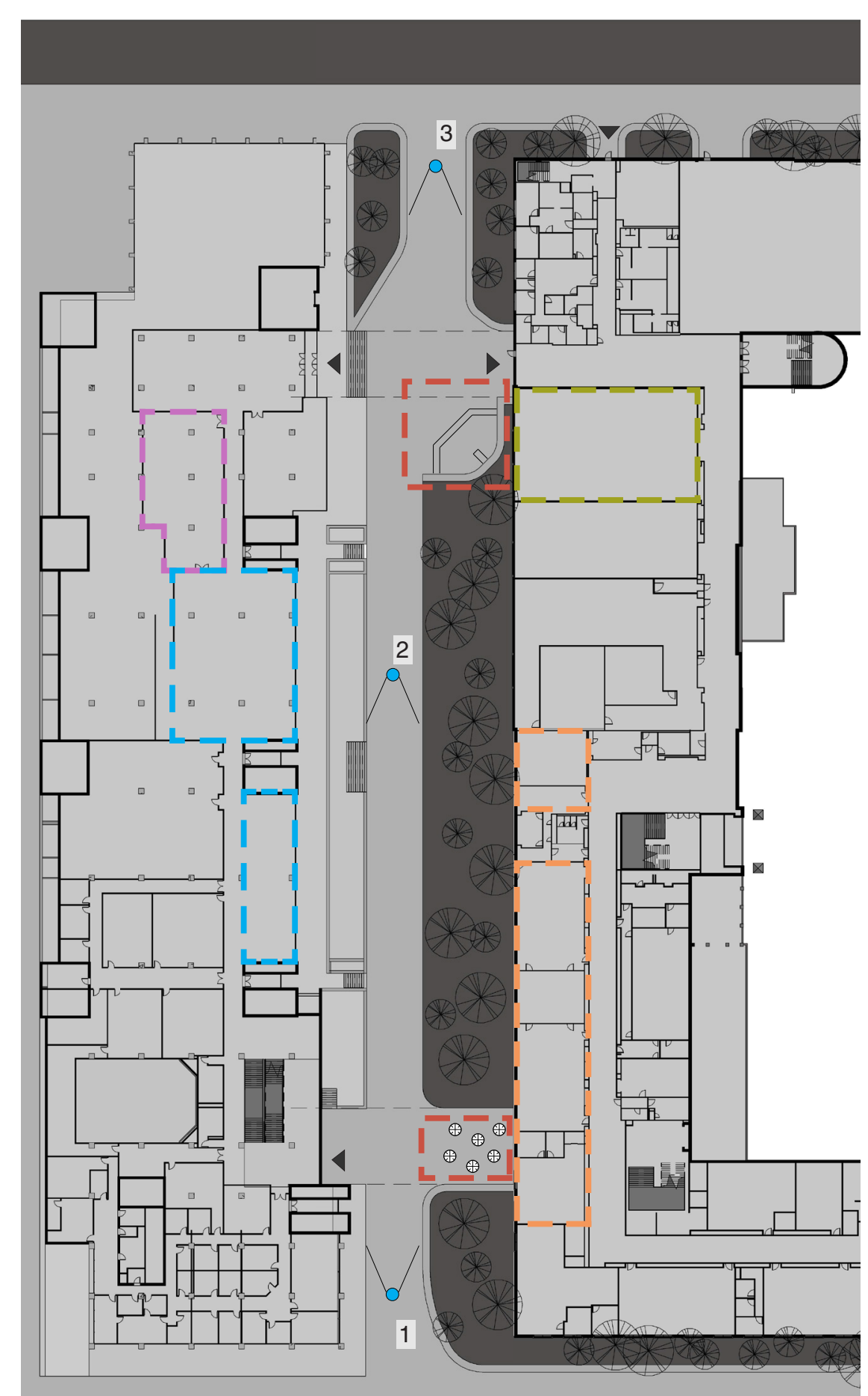



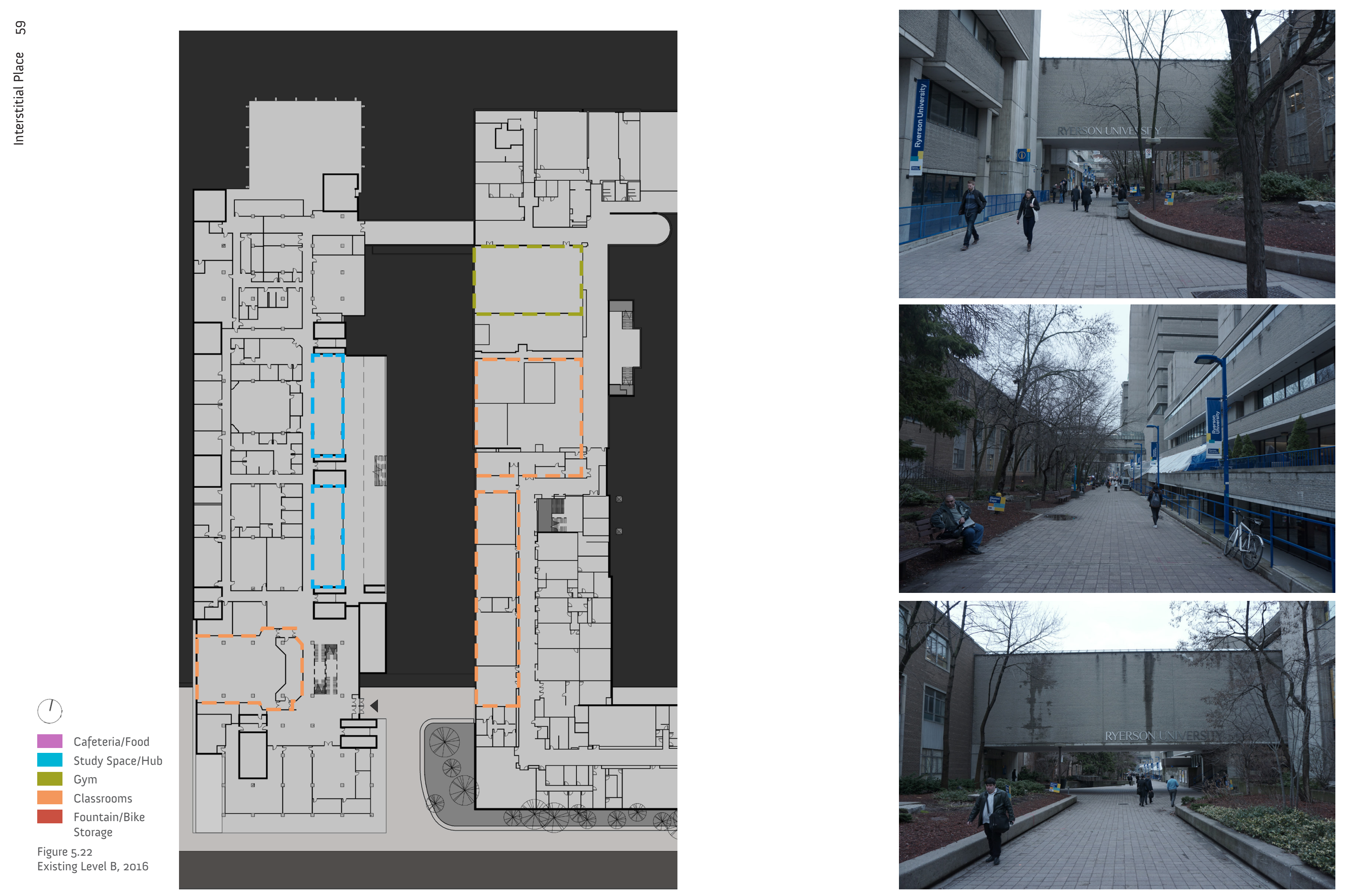

Figure 5.23
1. Existing Victoria St.

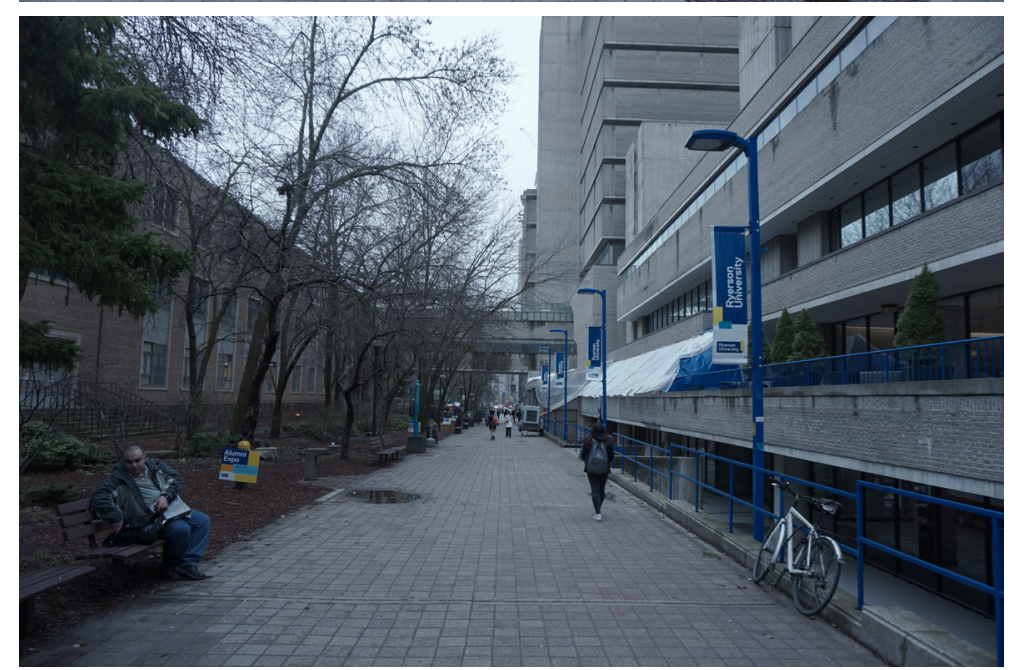

Figure 5.24
2. Existing Victoria St.

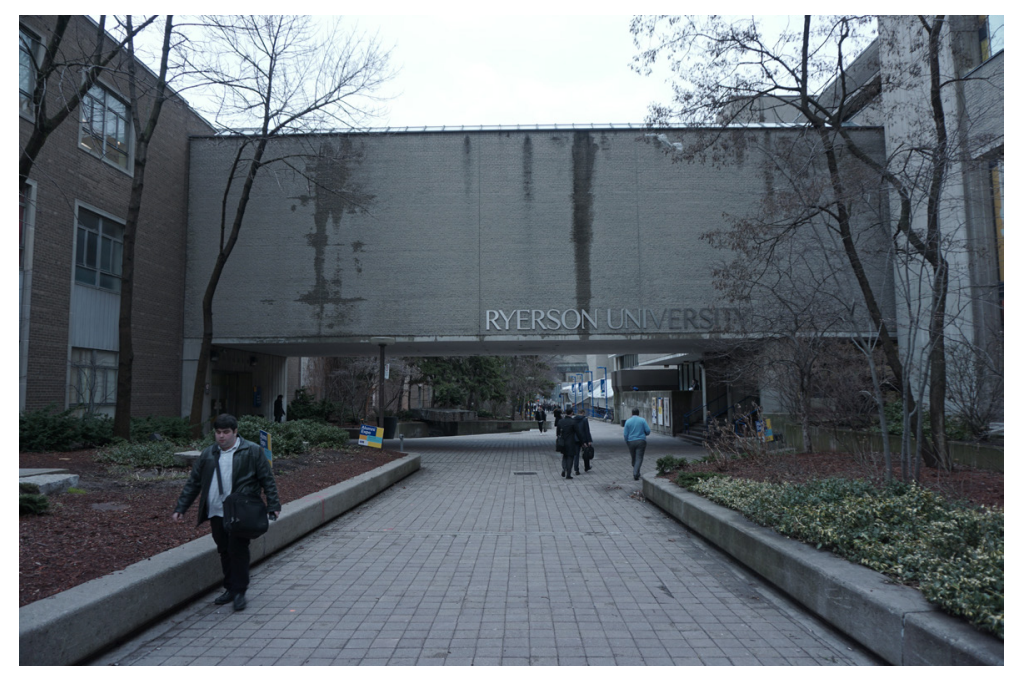




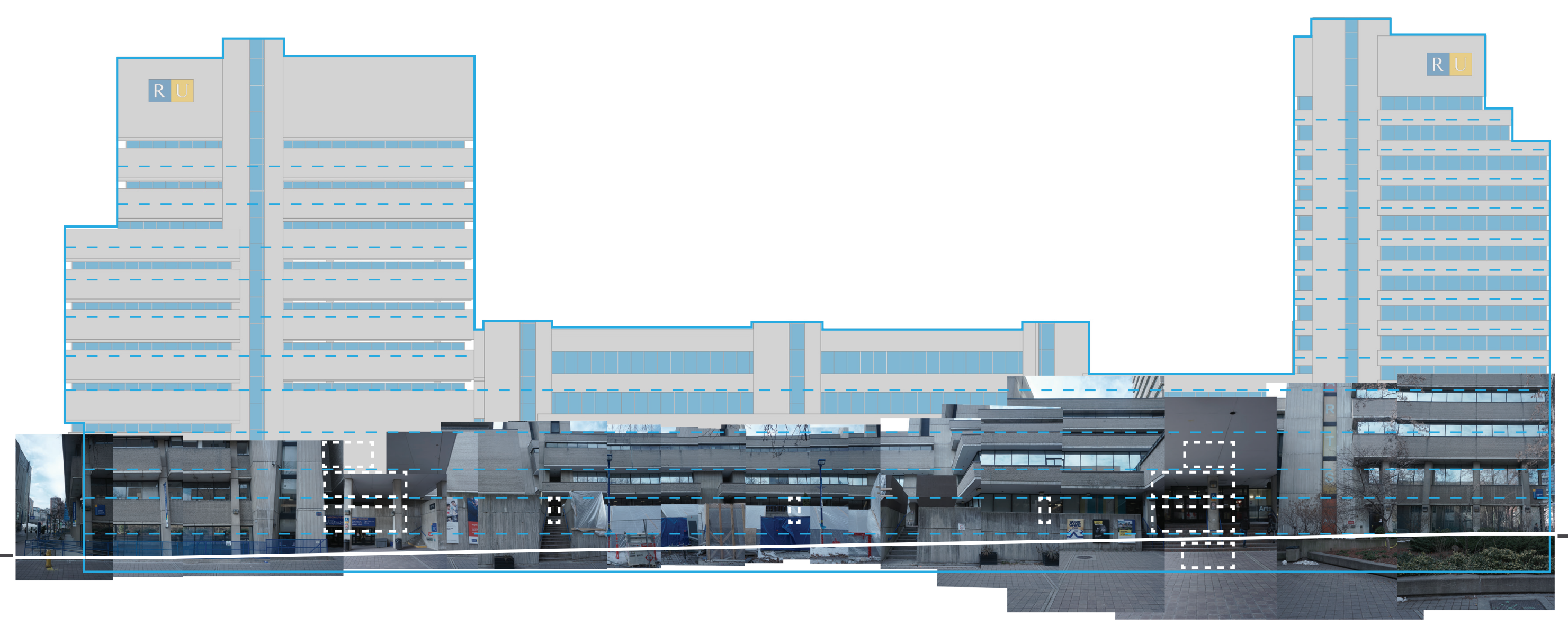
$-3-112$

Entrances

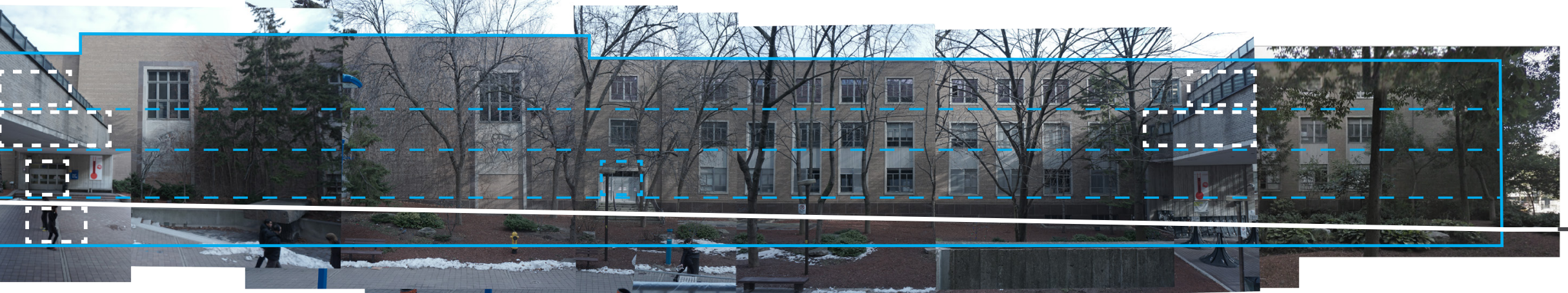




\section{CHAPTER 6 - DESIGN PROJECT}

\subsection{Introduction}

The design proposal re-imagines Victoria St. as a linear park by taking what is considered a non-place and an interstitial space and creates place and relevance. This is achieved by proposing a continuous landscape surface over a proposed hub space in order to add density and to establish new connections into both Kerr Hall and to the Library/Podium building. Through using principals of landscape and infrastructural urbanism three design strategies begin to create connectivity to the various scale of networks, activating the public space through the use of cross programming and lastly anticipating and facilitating engagement throughout the scope of the project.

\subsection{Design Strategies}

\subsubsection{Flow/Connectivity}

The first strategy aims to improve and establish new networks of navigation. It creates seamless connectivity at grade level, and takes into account grade changes by providing open and permeable boundaries to blur present boundaries between the building and the street. Use of the continuous surface helps to maintain continuous flow and movement.

\subsubsection{Activate}

The second strategy creates an outlet for activity and serves as the anchor program in order to infuse energy and vibrancy into the area. It responds to its context. It uses cross-programming in juxtaposition to create connective collisions that will diversity all encounters.

\subsubsection{Engage}

The last strategy looks to increase participation amongst the users of the building, and to encourage them to stop and stay within a particular space. Once Flow and Program are established, the proposal can begin to engage users at their intersection. This strategy understands how a physical space can affect humans' behavior and decisions. The architecture should provide an opportunity for social interaction throughout the journey through the project.

\subsection{Flow/Connectivity}

As site analysis has shown, permeability into both buildings was a large issue. Three major east-west connections between the two buildings were created as a result. Three new entrances on the west façade of Kerr Hall were added: one at the south, one at the north and one in the middle. These reinforced entrances opened up Victoria St. to lateral flow on the site. The new permeability creates a connection to the quad, one of Ryerson's notable public spaces. Another major issue with the site is the awkward slope of the grade that creates undesired changes in levels into the Podium building, and makes difficult entrance into Kerr Hall. The grade of the south end starts off I meter above the basement levels of both buildings and slopes towards the first level of both buildings on the site's north end. The proposal uses a series of ramps to create connections to the different levels of the respective buildings. The grades at both the south and north ends of the site remain the same. However, at the south end, a ramp slopes towards the basement level of the Podium building and toward 


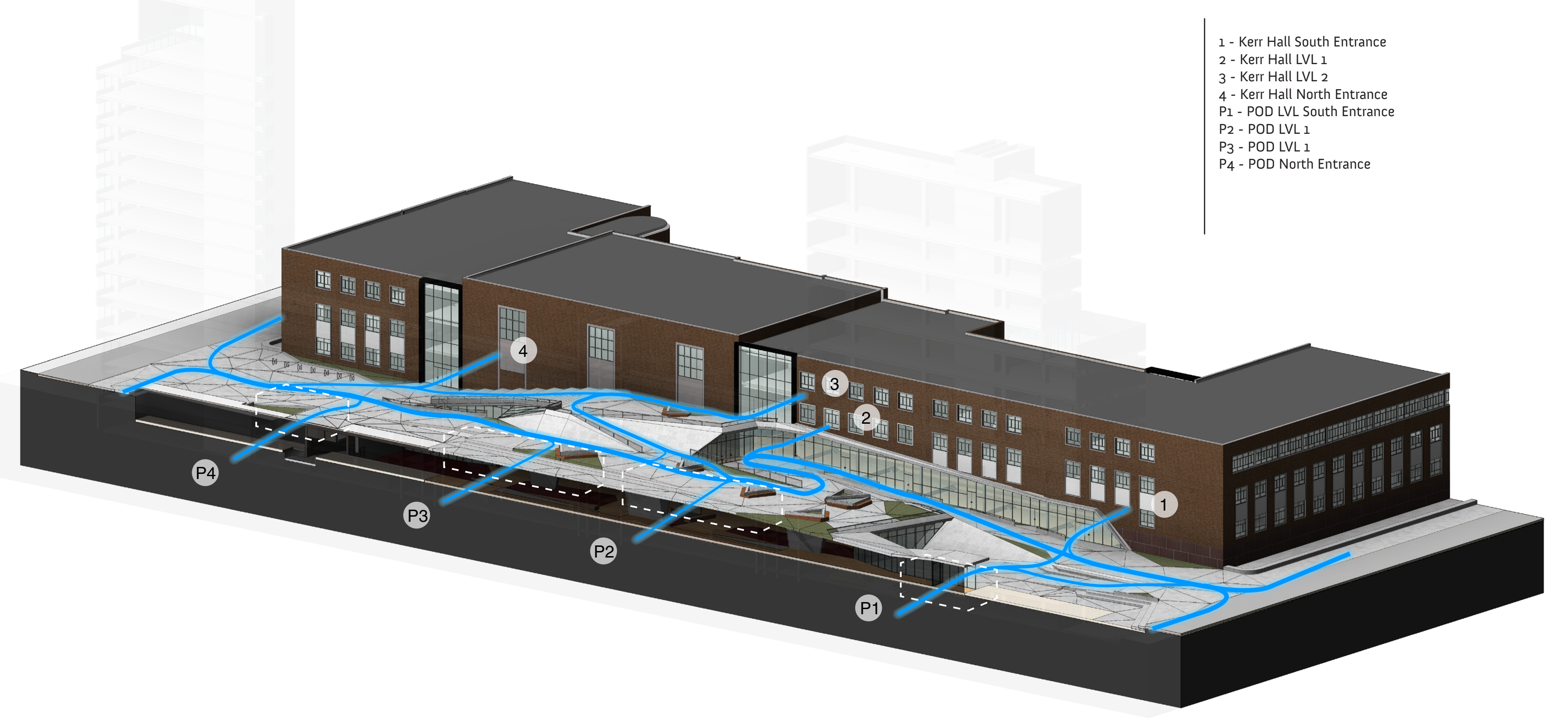




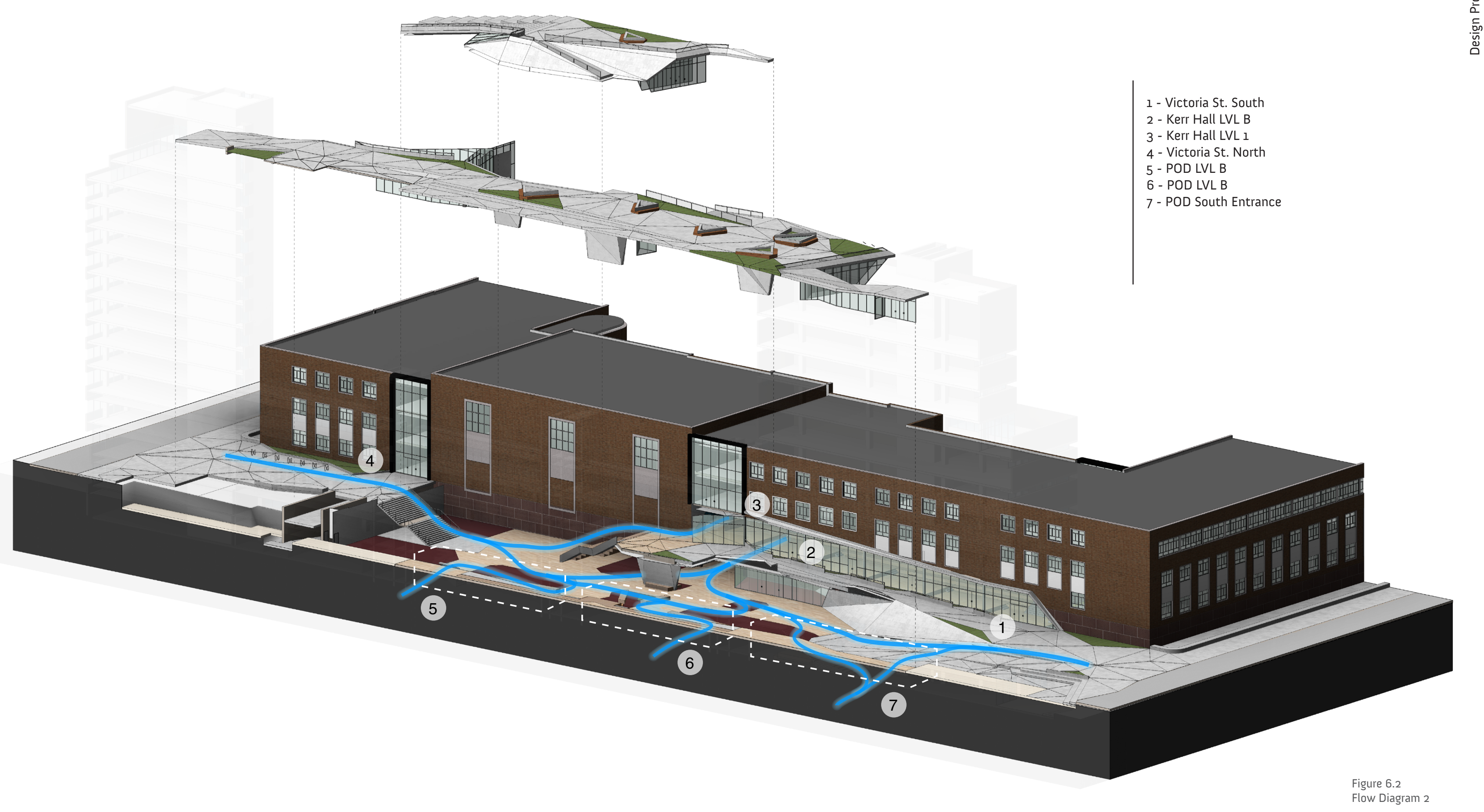




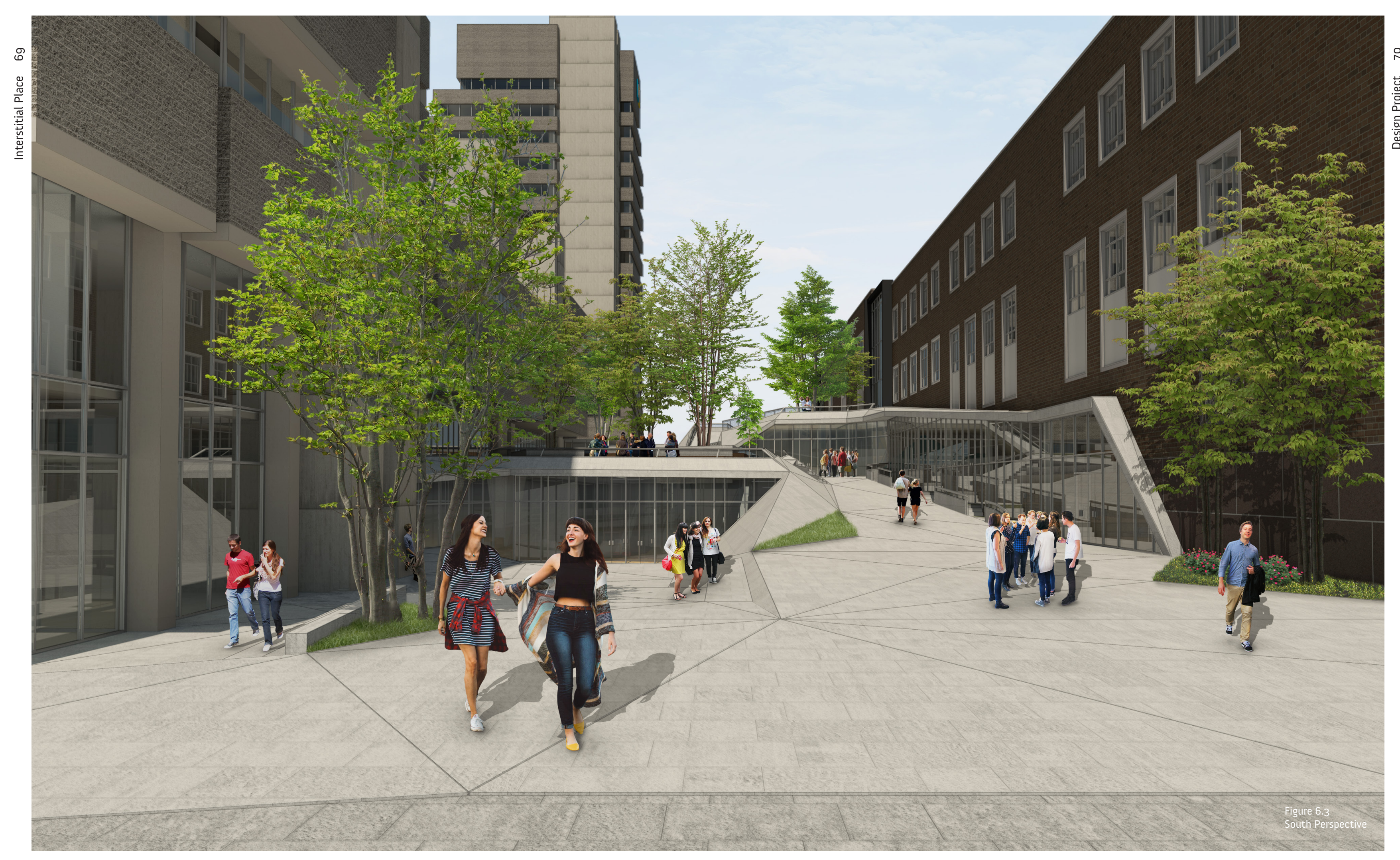




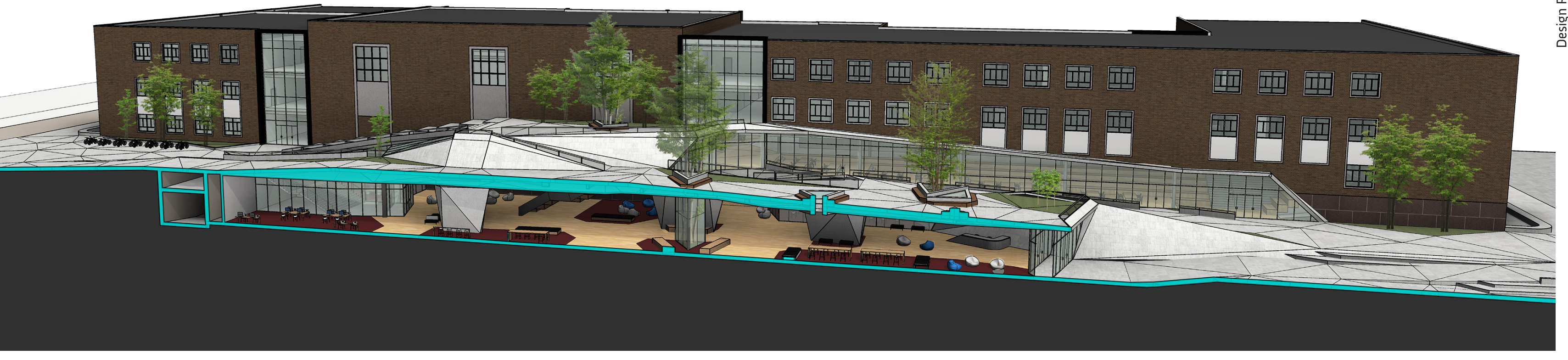

Figure 6.4
Sectional Perspective 1

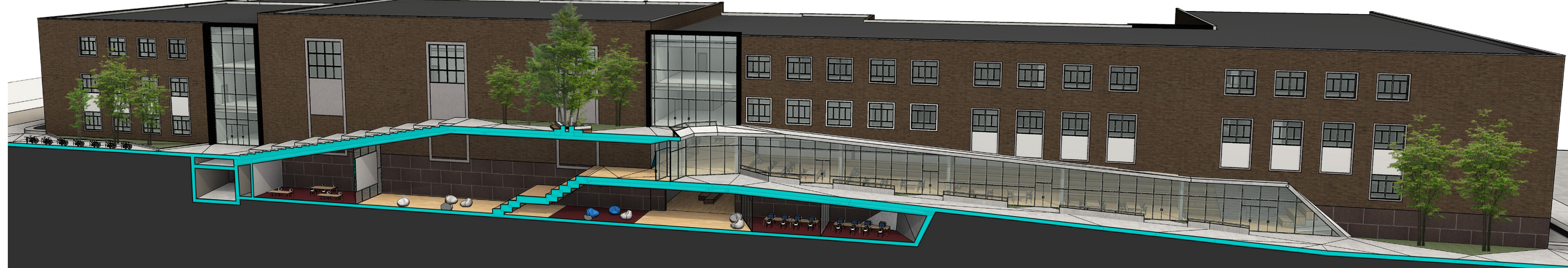



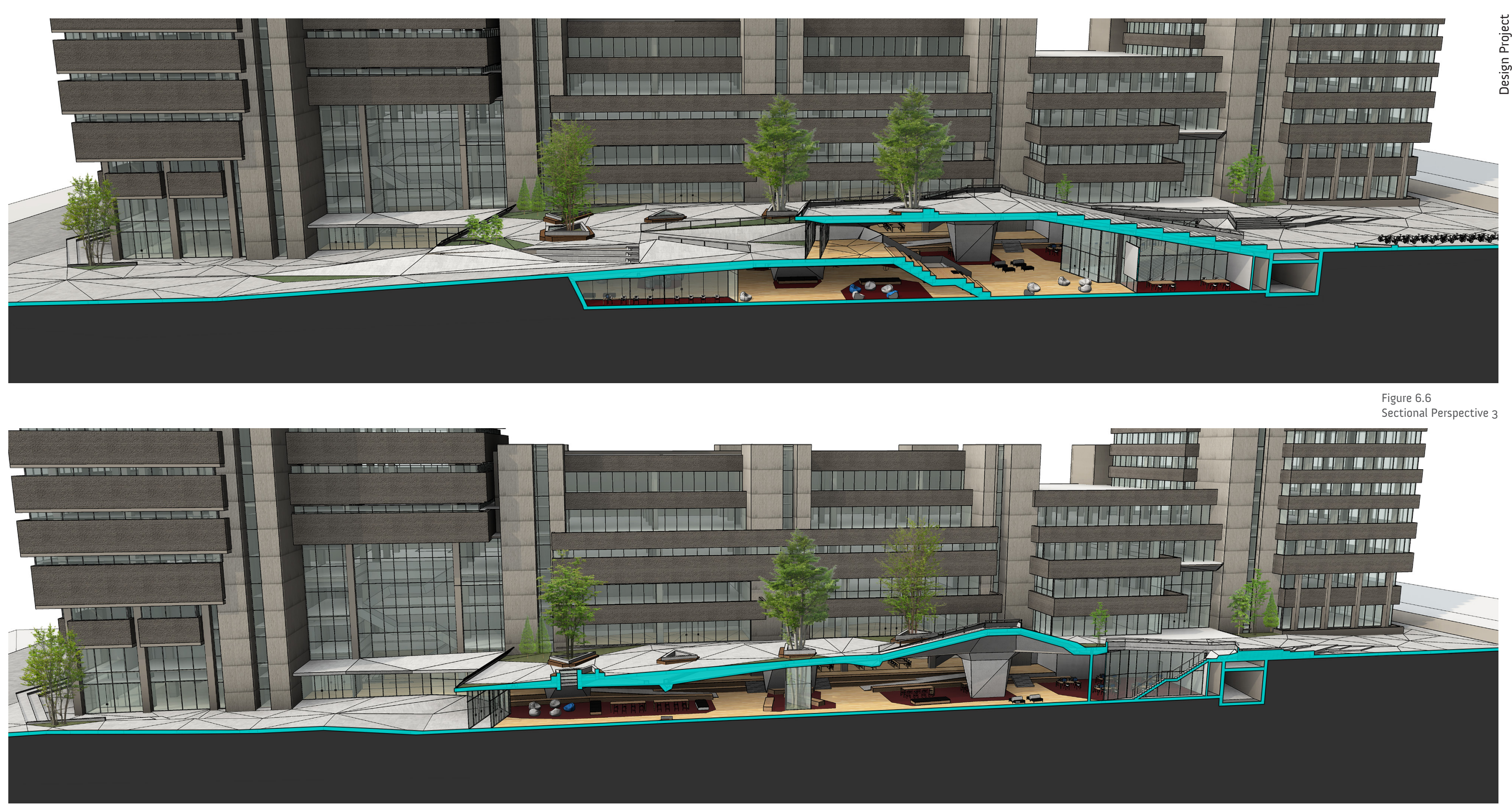


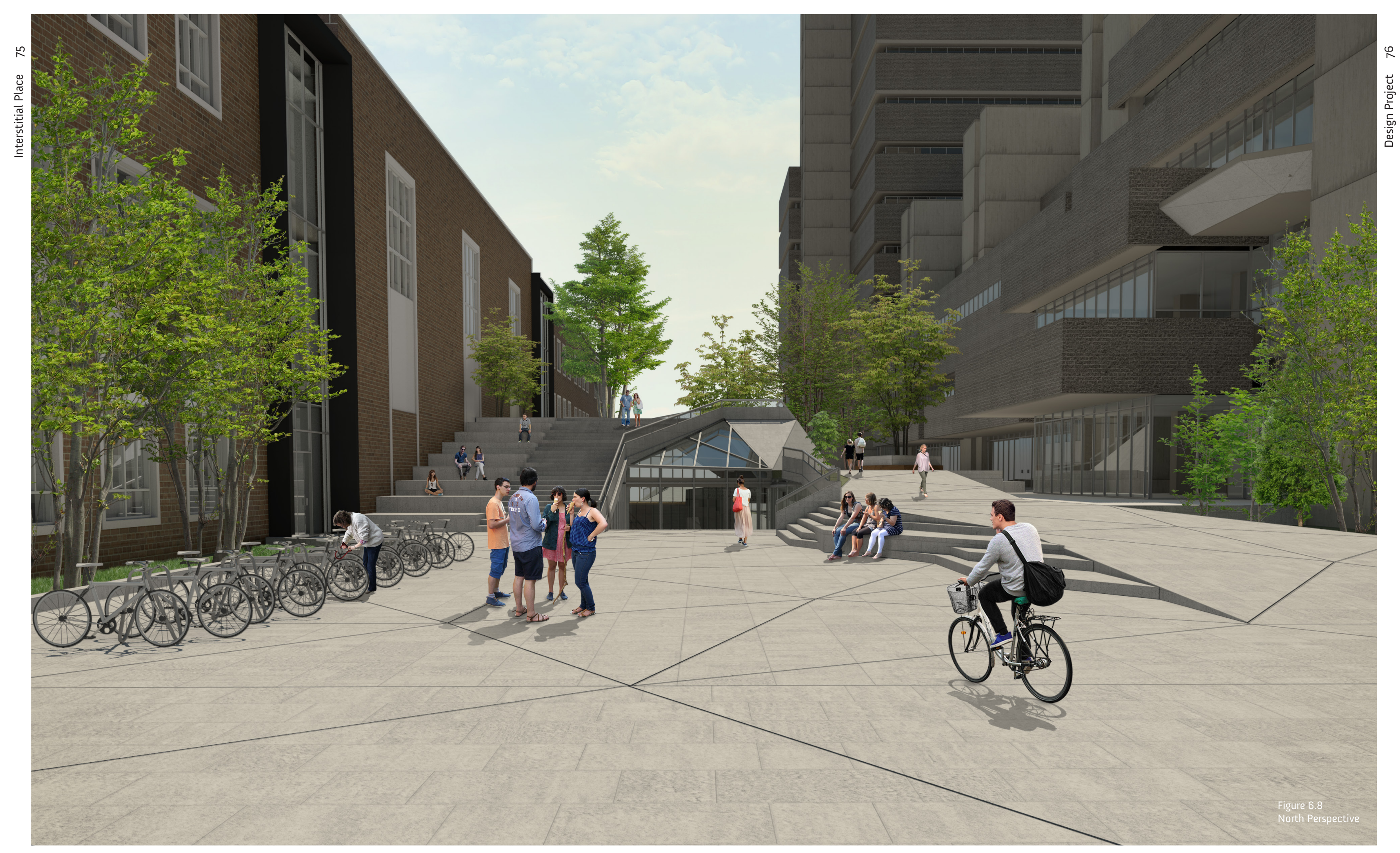


the entrance to the hub space underneath the park surface; another ramp gently slopes upward towards the first level of Kerr Hall where the new middle entrance is. A slight ramp from here connects to the main park surface of the project which integrates the existing terrace level of the Podium building. From here, the surface continues north and ends at the existing north grade. A secondary ramp from the main park surface connects to the second level of Kerr Hall to create a new entrance. From this level, a series of stepped seating slopes toward the grade at the north end. The entire system forms a continuous surface that connects to the different levels of the adjacent buildings and suggests flow and ease of movement. Beneath the surface, a new hub program is proposed that would create new links underground between both buildings. Two entrances, one at the south and one at the north, create a north-south connection beneath the surface.

\subsection{Activate}

With new entrances creating flow and interconnectivity on the site, the proposal uses the existing program of both buildings, in combination with new programs, to create a connective layering of programs that will activate the site. The Podium building's programming includes study spaces, the new hub, library, and dining area. Kerr Hall has classrooms, studios, the gym and the theatre. The proposal uses this existing program to further activate the surface through permeability, allowing it to spill out onto the next surface. The Podium's existing terrace level now seamlessly connects to the surface. The more open spaces at the north and south ends of the site, are intended to be flexible and non-programmed which allows the users to define their own spaces leaving the possibility for the space to be used in many different ways.

Amongst proposed new programming is study spaces in Kerr Hall. These study spaces would follow the slope of the ramp and begin to activate the south

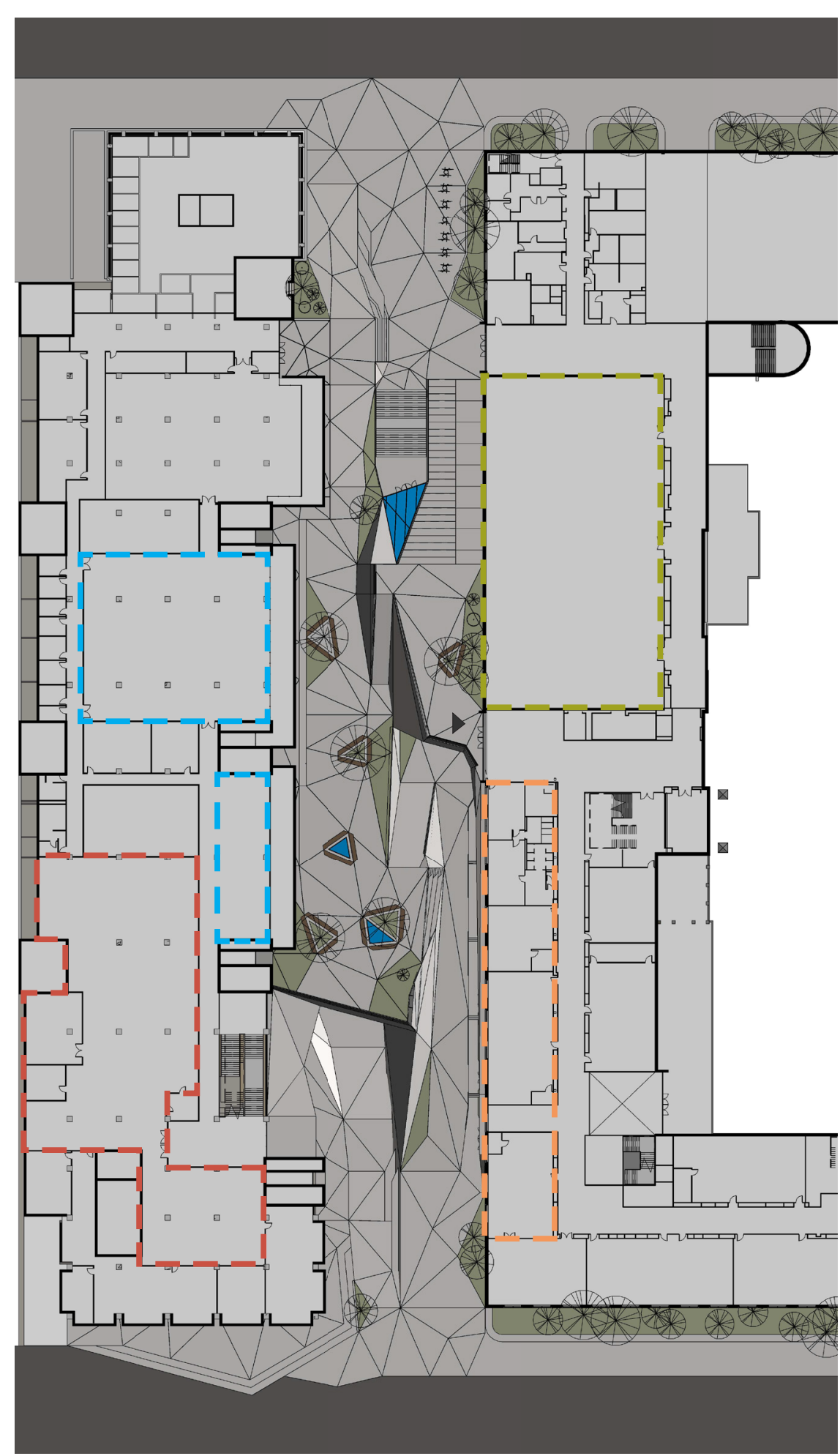



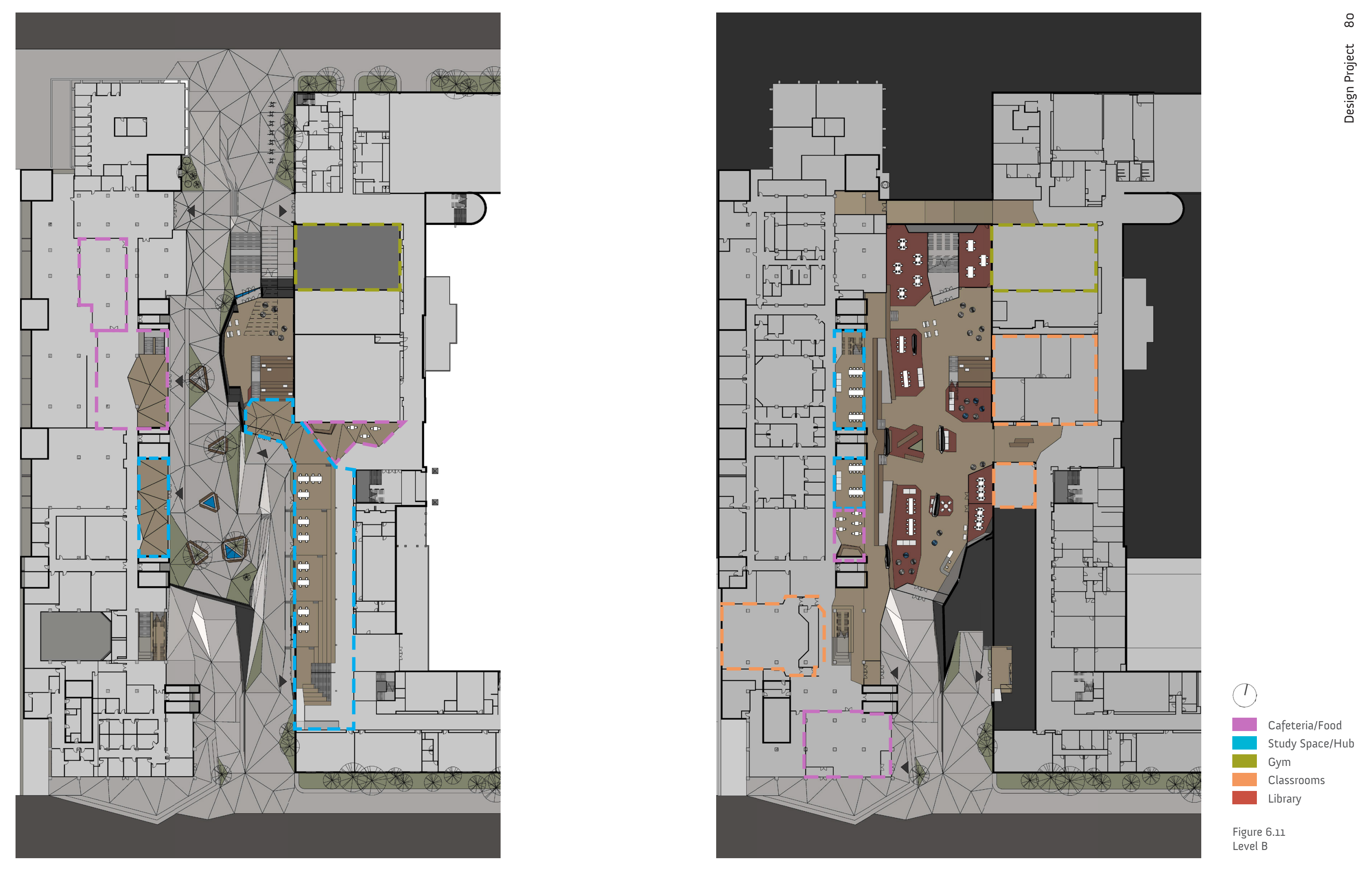


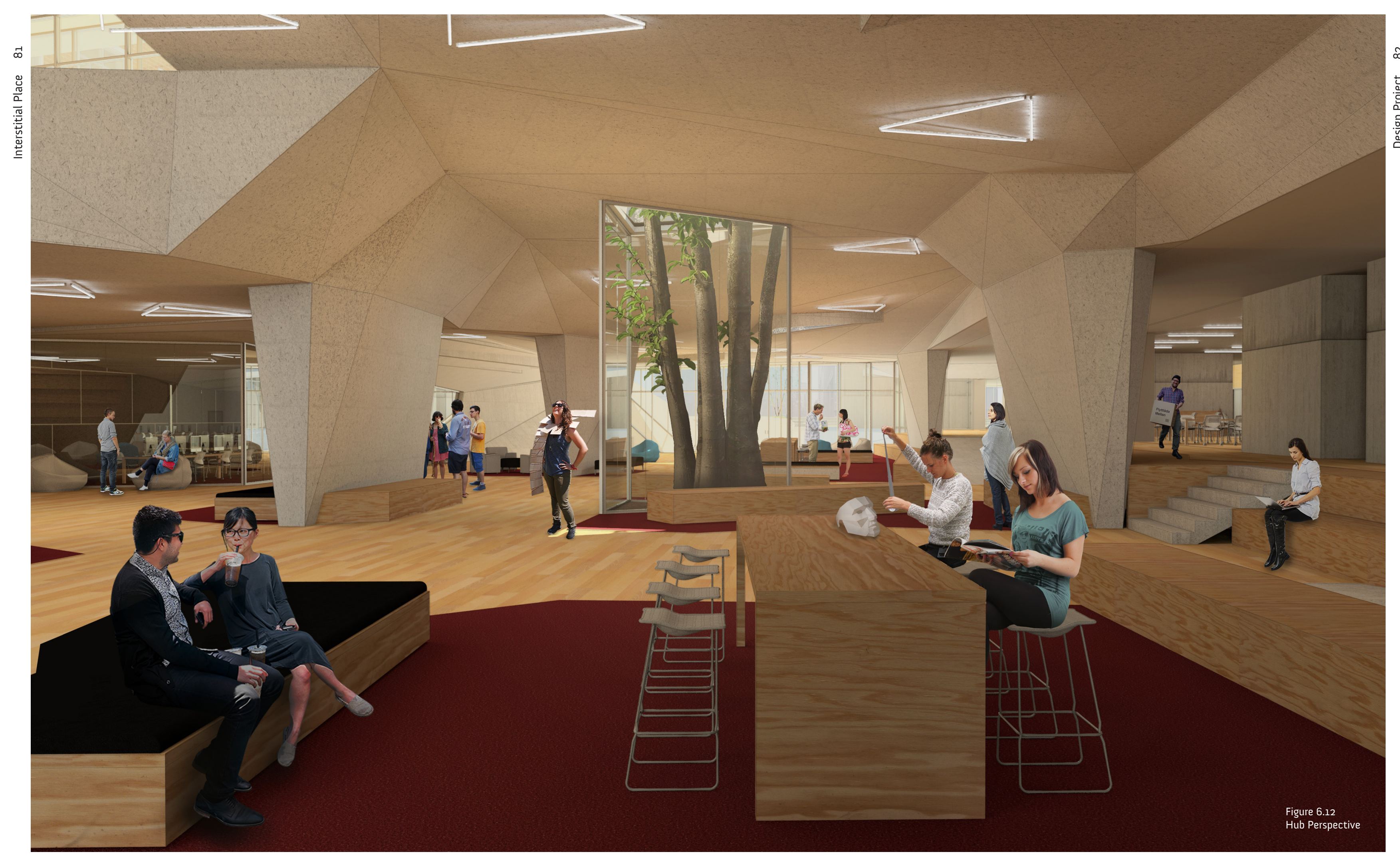




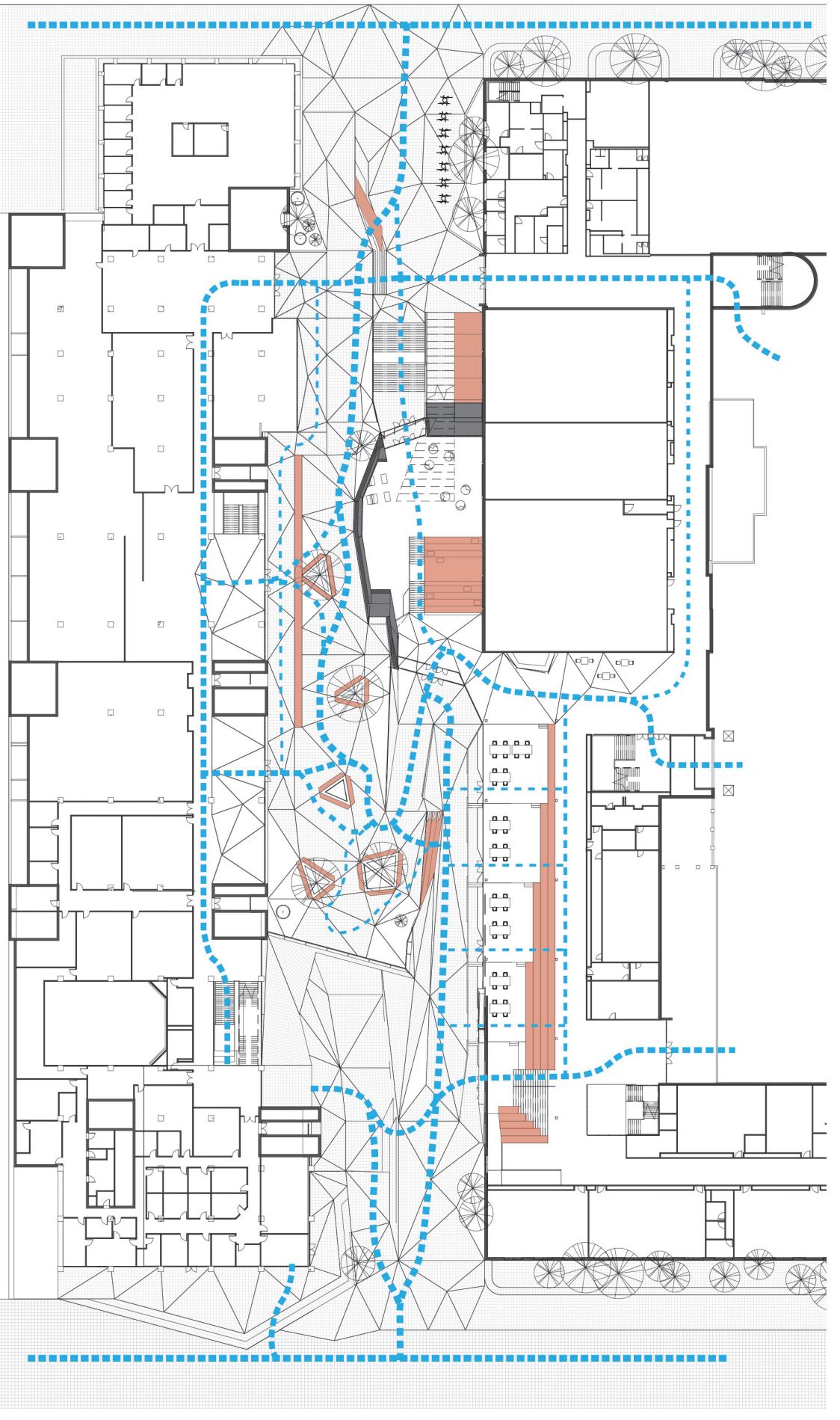

portion of the surface through their direct connectivity. They would be intended as an informal work environment. The main proposed program is the hub space underneath the surface that serves as living room for the university. The hub space is a large, flexible space that features different zones that provide students with an informal area to work in, with casual group areas, chill zones, individual work spaces, closed rooms and access to food. Currently, only the Student Learning Centre offers this type of informal work space to students. The emergence of this typology comes from a changing pedagogical approach that sees learning as a student-centered experience. Learning in this type of environment is a product of collaboration, dialogue and digital experience, with a strong emphasis on social aspects. Two new cafés are introduced, one at the top of the proposed tiered steps in Kerr Hall and in the Hub in the Podium Building. Lastly the south facade of the podium now connects and engages with the street where previously a carved-out moat separated the building from the street.

\subsection{Engage}

Once ease of movement and flow have been established and the proposed program will have created a destination; the intersection of both flow and activity are where the proposal engages its users. Designing spaces with fluidity, along with the blurring of boundaries between programs, provides a synthetic field for diverse social encounters. The landscape surfaces provide areas for sitting on stepped levels on the ramps and the surfaces, as well as landscape features that provide edges for gathering around. The various changes in levels are celebrated by using them as opportunities for engagement to set up seating at the transition between levels (See Fig. 6.13). On the interior of the hub, there is stepped seating on the vertical connection that weaves together circulation and social space. On the surface, benches will be placed around skylights and tree planters in anticipation of informal social interactions. 


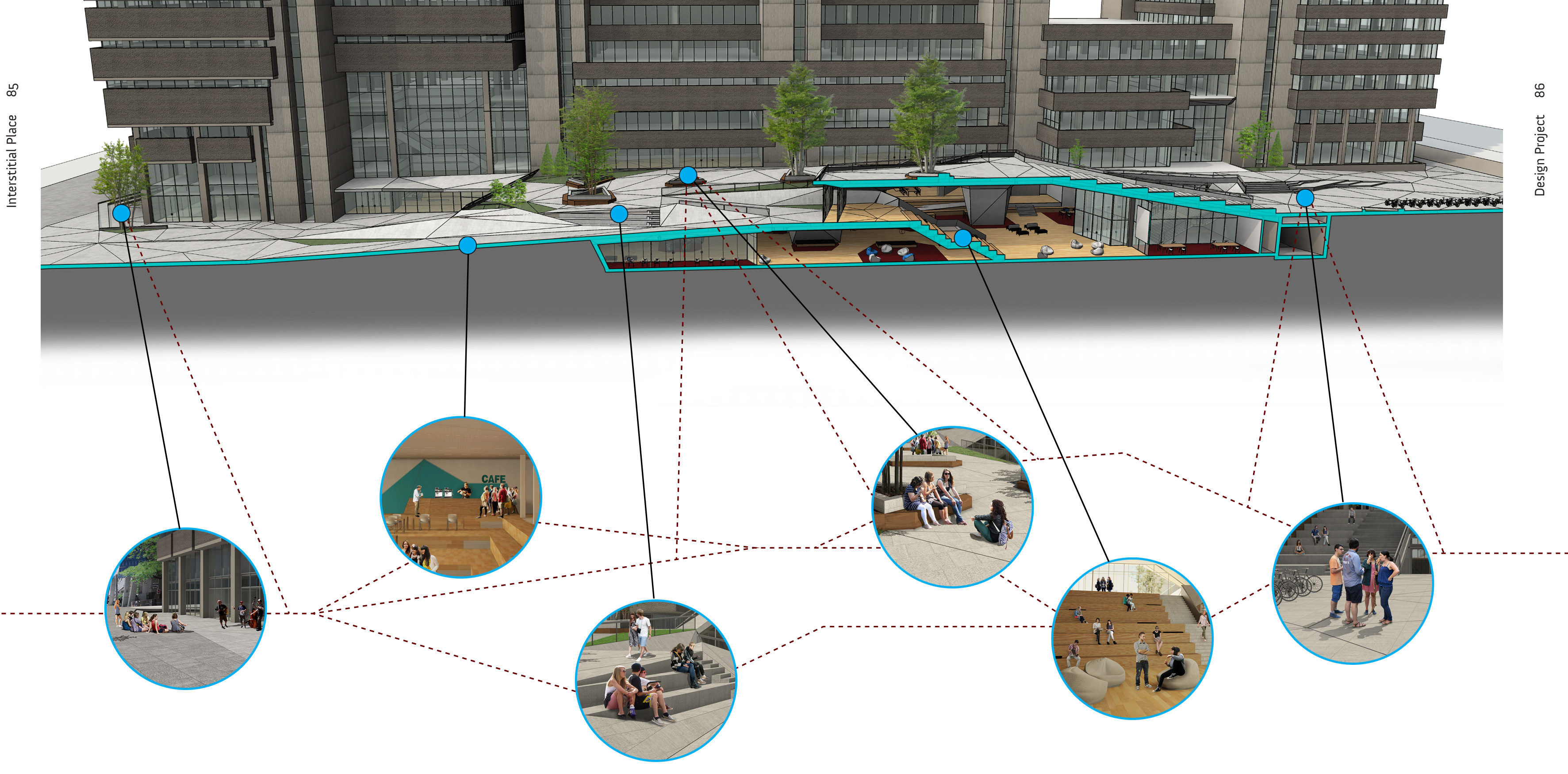

One of the tactics involves using visibility as a form of engagement. Studies have shown that the presence of people is inviting (Gehl, 2010, pg. 75). If they can see what is going on before them, they have the choice of participating or not. The proposal offers many long vistas across the project where people will be able to be seen walking or seated on the many different types of seating in the proposal. The fact that a range of activities is presented - from varieties of personal/private to social, or public - means that users have the opportunity to engage in activities that are appropriate for them (See Fig 6.14).
Figure 6.14 Interaction Vignettes 


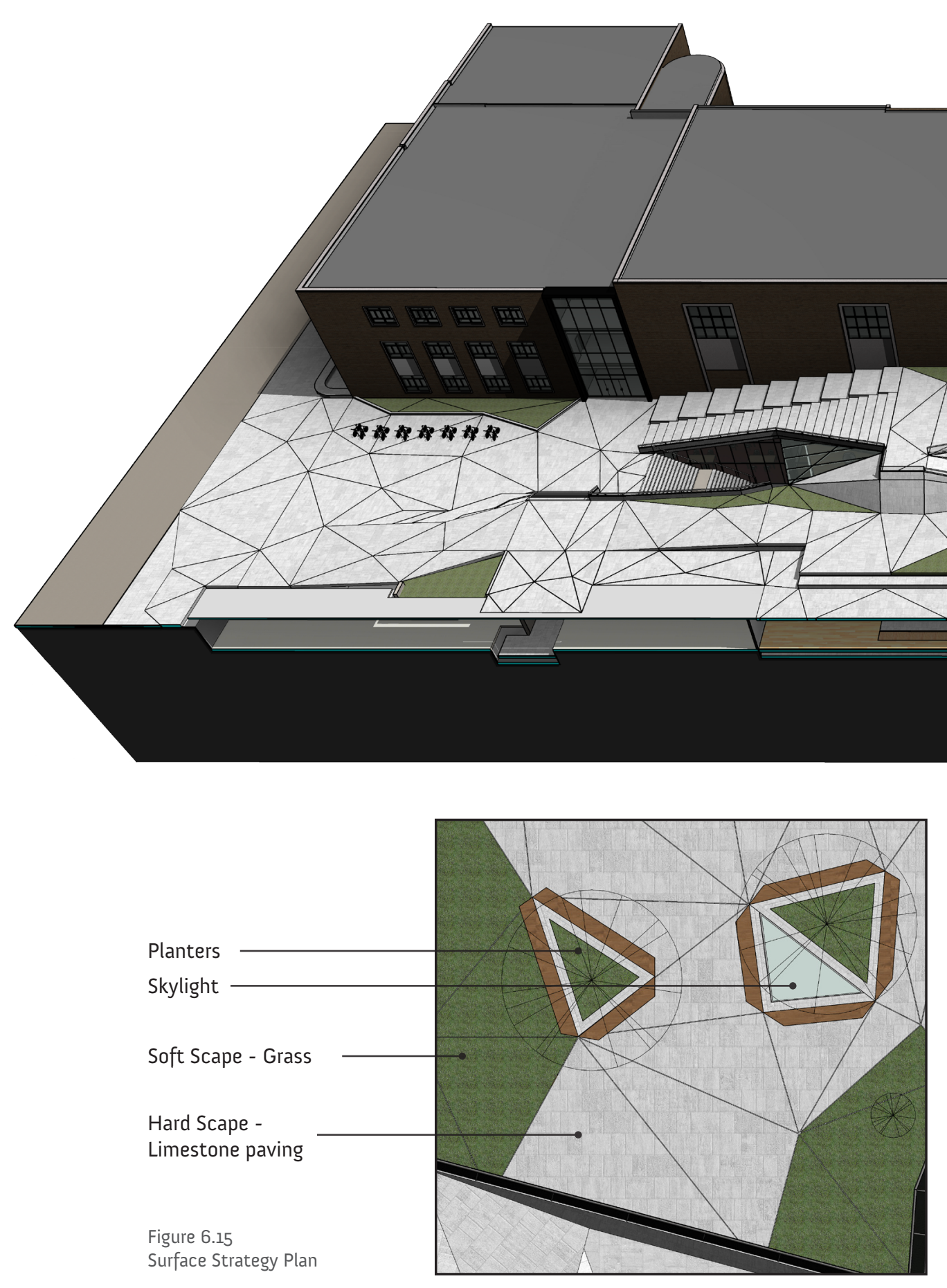

6.6 Surface Strategy

The surface continues the triangulated language of the folded planes as the pattern for the surface. Since, a large part of existing site was landscape area filled with trees, the proposal tries to incorporate as much soft-scaping and trees as possible (See Fig. 6.16). The soft-scaping is fit in near edges while trees are fit in planters. The hardscape surfaces are a light limestone paving to contrast lightly with the adjacent buildings while the soft-scaping is grasses and small plants. The skylights are triangles to fit within the pattern while raised planters hold planted trees in a similar fashion (See Fig. 6.15).
Figure 6.16 Surface Strategy Axo 


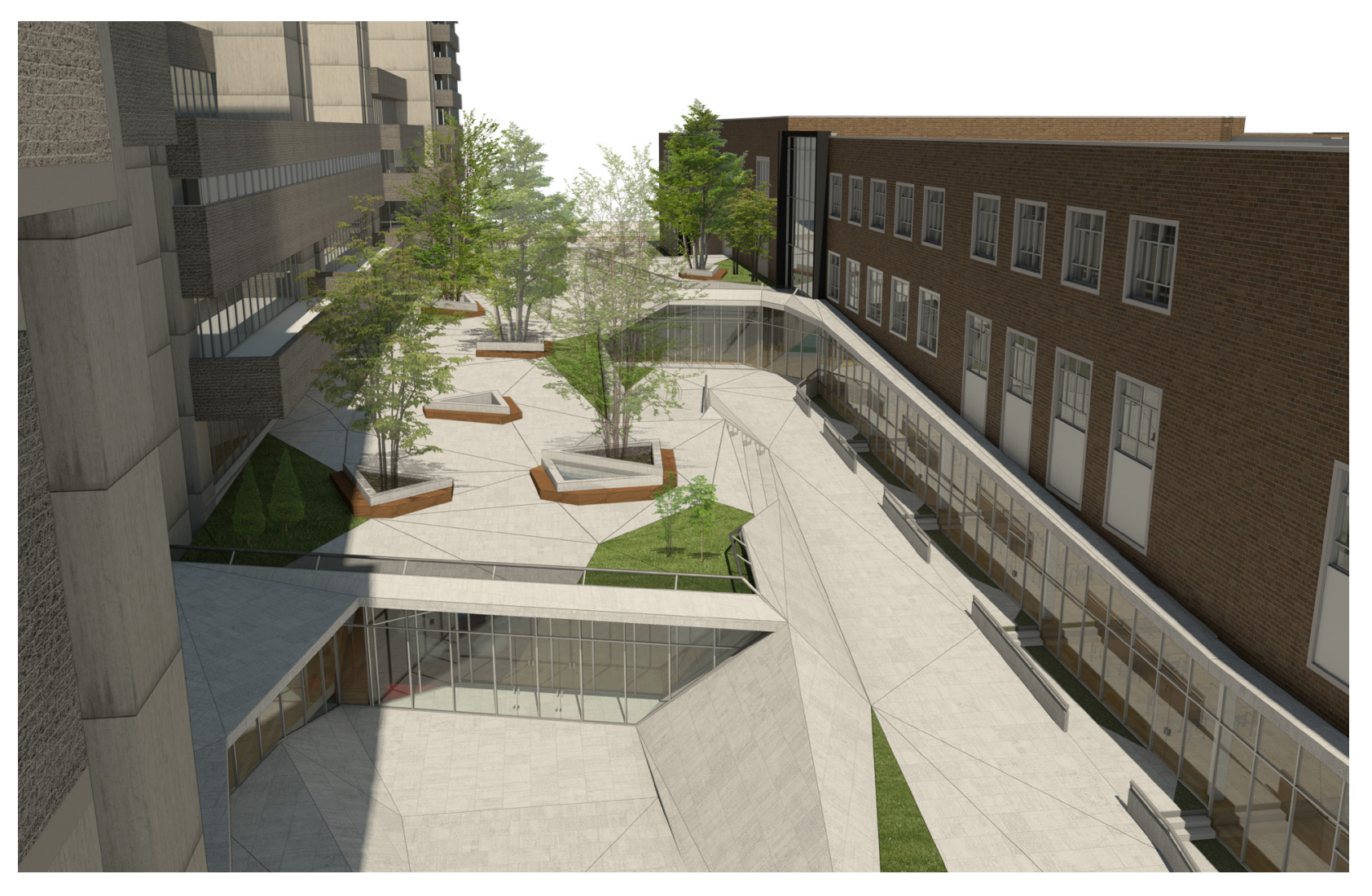

Figure 6.17
Aerial Perspective

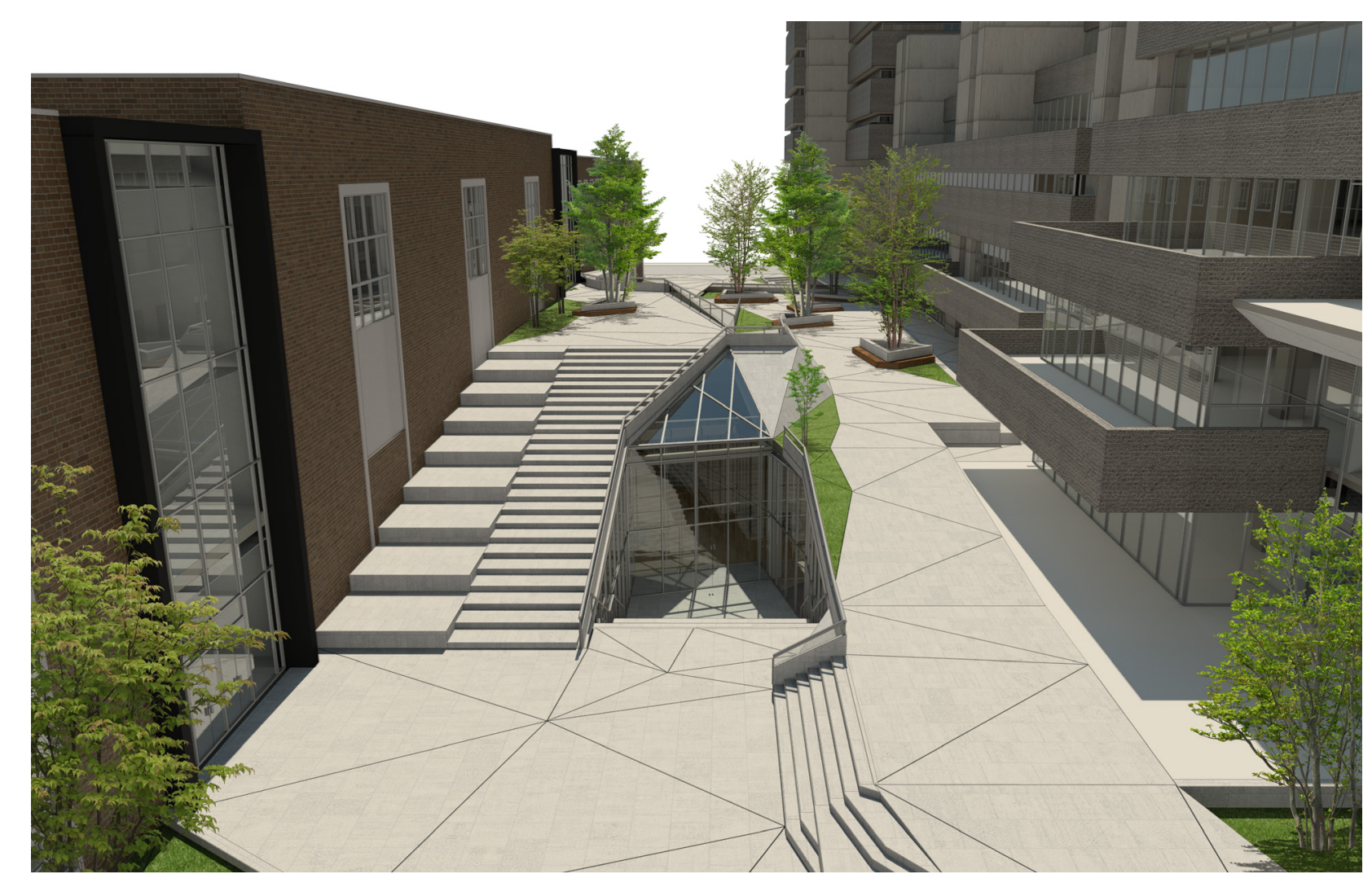

Figure 6.18
Aerial Perspective 

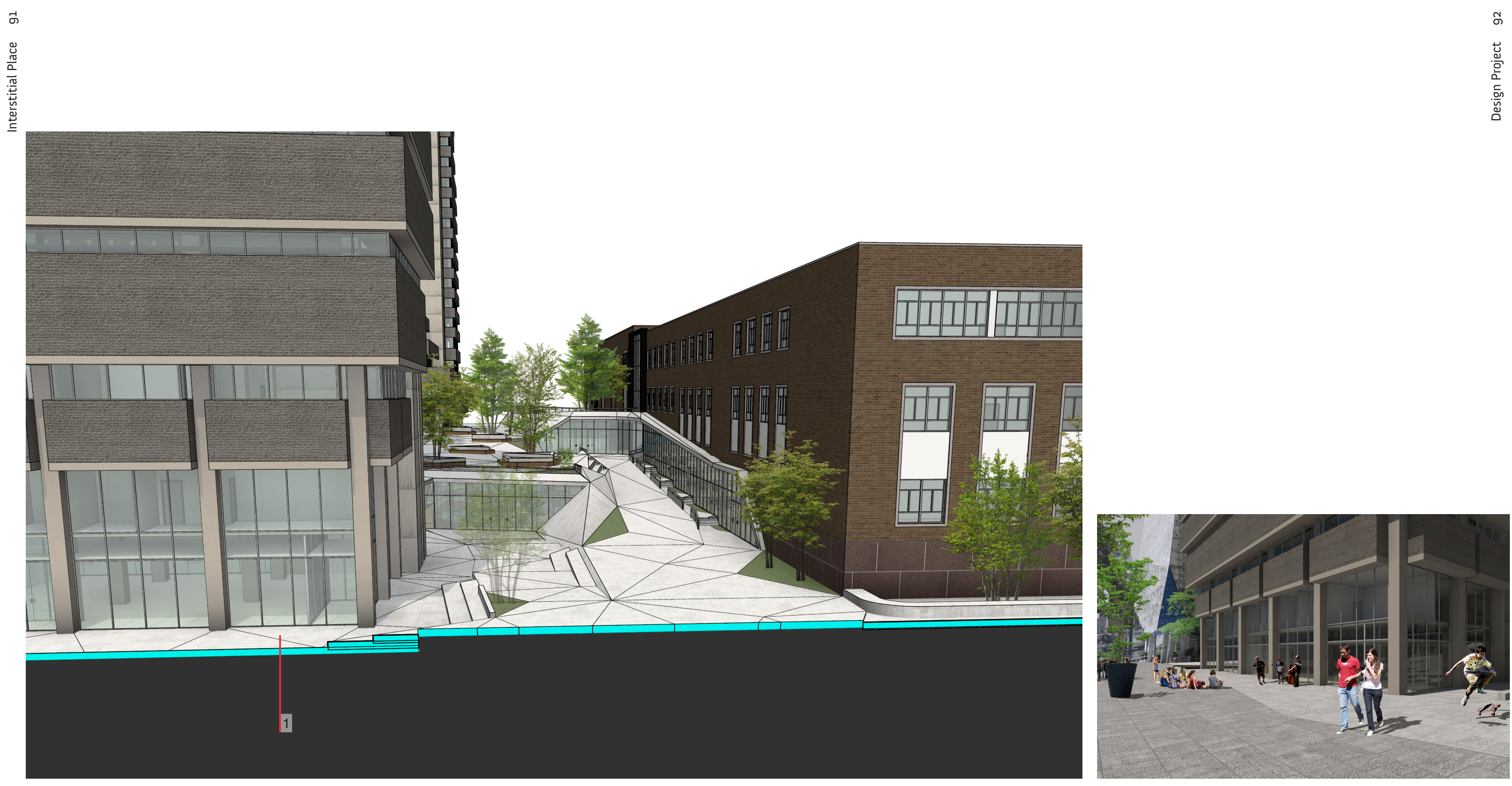


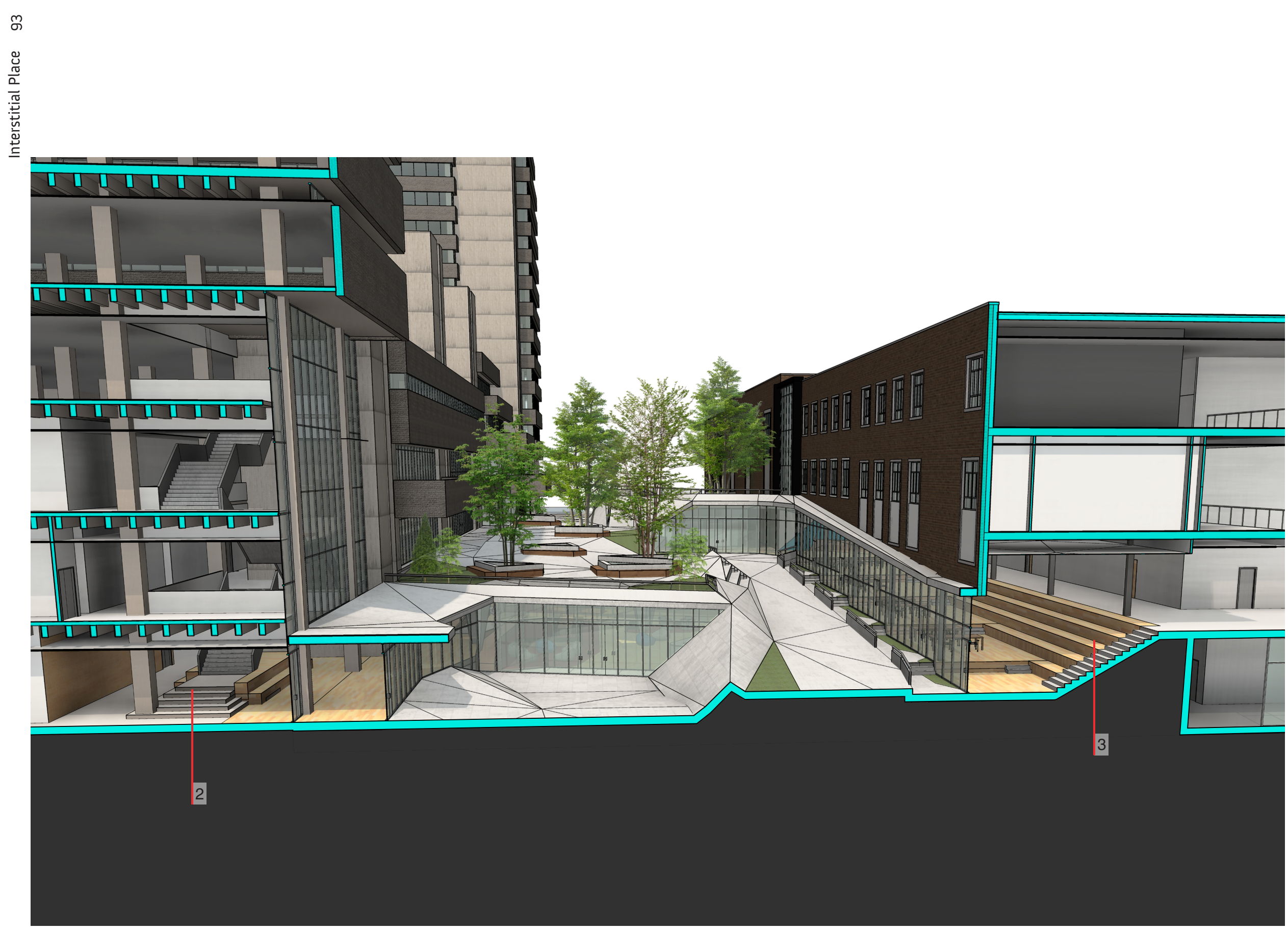

Figure 6.21
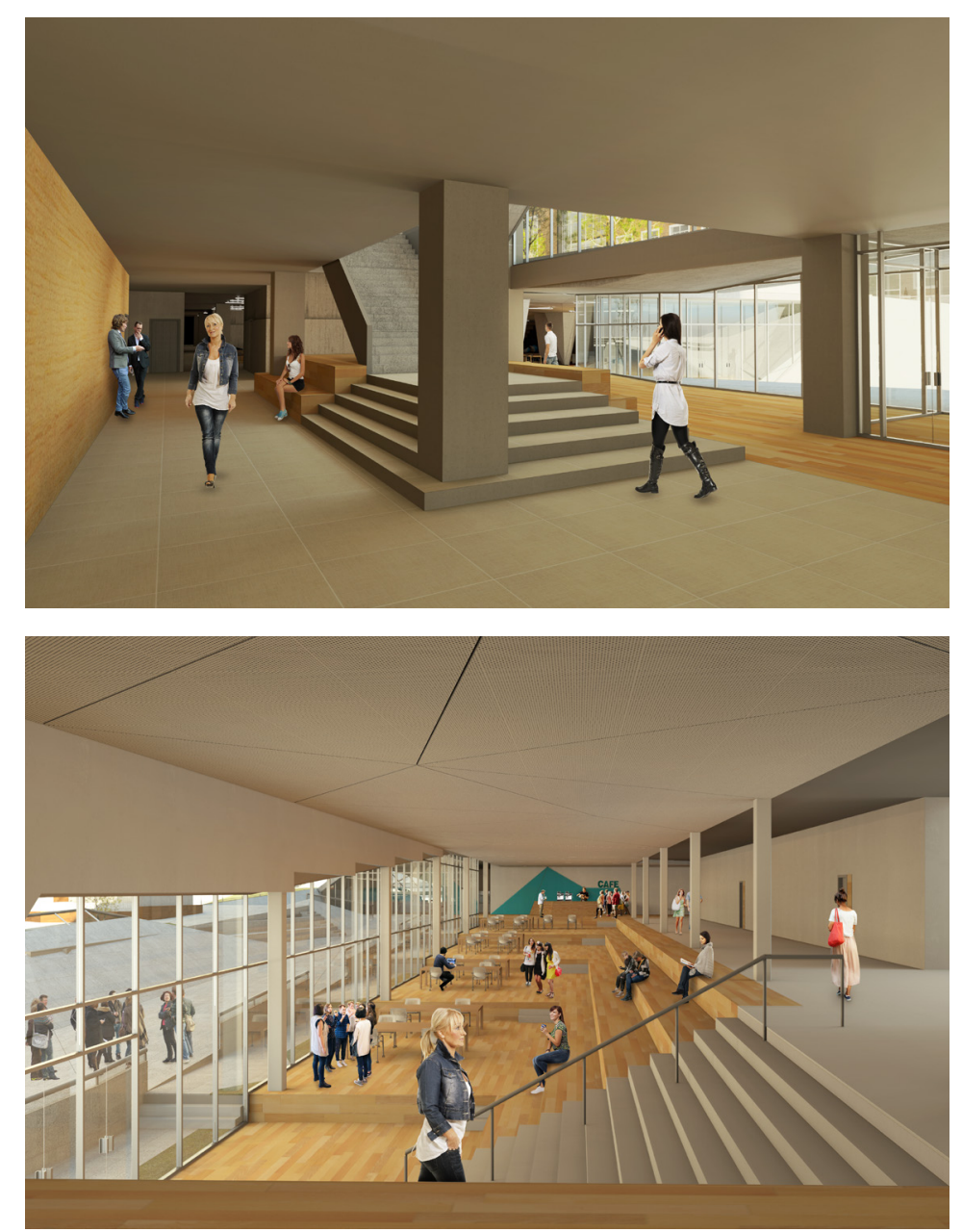

2. Podium Entrance Perspective

Figure 6.23

3. Kent Stepped Study Spaces 

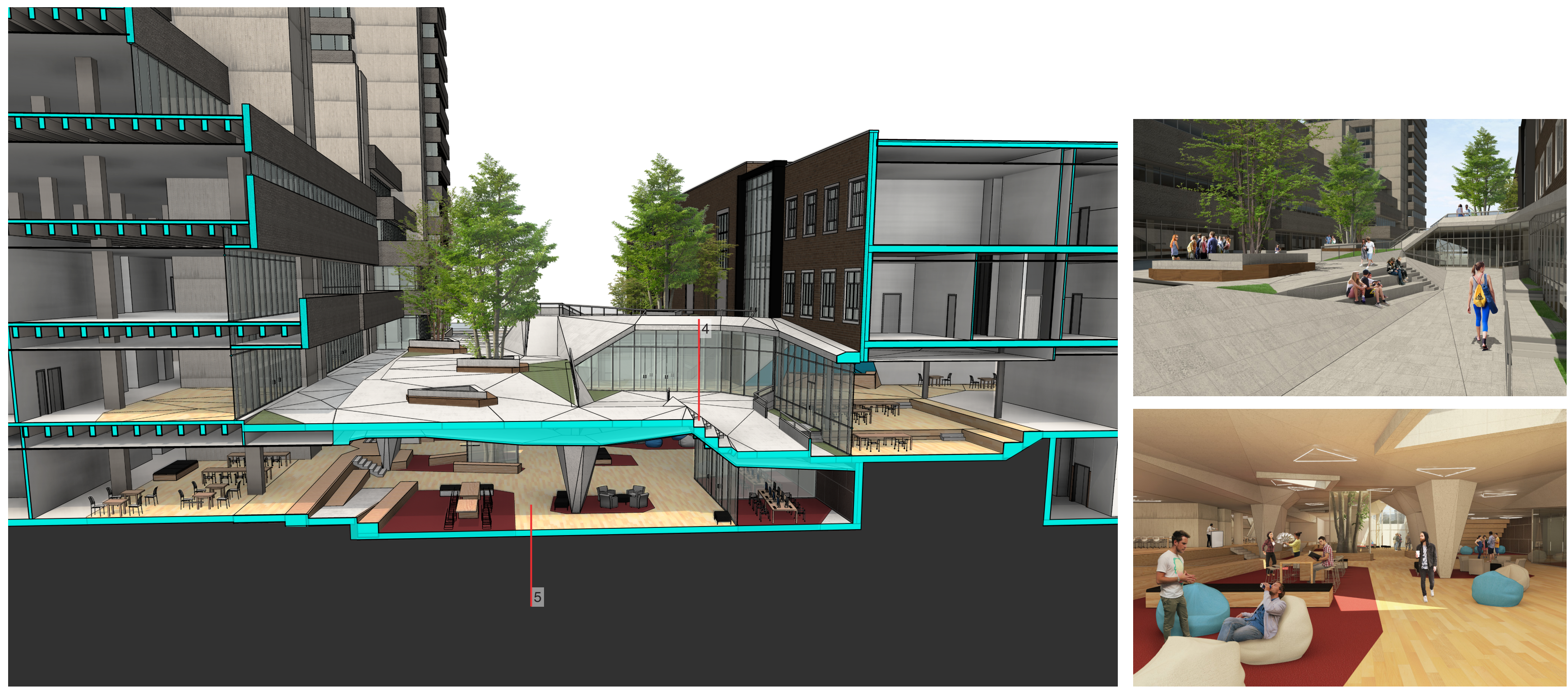

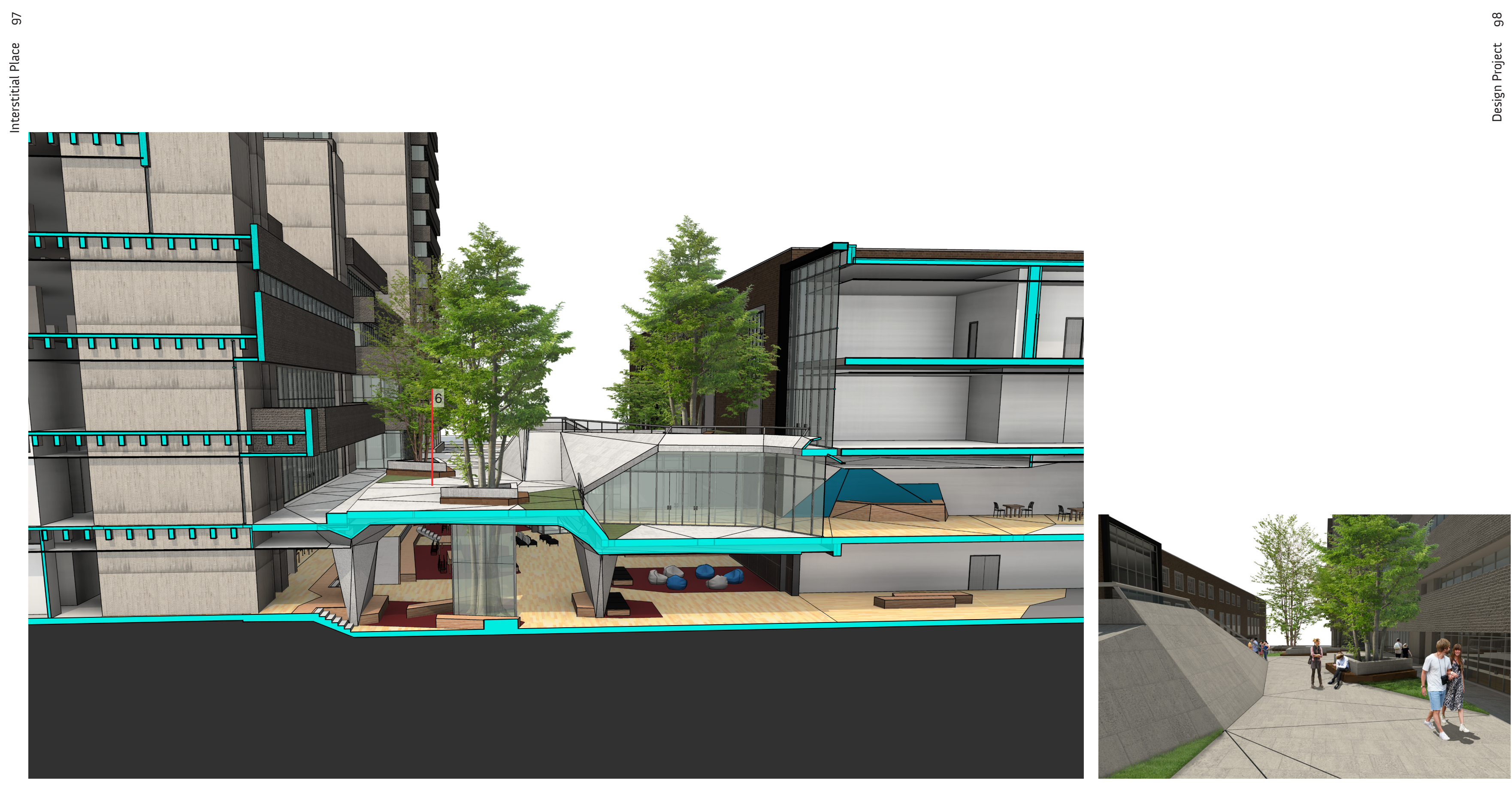


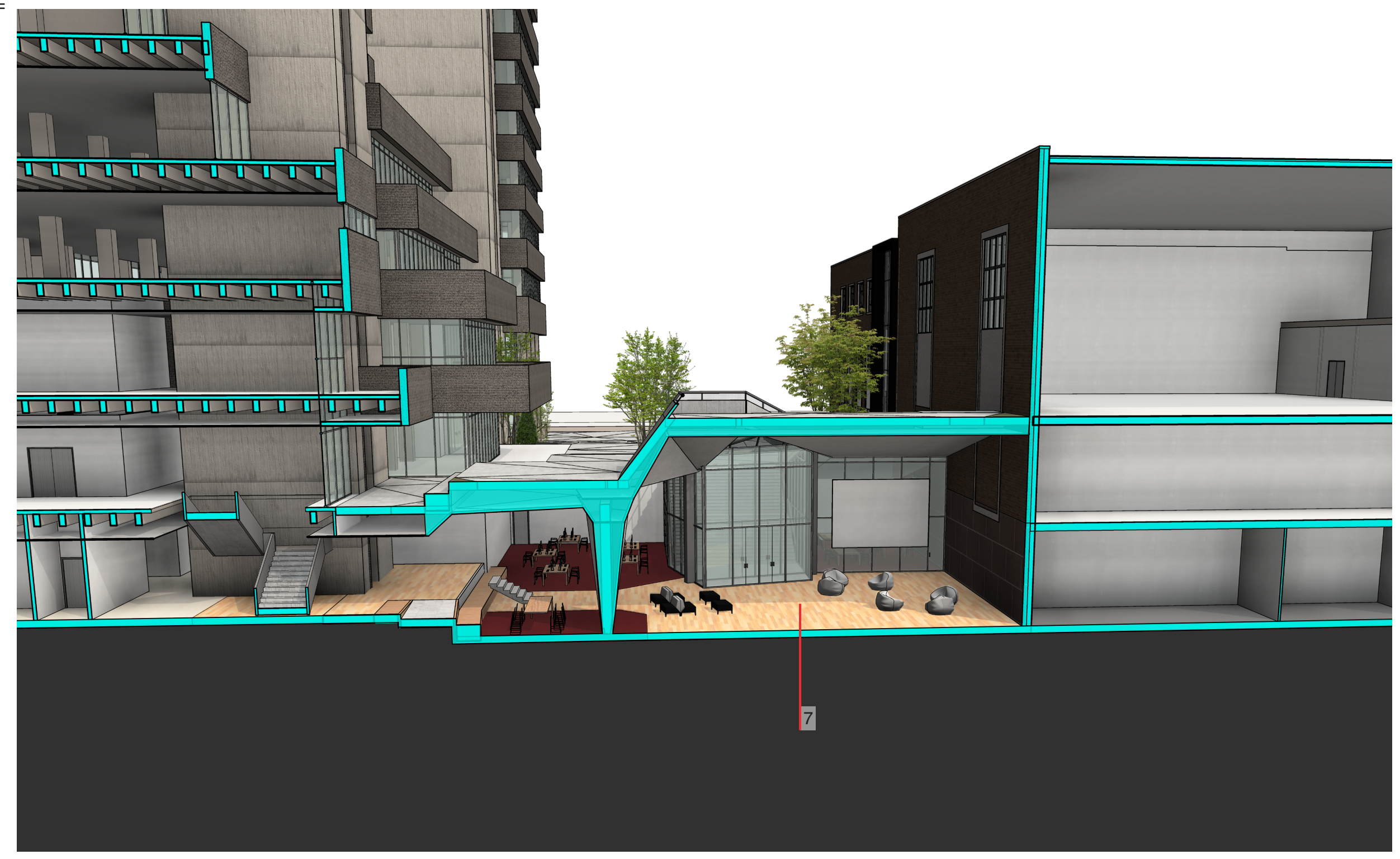

Figure 6.29
Sectional

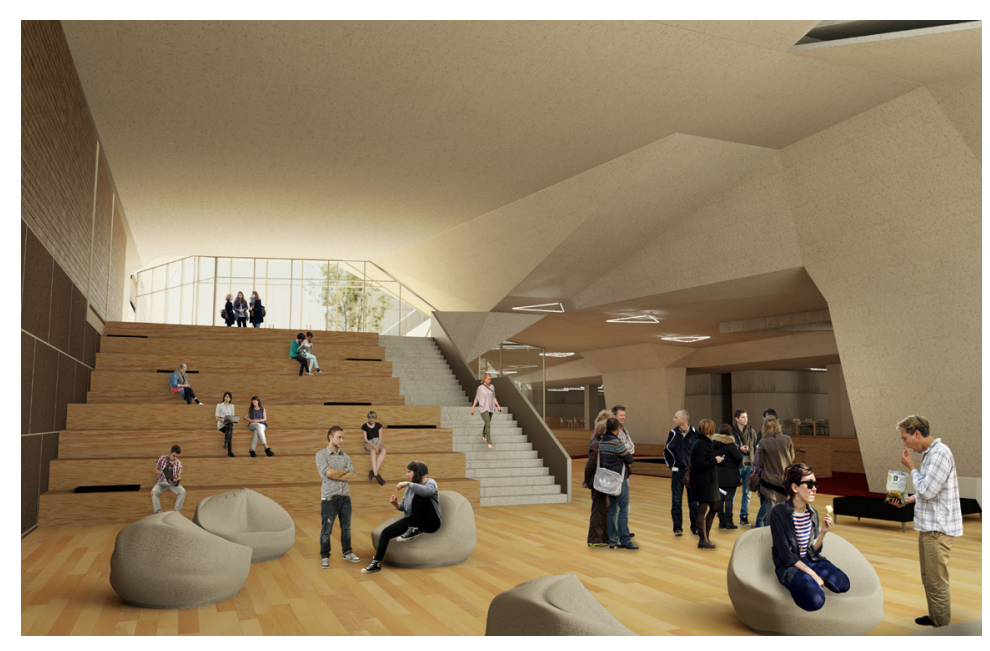

Figure 6.30
7 . Hub Perspect 


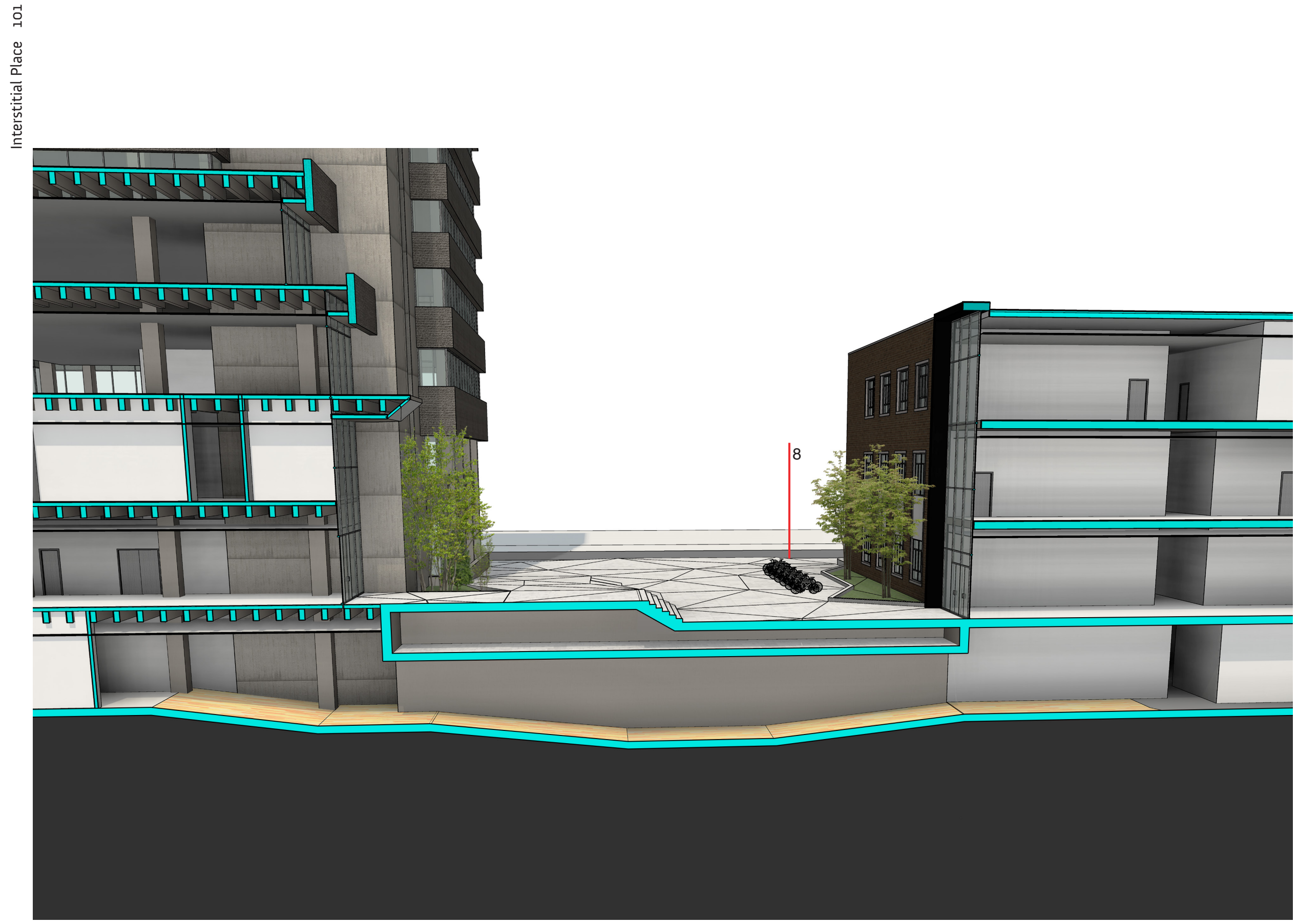

Figure 6.31

Sectional Perspective 10

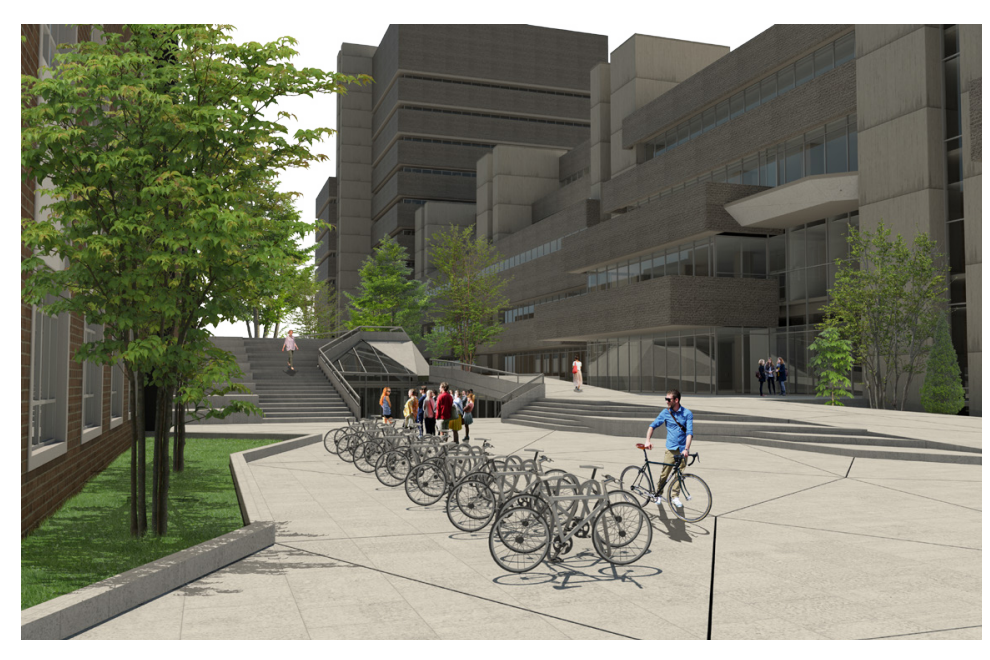

Figure 6.32
8. Bike Rack North Perspective 


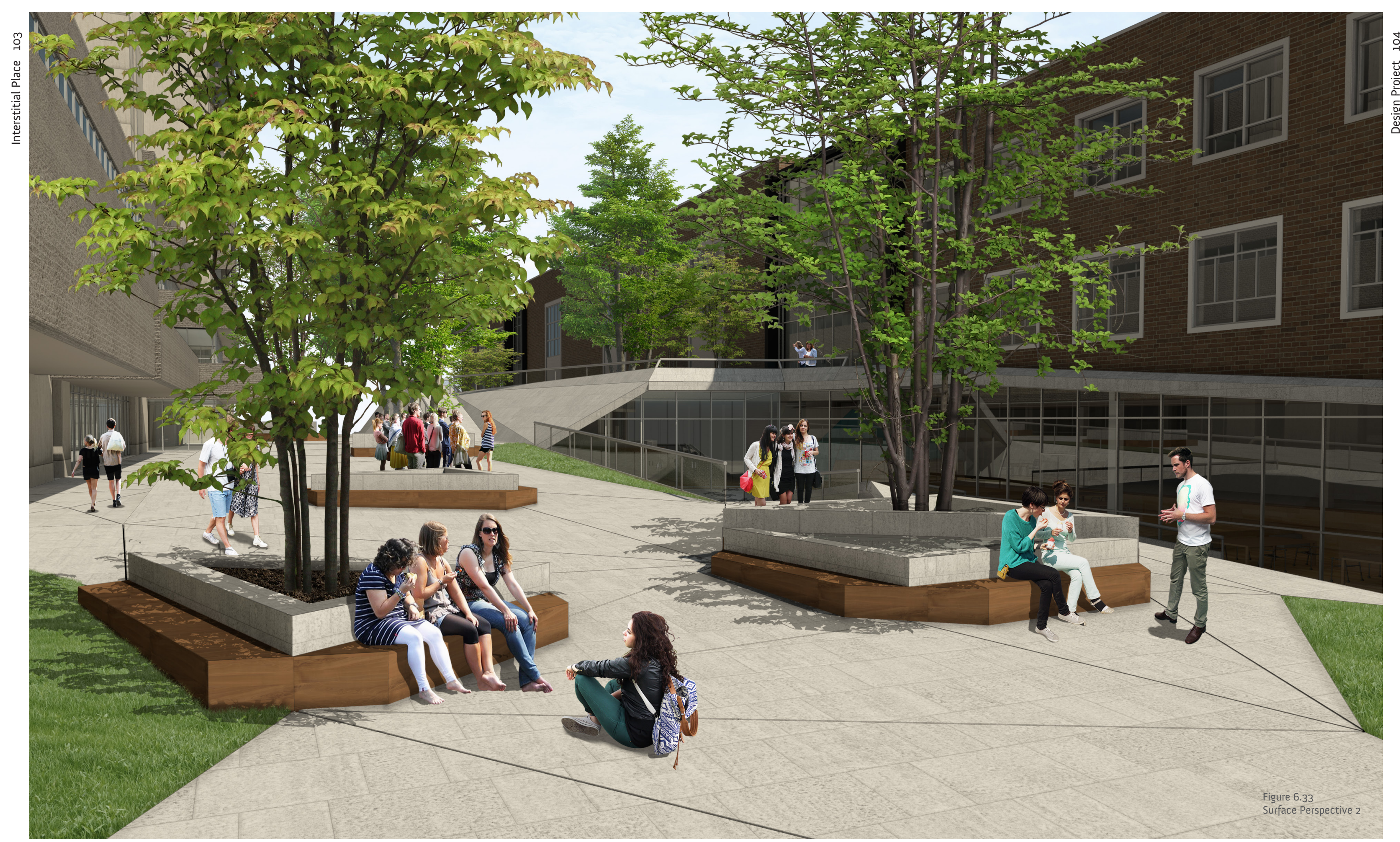


This research and design project has investigated architecture's role in creating a public domain within the contemporary city using an urban campus. To create place, theory suggests viewing the city as a field, using a horizontal surface as generator of a public domain rather than defining it solely on the city's vertical planes. In the increasingly densifying city, opportunities are to be found in the non-place; in-between areas that tend to disrupt the continuity of the urban fabric as alternatives to the typical public areas such as parks and squares. In considering these sites as opportunities for public engagement, we can look not only at a part of the city, but at how it can connect and support existing and new networks and can contribute towards an overall vibrant city. This thesis examines how the application of principals of landscape urbanism and infrastructural urbanism can achieve design goals even as they respond to specific site issues.

The issue of connectivity and flow is an critical one on Ryerson's campus, and can be addressed by increasing movement and by creating networks that provide access to the neighboring buildings. This proposal adds a continuous unifying surface material and geometry to connect the varying levels of adjacent buildings, blurring the boundaries between inside and out and creating new visual and physical connections. The proposal widens the street and opens it up vertically allowing people to perceive the street in its entirety through removing the eastern band of landscape and the two overhead bridges. Reconfiguring existing and creating new programs, provide new places for people to hang out and eat, as well as study. The change in levels is used to create stepped seating throughout the length of the surface providing places for people to engage socially. Soft-scaping is introduced to soften the harsh, opaque architecture of the adjacent buildings with trees planted in planters across the surface. Lastly, skylights bring natural light down into the hub space and an enclosed tree within the hub space creates a connection to nature below the surface.

Through the synthesis of architecture, infrastructure and landscape, the proposal refocuses the public life of the Ryerson's campus to spaces of movement to create new connections and relationships between building, landscape, and people. Through a continuous surface of social encounter, the proposal promotes cross-collaboration, a sense of community, and ultimately the transformation of an interstitial space of pure movement to a destination with a "sense of place". 

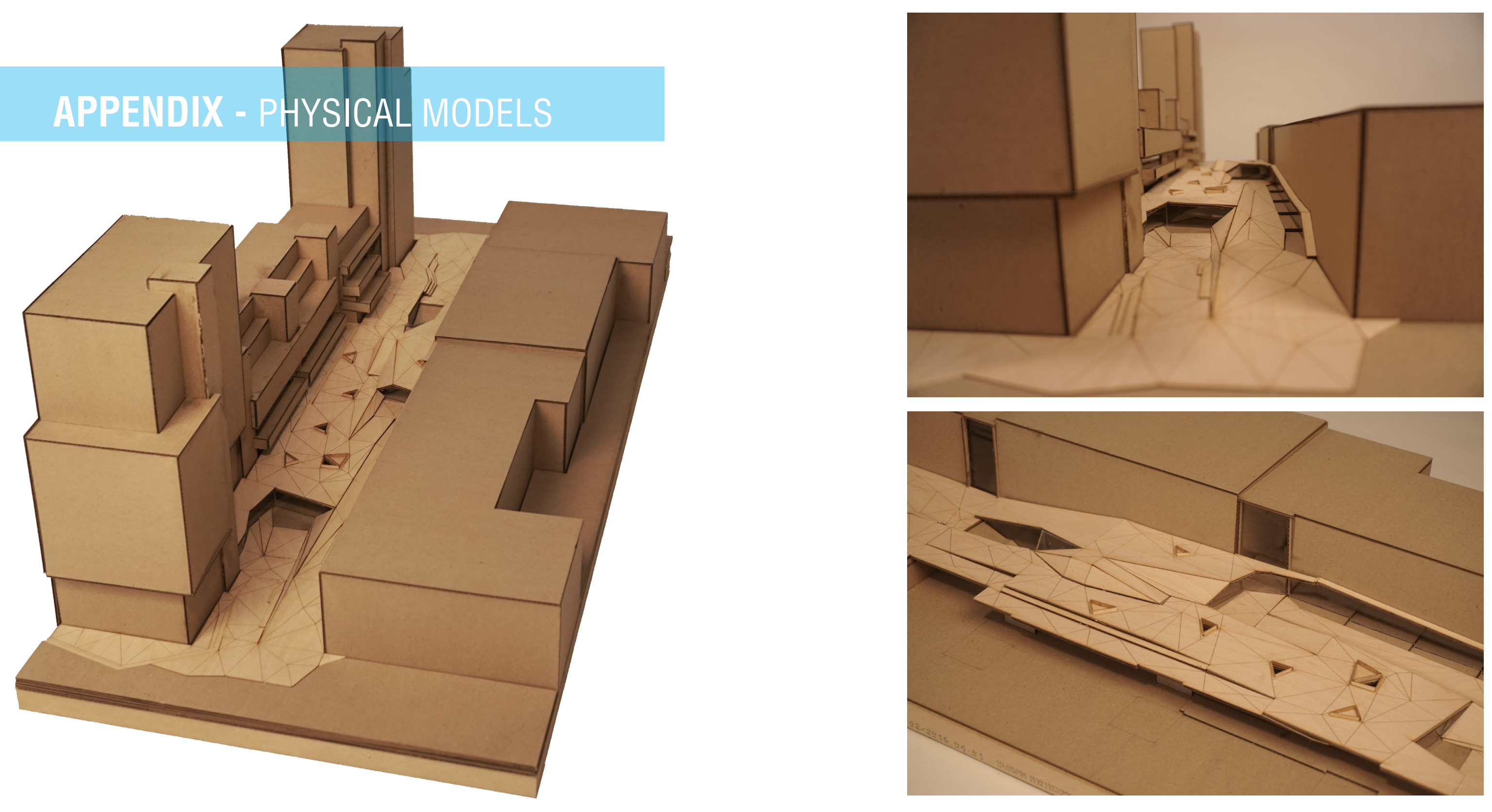

Physical Model 1

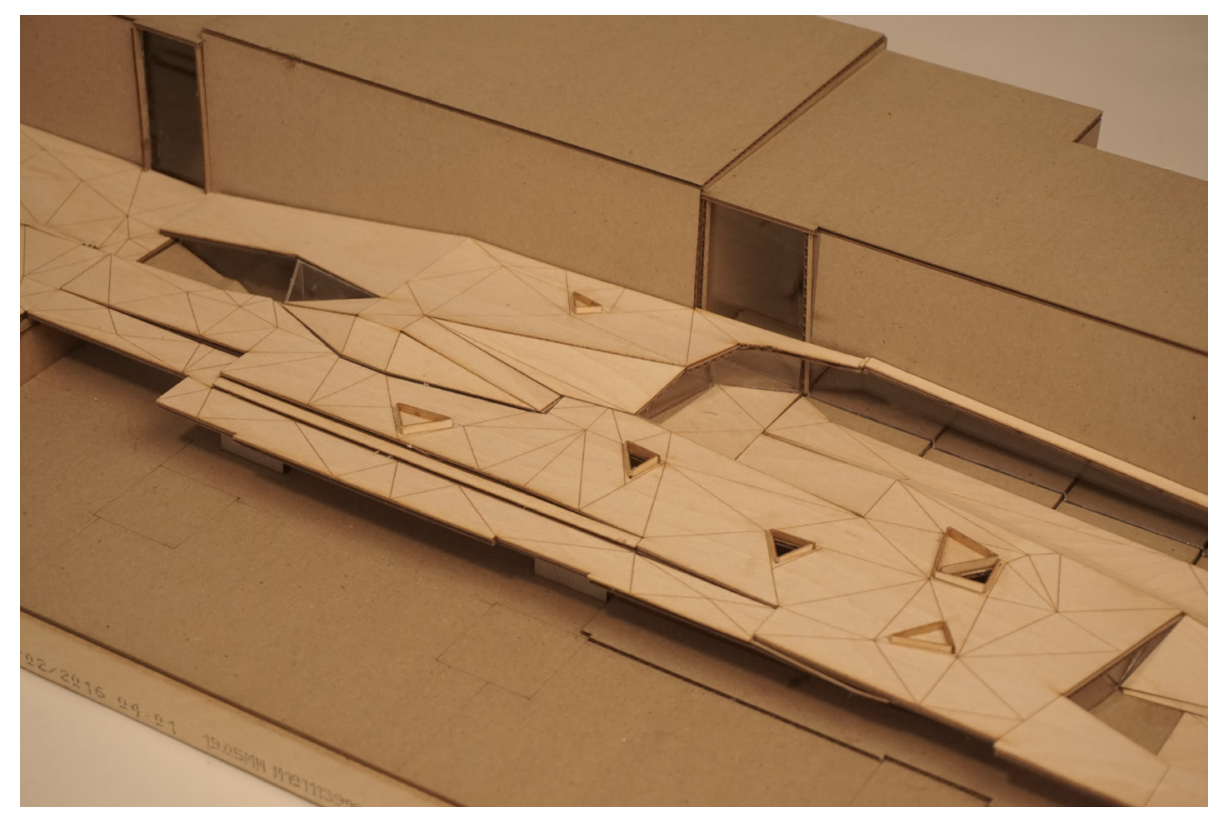

Physical Model 1 Aerial Perspective Physical Model 1
Surface Detail 


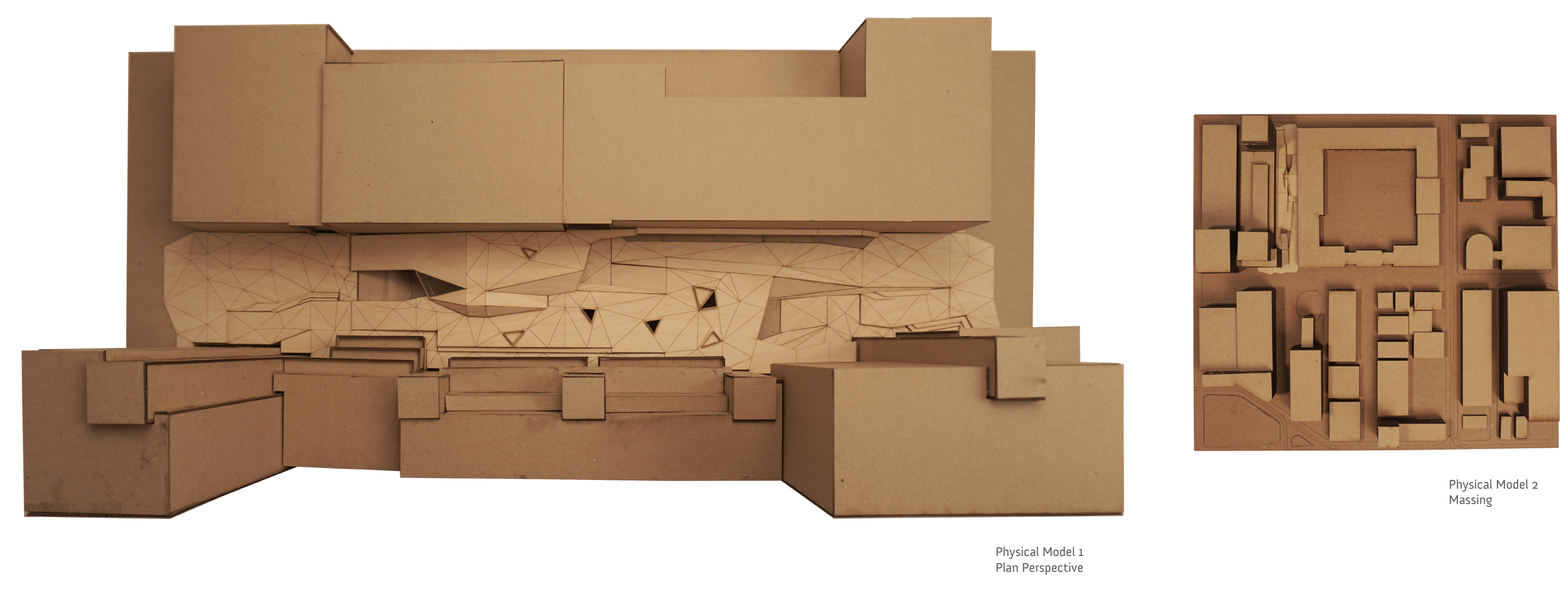




\section{APPENDIX - EXISTING SITE}

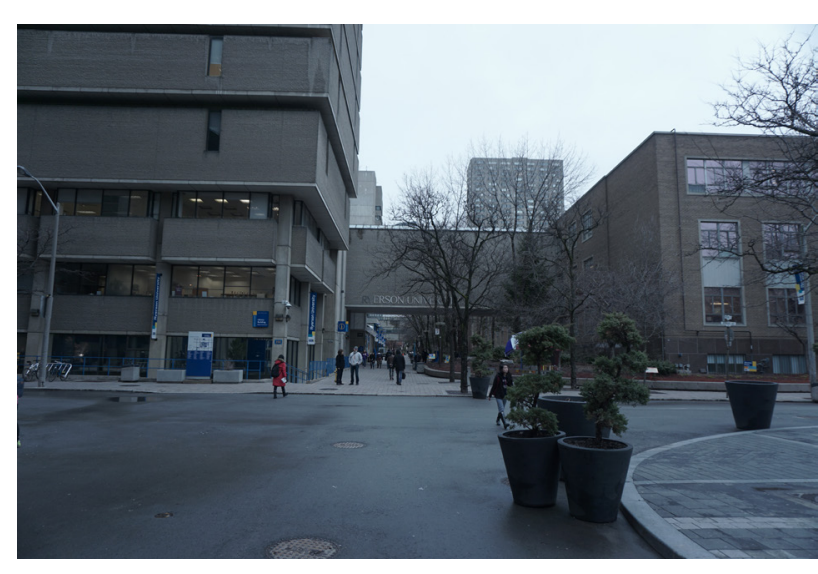

Walkthrough 1

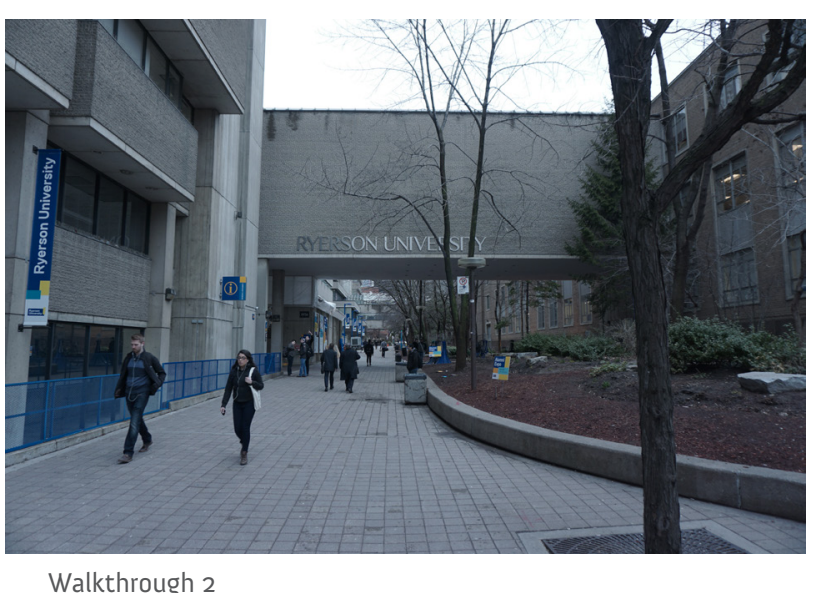

Walkthrough 2

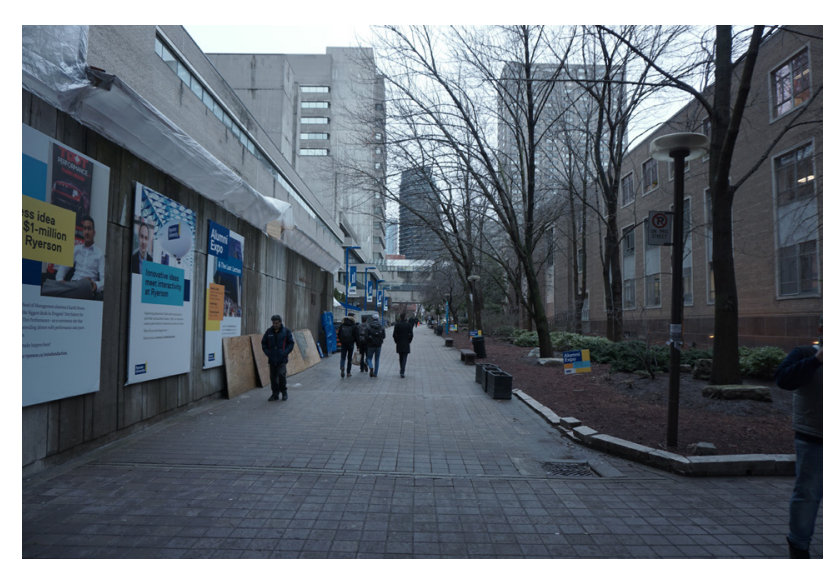

Walkthrough 3

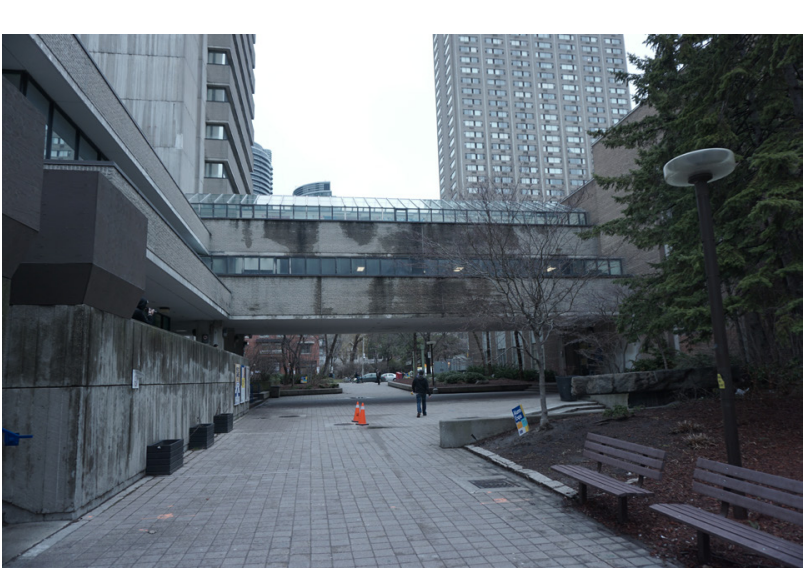

Walkthrough 4

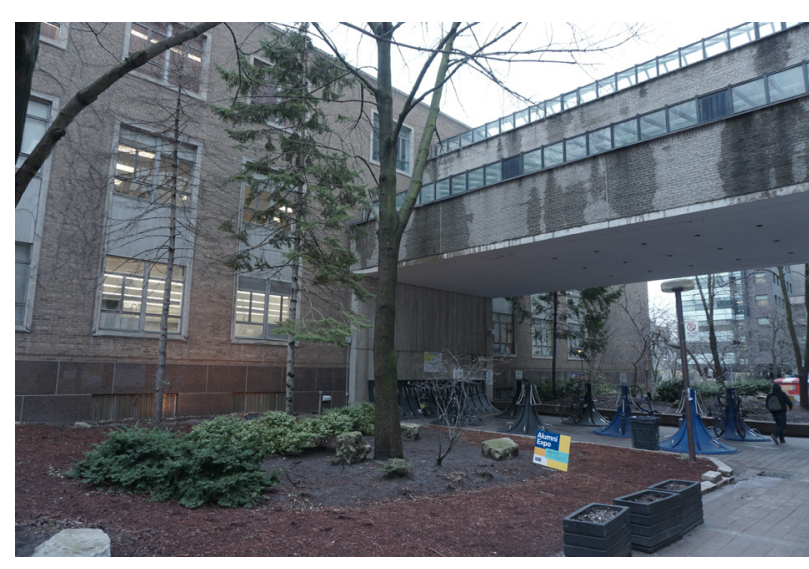

South Bridge - Lack of Keri Hall Entrance

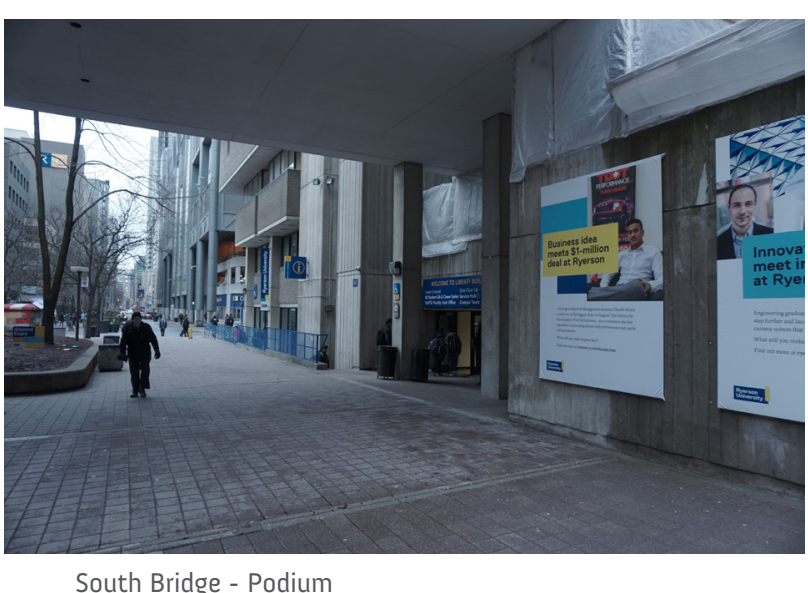

South Bridge - Podium
Entrance

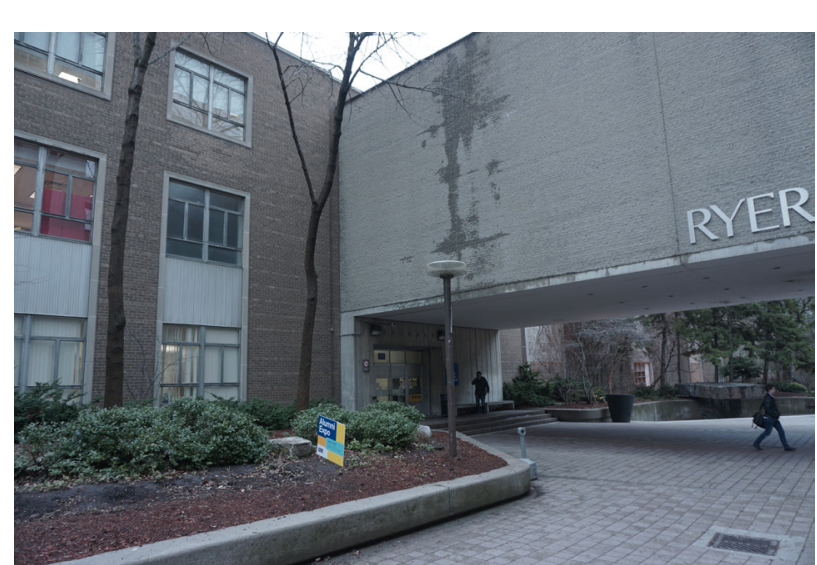

North Bride- Kerr Hall Entrance

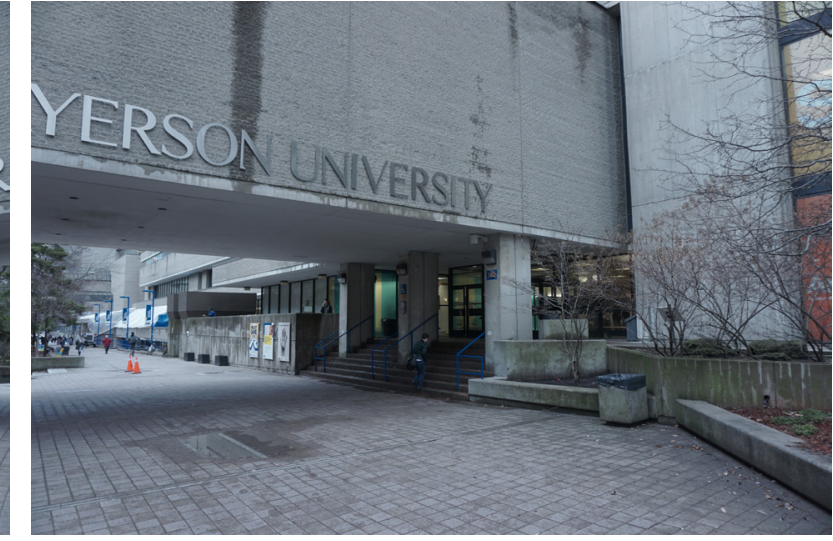

North Bridge - Podium 


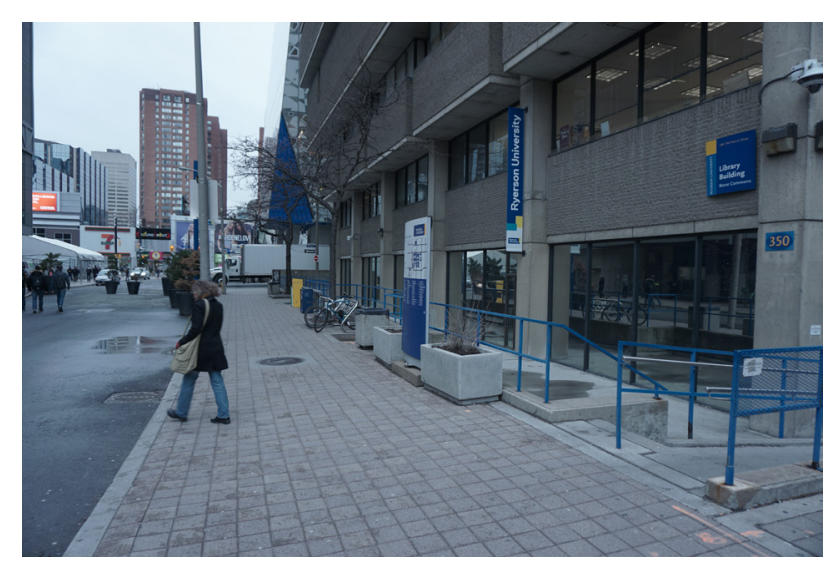
Gould St. - Podium/Library
'Moat' Condition

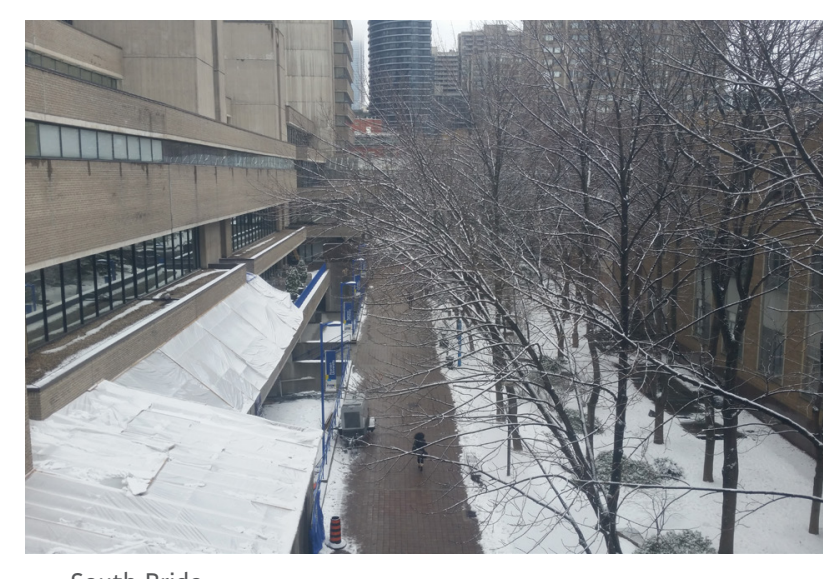

South Bride
Perspective - Winte

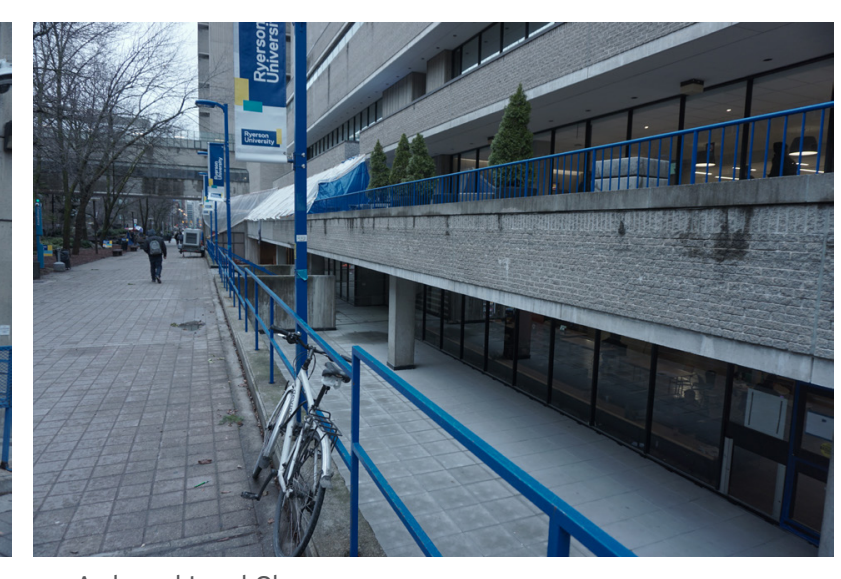

Awkward Level Changes -
Podium Building

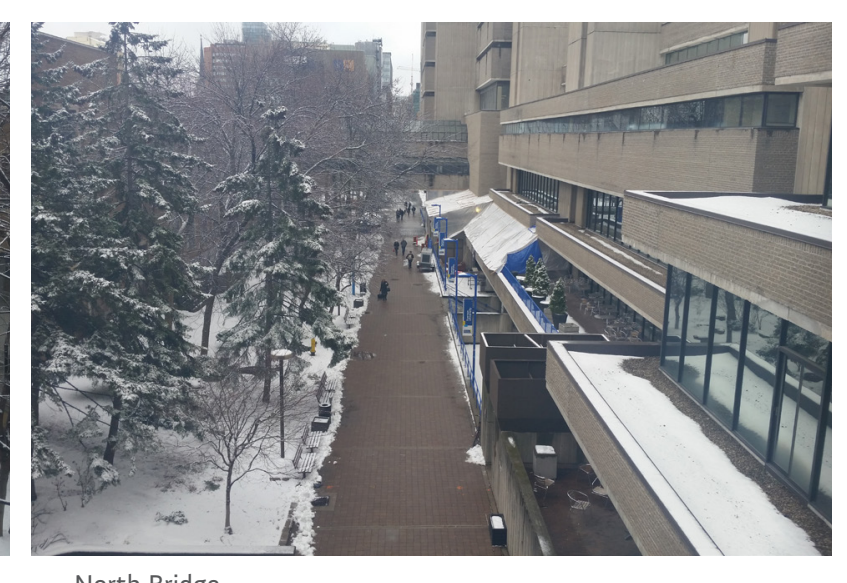

North Bridge
Perspective - Winter

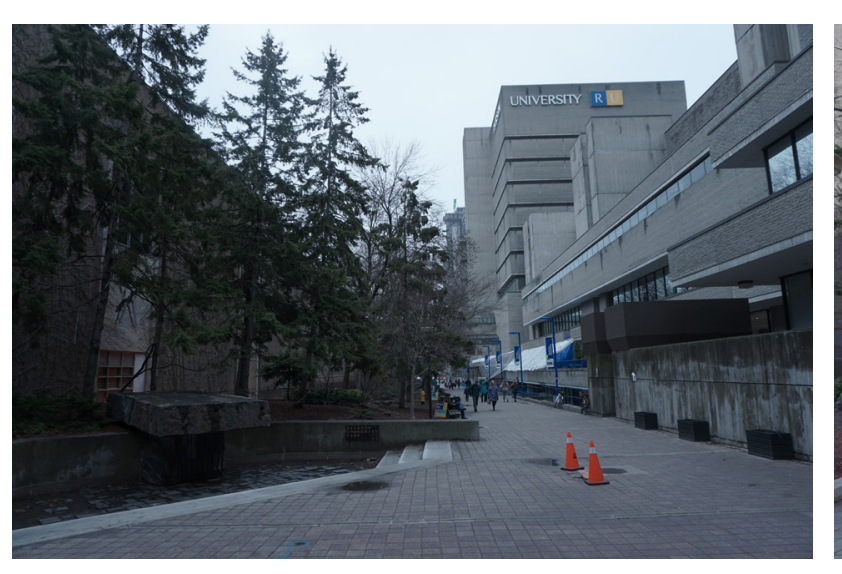

North Fountain

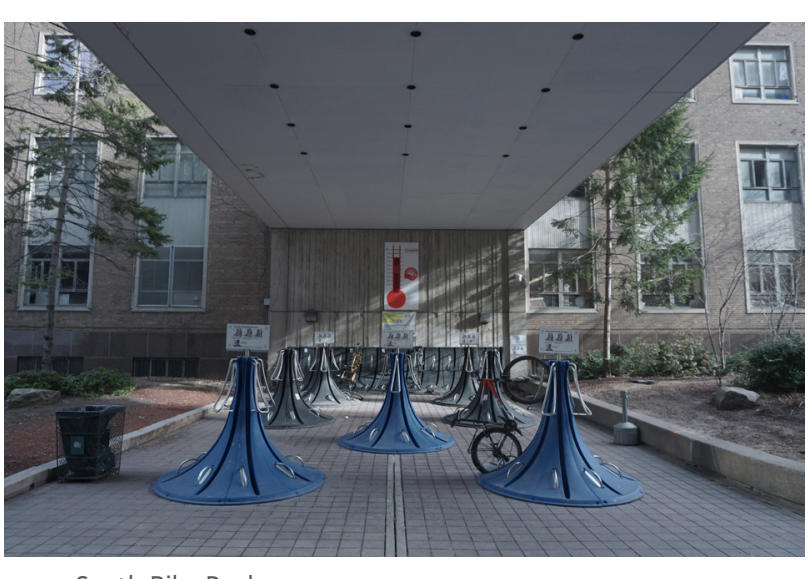

South Bike Racks

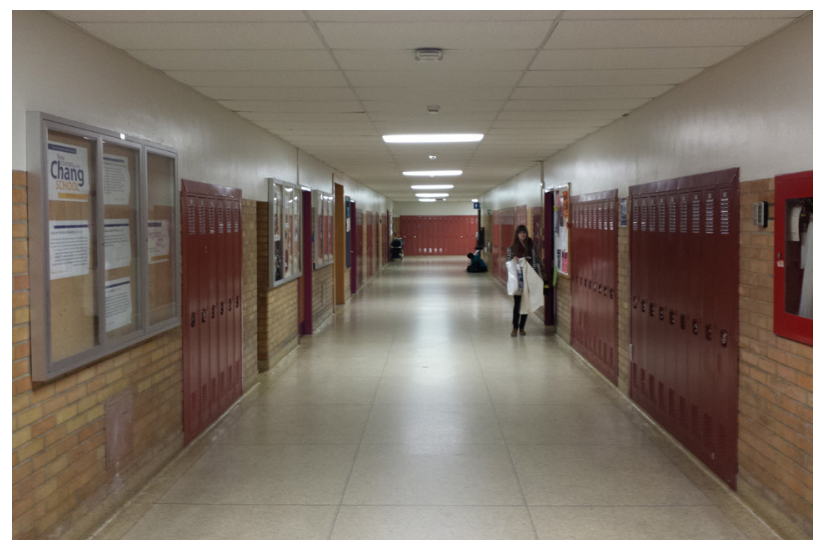

Existing Kerr Hall

Hallways

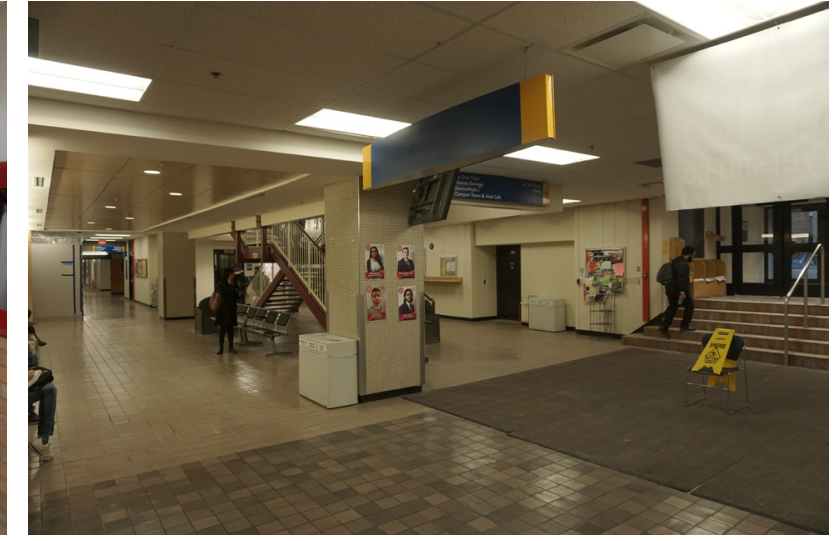

Existing Podium/Library 


\section{REFERENCES}

A Brief History of Ryerson University. (2012). Retrieved December 4, 2015, from http://library.ryerson.ca/asc/archives/ryerson-history/brief-history/

Agora. (2009). Retrieved July 18, 2016, from http://www.ancient.eu/agora/

Allen, S. (1999). Points + lines: Diagrams and projects for the city. New York: Princeton Architectural Press.

Allen, S., Stoll, K., \& Lloyd, S. (2010). Infrastructure as architecture: Designing composite networks. Berlin: Jovis.

Allen, S., \& McQ̨uade, M. (2011). Landform building: Architecture's New Terrain. Baden: Schirmer/Mosel.

Agnew, J. (1987). Place and Politics.

Augé, M. (1995). Non-places: Introduction to an anthropology of supermodernity. London: Verso.

Böck, I., \& Koolhaas, R. (2015). Six canonical projects by Rem Koolhaas: Essays on the history of ideas.

Castells, M. The Rise of the Network Society. Malden, MA: Blackwell, 1996. Print. Chung, Judy, \& Koolhaas (2001). Harvard Design School Guide to Shopping. Köln: Taschen. Print.

Corner, J. (1999). Recovering landscape: Essays in contemporary landscape architecture. New York: Princeton Architectural Press.

Dehaene, M., \& Cauter, L. D. (2008). Heterotopia and the city: Public space in a postcivil society.
London: Routledge.

Dovey, K. (2010). Becoming places: Urbanism/architecture/identity/power. London: Routledge. Ellin, N. (2006). Integral urbanism. New York: Routledge.

Frampton, K. (2002). Labour, work and architecture: Collected essays on architecture and design. London l: Phaidon Press.

Frampton, K. (1992). Modern architecture: A critical history (3rd ed.). London: Thames and Hudson.

Franck, K., \& Lepori, R. (2007). Architecture from the inside out: From the body, the senses, the site, and the community (2nd ed.). Chichester: Wiley-Academy.

Fishman, R. (1982). Urban utopias in the twentieth century: Ebenezer Howard, Frank Lloyd Wright, and Le Corbusier. Cambridge, MA: MIT Press.

Gehl, J. (2010). Cities for people. Washington, DC: Island Press.

Gould Street - Academic Planning - Ryerson University. Gould Street - Academic Planning Ryerson University. Web. 17 Apr. 2016.

Gussow, A., \& Wilbur, R. (1997). A sense of place: The artist and the American land. Washington D.C.: Island Press.

Heidegger, M. (1971). Poetry, language, thought. New York: Harper \& Row.

Holloway, L., \& Hubbard, P. (2001). People and place: The extraordinary geographies of everyday life. Harlow, England: Prentice Hall. 
Jackson, K. T. (1985). Crabgrass frontier: The suburbanization of the United States. New York: Oxford University Press.

Jacobs, J. (1961). The Death and Life of Great American Cities.

Koolhaas, R. (1994). Delirious New York: A retroactive manifesto for Manhattan (New ed.).

New York: Monacelli Press.

Koolhaas, R. (2001). Mutations: Rem Koolhaas, Harvard Project on the City, Stefano Boeri,

Multiplicity, Sanford Kwinter, Nadia Tazi, Hans Ulrich Obrist. Barcelona: ACTAR ;, 2000.

Print.

Koolhaas, R. (1995). Small, Medium, Large, Extra-large: Office for Metropolitan Architecture,

Rem Koolhaas, and Bruce Mau. 2d ed. New York, N.Y.: Monacelli, 1998. Print.

Madanipour, A. (1996). Design of urban space: An inquiry into a socio-spatial process. Chichester: Wiley.

Mehta, V. (2013). The street: A quintessential social public space. London: Routledge.

Meiss, P. (1990). Elements of architecture: From form to place. London: Van Nostrand Reinhold. Mumford, L. (1964). The highway and the city. New York: New American Library.

Norberg-Schulz, C. (1988). Architecture: Meaning and place : Selected essays. New York, N.Y.: Rizzoli International Publications.

Norberg-Schulz, C. (1980). Genius loci: Towards a phenomenology of architecture. New York: Rizzoli.

Oldenburg, R. (1989). The great good place: Cafés, coffee shops, community centers, beauty parlors, general stores, bars, hangouts, and how they get you through the day. New York: Paragon House.

Rapoport, A. (1987). Pedestrian Street Use: Culture and Perception, in Anne V. Moudon, (1987), Public Street for Public Use. New York, Van Nostrand Reinhold

Relph, E. (1976). Place and placelessness. London: Pion.

Rossi, A., \& Eisenman, P. (1982). The architecture of the city. Cambridge, Mass.: MIT Press.
Ryerson University Masterplan. (2008). Retrieved December 4, 2015, from

http://www.ryerson.ca/content/dam/about/masterplan/masterplan_ptı.pdf

Scrivene, L. (2007, September 16). A PATH through the maze | Toronto Star. Retrieved July 18 , 2016, from https://www.thestar.com/news/gta/2007/og/16/a_path_through_the_ maze.html

Stagg, Ronald. Serving Society's Needs A History of Ryerson Polytechnic University. Department of History. Web.

Sternberg, E. (2006). Neuroscience and Architecture: Seeking Common Ground. Retrieved April

16, 2015, from http://www.sciencedirect.com/science/article/pii/S0092867406013043

Stickells, L. (2008) In Heterotopia and the city: Public space in a postcivil society edited by Dehaene, M. London: Routledge.

The Roman Forum. (2012, January 18). Retrieved July 18, 2016, from

http://www.ancient.eu/article/26/

Trancik, R. (1986). Finding lost space: Theories of urban design. New York: Van Nostrand Reinhold. Treib, M. (2009). Spatial recall: Memory in architecture and landscape. New York: Routledge.

Tschumi, B. (1996). Architecture and disjunction. Cambridge, Mass.: MIT Press.

Tschumi, B. (2003). The state of architecture at the beginning of the 21st century. New York: Monacelli Press.

Tschumi, B. (n.d.). Bernard Tschumi Architects. Retrieved December 4, 2015, from http://www.tschumi.com/history/

Tuan, Y. (1977). Space and place: The perspective of experience. Minneapolis: University of Minnesota Press.

Unwin, S. (2003). Analysing architecture. London: Routledge.

Waldheim, C. (2006). The landscape urbanism reader. New York: Princeton Architectural Press.

Wall, A. (1999) In Recovering landscape: Essays in contemporary landscape architecture edited by Corner, J. New York: Princeton Architectural Press. 